Universidad Nacional de La Plata

Facultad de Ciencias Naturales y Museo

\title{
Ancestralidad y factores de riesgo en Fisuras Orales
}

LiC. MARÍA Rita SANTOS

Directora: DRA. GRACIELA BAILLIET

Co-Director: DR. Claudio BRAVI

Agosto 2012 
A Juana y a Mecha, por supuesto. 


\section{AgRAdeCimientos}

Agradezco a la U.N.L.P. y a la Universidad pública y gratuita.

A las instituciones y autoridades que propiciaron la realización de esta tesis: ANPCyT, CONICET e IMBICE.

A los niños y sus familias que participaron en este estudio.

A mis directores, Graciela Bailliet y a Claudio Bravi, por el apoyo y la confianza.

A los Goitía y a los López Camelo, por el amparo y la incondicionalidad.

A mis amigos del IMBICE, de la facultad y de la vida.

A Tatana, Jorge y Tomi.

A mamá, Gera, Caro, Viole, Gerito y "bebé".

Porque a lo largo de estos años, me han acompañado de diversas maneras. Porque los quiero y me quieren bien.

Especiales agradecimientos a Mechita, Hebe y Mariana, por su generosidad, por acompañarme en la correción del manuscrito.

A mi Juana por hacer mis días felices.

A mi querida hermana Mechita (gracias infinitas!)

A vos Papá, porque la inclinación en tu mano de arquero, ha sido para mi felicidad. 


\section{ÍNDICE}

RESUMEN

$\begin{array}{ll}\text { AbSTRACT } & 2\end{array}$

INTRODUCCIÓN

1. FISURAS ORALES 3

1.1 Clasificación y descripción de las fisuras orales 3

1.2 Descripción y epidemiología de labio leporino con o sin paladar hendido 3

1.3 Frecuencia de las fisuras orales 4

1.4 Desarrollo orofacial 5

$\begin{array}{ll}1.5 \text { Etiología, genes versus ambiente } & 6\end{array}$

$\begin{array}{ll}\text { 1.6 Búsqueda e identificación de genes candidatos } & 7\end{array}$

2. POLIMORFISMOS EN EL ADN 8

$\begin{array}{ll}2.1 \text { Metabolismo de xenobióticos } & 8\end{array}$

2.1.1 Reacciones de fase I $\quad 8$

2.1.2 Reacciones de fase II 9

$\begin{array}{lr}2.2 \text { Polimorfismo de acetilación } & 9\end{array}$

2.2.1 N-acetiltransferasas 9

2.2.2 NAT2 9

3. ANCESTRALIDAD 10

4. PROPÓSITO DEL TRABAJO 12

OBJETIVOS 13

MATERIALES Y MÉTODOS

1. Características de la muestra utilizada $\quad 15$

2. Análisis molecular 16

2.1 Determinación de polimorfismos de NAT2: PCR-RFLP 16

$\begin{array}{ll}2.2 \text { Tipificación de haplogrupos del cromosoma Y } & 18\end{array}$

$\begin{array}{ll}2.3 \text { Tipificación de haplogrupos mitocondriales } & 20\end{array}$

3. Análisis estadístico 24

3.1 Variabilidad genética 24

$\begin{array}{ll}3.2 \text { Estructura de la población } & 24\end{array}$

3.3 Análisis de asociación de los polimorfismos de NAT2 con LL/PH 24 RESULTADOS

1. Caracterización de la población 30

2. Cálculo de riesgo de polimorfismos del gen NAT2 36 
2.1 Transmisión alélica $\quad 37$

$\begin{array}{ll}2.1 .1 \text { Test de Weinberg } & 37\end{array}$

2.1.2 Test de Desequilibrio de Transmisión (TDT) 41

2.1.3 Análisis no pareado de genotipos de los casos y de los padres (GHRR) 42

2.1.4 Análisis pareado de genotipos de los casos y paternos (MGHR) 42

DISCUSIÓN

CONCLUSIONES

BIBLIOGRAFÍA

$\begin{array}{ll}\text { ANEXOS } & 72\end{array}$ 


\section{RESUMEN}

La fisura labiopalatina no sindrómica (LL/PH) constituye una malformación congénita que presenta las características de una patología multifactorial; varios genes candidatos se han estudiado con el fin de describir la predisposición genética de esta malformación. Se consideró de especial interés a los genes NATs que codifican para las $\mathrm{N}$-acetiltransferasas, enzimas responsables de la biotransformación de arilaminas, fármacos de hidrazina, y de un gran número de toxinas y carcinógenos presentes en la dieta, humo de cigarro y medio ambiente. Lo expuesto anteriormente ha despertado la sospecha de un posible rol de NAT2 en la manifestación de LL/PH en el recién nacido expuesto. En primer lugar, se evaluó el desequilibrio de ligamiento de los alelos del gen NAT2 que determinan fenotipo acetilador lento en 97 tríos completos (caso-padres-madres) y en 174 incompletos (caso-padre/madre) de maternidades del ECLAMC, Argentina. Se analizaron las variantes $* 4, * 5, * 6 \mathrm{y} * 7$ por PCR-RFLP. A partir del método TDT se evidenció asociación positiva entre el alelo * 5 y LL/PH $(\mathrm{OR}=1,61 ; \mathrm{p}=0,031)$. Con el modelo de regresión lineal que mide los efectos maternos y del caso, se observó un riesgo mayor para los genotipos 55 de los casos $(\mathrm{OR}=2,24 ; \mathrm{p}=0,050)$, sin influencia del genotipo materno. Estos hallazgos demuestran que el alelo * 5 es significativamente mayor en los casos con la anomalía congénita LL/PH. En segundo lugar, debido a la heterogeneidad de la contribución genética en las poblaciones argentinas actuales, analizamos la ancestralidad. En los linajes mitocondriales, se observó una frecuencia del $88 \%$ de haplogrupos nativos americanos, mientras que para el cromosoma Y, los haplogrupos nativos mostraron una frecuencia de $22 \%$, variando notablemente de un centro asistencial a otro. Estos resultados sugieren una fuerte contribución nativa para la línea materna pero no para la paterna en las poblaciones urbanas actuales, indicando de esta forma concordancia con los registros históricos sobre mestizajes en Centro y Sudamérica, que involucró mayormente a mujeres americanas y hombres extranjeros. 


\section{ABSTRACT}

Non-syndromic cleft lip (LL/PH) is a congenital malformation that shows the characteristics of a multifactorial pathology; aiming to describe its genetical predisposition, several candidate genes have been studied. NATs genes were considered with special interest since these codify for $\mathrm{N}$ acetiltransferases, the enzymes responsible for the biotransformation of arilamines, hydrazine drugs and a great number of toxins and carcinogens present in the diet, cigarette smoke and environment. For this, there have been suspicions about the possible role of NAT2 in the LL/PH manifestation on the exposed newborn. Firstly, we evaluated the linkage disequilibrium of the alleles of NAT2 that determine the slow acetylator phenotype in trios, 97 full (case-mother-father) and in 174 incomplete (case-mother/father) of ECLAMC maternities in Argentina. We analized the *4, *5, *5 and $* 7$ variants by PCR-RFLP. By TDT we found a positive association between the allele $* 5$ and $\mathrm{LL} / \mathrm{PH}(\mathrm{OR}=1.61, \mathrm{p}=0.031)$. With the lineal regression model that measures the maternal and case effects, we found a higher risk for the 55 genotypes of the cases $(\mathrm{OR}=2.24, \mathrm{p}=0.050)$, without the influence of the maternal genotype. These findings show that the $* 5$ allele is significantly higher in the cases with the congenital anomaly LL/PH. Secondly, due to the heterogeneity of the genetical contribution in contemporary Argentinean populations, we studied ancestry. In the mitochondrial lineages we found a high frequency of Native American haplogroups (88\%), while for the Y-chromosome the Native American haplogroups had a frequency of $22 \%$, varying considerably between centers. These findings suggest a strong Native American contribution in the maternal line but not in the paternal of urban contemporary populations, thus matching the historical records of admixture in Central and South America, where it was mostly between Native American women and foreign men. 


\section{INTRODUCCIÓN}

"What we know is a drop; what we don't know is an ocean".

Isaac Newton

En el presente trabajo se evalúa si polimorfismos del gen NAT2 están $\operatorname{asociados}^{1}$ con una malformación congénita particular: labio leporino con o sin paladar hendido (LL/PH).

\section{Fisuras ORALES}

\subsection{CLASIFICACIÓN Y DESCRIPCIÓN DE LAS FISURAS ORALES}

Labio leporino con o sin paladar hendido (LL/PH) es parte de las llamadas fisuras orofaciales (FO), las cuales son hendiduras que involucran estructuras de la cara o de la boca. Estos defectos son consecuencia de la falta de unión de los procesos que forman la cara y el paladar, durante la cuarta y quinta semana del desarrollo embrionario. Dependiendo de los procesos involucrados que por alguna causa no se fusionaron, se generan diferentes hendiduras faciales (facial oblicua, labio hendido lateral unilateral, labio hendido lateral bilateral, labio hendido medial, labio hendido inferior) con o sin hendiduras palatinas (hendidura medial, hendidura lateral y hendidura del paladar completo). Ver Figura 1.

Las FO son un grupo heterogéneo de anomalías muy similares estructuralmente, pero de origen aparentemente diferente (Tolarova y Cervenka, 1998). Este grupo comprende las fisuras orofaciales "típicas" (labio leporino, LL; labio leporino con paladar hendido, LL/PH y fisura sólo de paladar, PH) y las fisuras "atípicas" (fisura medial, transversa, oblicua, y otros tipos de fisuras de Tessier ${ }^{2}$ ). Tanto las fisuras "típicas" como las "atípicas" pueden presentarse en forma aislada, como parte de una secuencia primaria de defectos congénitos o junto a múltiples anomalías patogénicamente relacionadas (síndrome) (Tolarova y Cervenka, 1998).

\subsection{DESCRIPCIÓN Y EPIDEMIOLOGÍA DE LABIO LEPORINO CON O SIN PALADAR HENDIDO} (LL/PH)

Las formas no sindrómicas de labio leporino representan el $70 \%$ de las hendiduras orofaciales (Milerad y col., 1997). Los individuos afectados tienen fisura del labio o fisura del labio y paladar. La fisura nunca es facial oblicua ni se desarrolla en la línea media de la cara. La presencia de esta última, es indicativa de otro desorden subyacente, como por ejemplo holoprosencefalia.

\footnotetext{
${ }^{1}$ Asociación. Ocurrencia simultánea de una enfermedad o fenotipo y la presencia de un alelo en una frecuencia estadísticamente significativa.

${ }_{2}$ Paul Tessier. Médico cirujano quien describió y clasificó en forma completa las deformidades embriogénitas faciales en los tejidos blandos y óseos.
} 
En LL/PH las fisuras unilaterales son más comunes que aquellas bilaterales. En las primeras la prevalencia en la parte izquierda de la cara es mayor que en la región derecha. La relación entre lado izquierdo, lado derecho y bilateral es 6:3:1 (Lettieri, 1993). Anatómicamente la fisura labial puede ser completa o incompleta. Completa cuando abarca el labio y se extiende hasta la nariz. Incompleta es cuando la fisura no supera los límites del labio. Habitualmente LP y PH ocurren conjuntamente. En la mayoría de los casos de LL/PH la fisura ocurre tanto en el paladar primario como en el secundario.

Figura 1. Tipos de fisuras orofaciales.

I. Hendiduras faciales. A: hendidura facial oblicua, B: labio hendido lateral, C: labio hendido medial, D: labio hendido inferior.

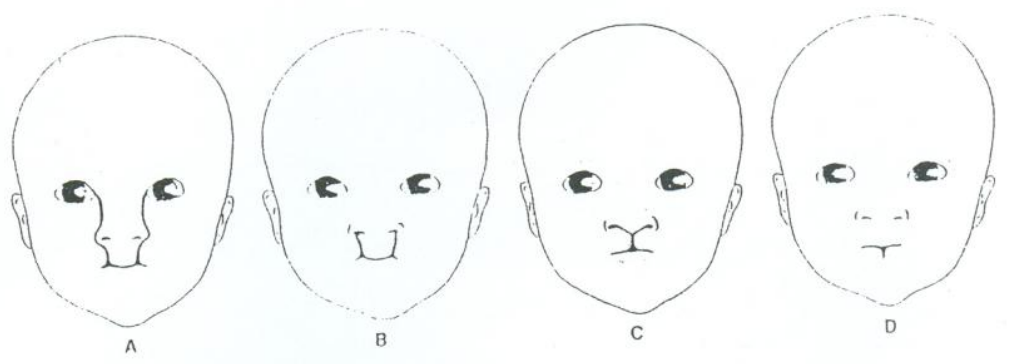

II. Hendiduras palatinas. Paladar hendido, A: medial, B: lateral, C: completo.
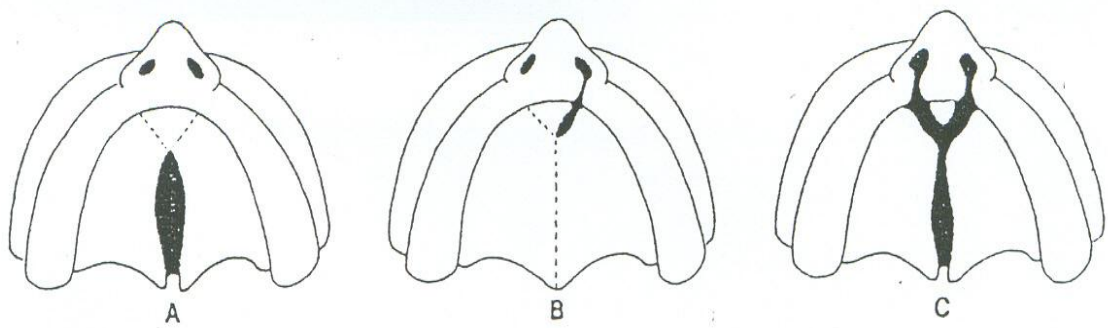

\subsection{FRECUENCIA DE LAS FISURAS ORALES}

La prevalencia de las fisuras orofaciales varía de $1 / 500$ a 1/2500, dependiendo del origen geográfico, la ancestría (Bender, 2000; Tolarova y Cervenka, 1998) y de las condiciones socioeconómicas (Schutte y Murray, 1999). Se registran las mayores frecuencias en poblaciones asiáticas (12-13 cada 10000 nacimientos para China, 16/10000 en Japón) y en las poblaciones amerindias descendientes de las asiáticas (amerindios de América del Norte y del Sur). En Sudamérica, 10 niños de cada 10000 nacidos vivos poseen alguna de estas afecciones (www.eclamcnet.net). En las poblaciones de origen europeo (Europa y americanos descendientes de europeos) la frecuencia es intermedia, registrándose las más bajas (3 de cada 10000 nacimientos) en afro-descendientes (Bender, 2000; Croen y col., 1998; López-Camelo y Orioli, 1996; Schutte y Murray, 1999; Tolarova y Cervenka, 1998). 


\subsection{DESARROLLO OROFACIAL}

"...find out the cause of this effect, or rather say, the cause of this defect, for this effect defective comes by causes". Shakespeare, Hamlet, act II, scene II

El paladar primario es la piedra fundamental del labio superior y de la porción anterior del paladar. $\mathrm{Su}$ correcta embriogénesis es fundamental para el desarrollo normal de la cara y su malformación conlleva profundas consecuencias clínicas y sociales.

El desarrollo orofacial comienza con la aparición de la placa precordal en el disco embrionario a los catorce días posteriores a la concepción (Sperber, 2001). Esta placa define el lugar donde se va a ubicar la futura boca o estomodeo, la cual se vuelve una depresión debido a la disposición de 5 primordios. El de posición media se denominada frontonasal y los pares bilaterales maxilar y mandibular (Ferguson y col., 2000). Estos 5 primordios son el resultado de la migración y proliferación mitótica del ectomesénquima, derivado de las crestas neurales y originado de la región caudal del mesencéfalo y romboencéfalo del futuro cerebro (Rossel y Capecchi, 1999).

La formación del labio superior involucra una extraordinaria combinación de elementos de las prominencias frontonasal y maxilar, estas últimas componentes del primer arco faríngeo, denominado mandibular. En ambos ángulos infero-laterales de la prominencia frontonasal comienzan a aparecer las plácodas olfatorias. Estas últimas resultan posteriormente invaginadas debido a la elevación de la prominencia frontonasal en crestas que determinarán las prominencias nasales laterales y mediales de ambos lados. Las placodas nasales olfatorias, así invaginadas, formarán las fosas nasales que serán las precursoras de las narinas anteriores.

Posteriormente, las prominencias nasales mediales bilaterales formarán el tubérculo y proporcionarán la plataforma para el futuro paladar primario (Dierwert y Shiota, 1990). Así, el labio superior se completa por la fusión de las proyecciones nasales mediales con las prominencias maxilares laterales, requiriendo para ello un tiempo crítico de correlación de crecimiento, ubicación espacial y desintegración de la superficie de contacto (Dierwert y Wang, 1992). La fusión de las prominencias no sólo permitirá la continuidad del labio superior sino también la separación de los orificios nasales del estomodeo. El componente medio de la prominencia frontonasal formará el tubérculo y el filtrum del labio superior, la punta de la nariz y el paladar primario. De este último surgirá la intermaxila (premaxila), dónde se emplazarán los futuros incisivos (Mooney y col., 1992, 1991; Siegel y col., 1991). Finalmente, la osificación del paladar primario se inicia en la octava semana en la prominencia nasal media y se extiende hacia la línea de fusión con las prominencias maxilares. 
La quijada y los labios inferiores se constituyen por la fusión medial de las dos prominencias mandibulares. La mandíbula es la parte de la cara que se forma primero. Esta característica podría explicar la poca frecuencia de fisuras en el labio inferior en relación al superior (Oostron y col., 1996). El retraso en la formación del labio superior permitiría el accionar de teratógenos, aunque indudablemente hay factores genéticos responsables de las discrepancias en las frecuencias de fisuras en el labio superior versus fisuras en el labio inferior.

El paladar secundario se denomina así pues se forma después del primario y constituye tanto el piso de las cavidades nasales como así también el techo de la boca. Está conformado por el paladar duro anterior y el paladar blando posterior. Tres elementos son fundamentales para la constitución del definitivo paladar: los dos procesos laterales del maxilar y el paladar primario derivado de la prominencia frontonasal. Inicialmente, estos tres elementos se encuentran separados debido al significativo espacio que ocupa la lengua en el canal estomodeal (Kimes y col., 1991).

A las 8 semanas posteriores a la concepción, se observa una remarcable transformación de las placas palatinas. Ambas se elevan desde una posición vertical hacia una horizontal sobre la lengua, como un preludio de su encuentro y fusión. Esta transición de vertical a horizontal se completa en términos de horas. En relación con esto último, existe una diferencia en tiempo de fusión entre géneros (Burdi y Faist, 1967), retrasándose en los embriones de sexo femenino. Este retraso podría explicar la mayor incidencia de fisura del paladar en ellas. La fusión de las placas palatinas comienza en su parte media y continua anterior y posteriormente formando una unión epitelial que finalmente se desintegra. Por último, la parte anterior de las placas se fusionan con el paladar primario y a su vez, el tabique nasal crece hacia abajo y se une con la parte cefálica del paladar.

\subsection{ETIOLOGÍA, GENES VERSUS AMBIENTE}

"An surely we are all out of the computation of our age, and every man is some months elder than he bethinks him; for we live, move, have a being and are subject to the actions of the elements, and the malice of diseases, in that other world, the truest Microcosm, the Womb of our mother".

Sir Thomas Brownne, Religio Medici, 1642

Entre las probables causas que generan fisuras orales se encuentran, al igual que en las demás enfermedades multifactoriales, factores genéticos (genes candidatos), factores ambientales o una combinación de ambos (van Rooij y col., 2003). Aunque los factores genéticos son los mayores contribuyentes a la etiología de LL/PH, el ambiente también participa en esta anomalía. Esto ya fue señalado por Warkany y Schraffenberger (1946) quienes observaron una alta incidencia de malformaciones congénitas, incluyendo paladar hendido, en ratones privados de riboflavina. Una gran cantidad de estudios de factores ambientales y LL/PH han sido llevados a cabo, y a la fecha, 
ningún factor de riesgo ${ }^{3}$ ha demostrado una asociación contundente. Sin embargo, el consumo materno de alcohol, tabaco y antiepilépticos aumentan sólo débilmente el riesgo de tener un recién nacido con LL/PH y otras malformaciones (Artama y col., 2005; Shaw y Lammer, 1999). Resultados ambiguos o asociaciones igualmente débiles han sido probadas para ácido fólico y otros nutrientes, enfermedades maternas, stress durante el embarazo, exposiciones a químicos y el uso de corticosteroides (Hayes, 2002).

La evidencia de que factores genéticos juegan un rol fundamental en la etiología de LL/PH proviene de observaciones epidemiológicas. En un estudio de cohorte, aproximadamente el $20 \%$ pacientes con LL/PH tenían familiares afectados y se observó además, que la prevalencia estaba aumentada en parientes de segundo y tercer grado (Christensen y Mitchell, 1996). Más aún, los valores de concordancia en gemelos monocigóticos $(60 \%)$ son considerablemente más altos que el valor calculado entre gemelos dicigóticos y mellizos (5-10\%) (Christensen y Fogh-Andersen, 1993; Christensen y Mitchell, 1996; Farrall y Holder, 1992).

\subsection{BÚSQUEDA E IDENTIFICACIÓN DE GENES CANDIDATOS}

Una variedad de estudios genéticos han sido llevados a cabo a fin de identificar genes candidatos y loci responsables de las fisuras orales (Lidral y Murray, 2004). En la tabla 1 pueden verse algunos genes propuestos como gen principal responsable de LL/PH, y algunas evidencias de su plausibilidad biológica (expresión génica) y de estudios de ligamiento y asociación en humanos.

Tabla 1. Algunos genes candidatos propuestos como responsables de LL/PH.

\begin{tabular}{|c|c|c|c|c|c|}
\hline Gen & $\begin{array}{c}\text { Locus } \\
\text { Humano/ratón }\end{array}$ & $\begin{array}{c}\text { Evidencias en } \\
\text { modelos animales }\end{array}$ & $\begin{array}{l}\text { Fenotipo de } \\
\text { transgénicos }\end{array}$ & $\begin{array}{l}\text { Estudios de } \\
\text { Ligamiento }\end{array}$ & $\begin{array}{l}\text { Estudios de } \\
\text { Asociación } \\
\text { (LD/TDT) }\end{array}$ \\
\hline MTHFR/ SKI & $1 \mathrm{p} 36 / 4$ & $\mathrm{KO}$ & LH, PH & + & $++/-$ \\
\hline TGFA & $2 \mathrm{p} 13$ & PB & & - & $++/-$ \\
\hline MSX1 & $4 p 16 / 5$ & $\mathrm{~PB} / \mathrm{KO}$ & $\mathrm{PH}, \mathrm{AD}$ & + & $++/-$ \\
\hline TGFB3 & $14 q 24 / 12$ & $\mathrm{~PB} / \mathrm{KO}$ & $\mathrm{PH}, \mathrm{AD}$ & - & $++/-$ \\
\hline GABRB3 & $15 q 11 / 7$ & $\mathrm{KO}$ & $\mathrm{PH}$ & - & + \\
\hline Clf1 & $17 q / 11$ & ME & $\mathrm{LH}$ & SD & SD \\
\hline Clf2 & $5 q$ ó 9q / 13 & ME & LH & SD & SD \\
\hline
\end{tabular}

KO: knockout; PB: Plausibilidad biológica; ME: Mutación espontánea; LH: Labio hendido; PH: Paladar hendido; AD: Anomalías dentales; (+): un estudio de evidencia positiva; (-): un estudio de evidencia negativa; (++): más de un estudio de evidencia positiva; SD: sin datos (Modificado de Murray, 2002).

\footnotetext{
${ }^{3}$ Factor de riesgo. Es una variable cuya presencia en un individuo indica que el mismo tiene mayor probabilidad de padecer un evento (Castiglia,1998).
} 
La naturaleza de la contribución genética a la etiología de LL/PH no ha sido dilucidada. Los genes candidatos y factores ambientales estudiados a la fecha explican sólo el 25\% de los casos de LL/PH (Vieira, 2008).

\section{Polimorfismos EN EL ADN}

Las mutaciones se definen como variaciones en una secuencia dada de ADN de un individuo, tales como sustituciones, deleciones e inserciones de nucleótidos. Por definición, una mutación puede considerarse un polimorfismo cuando su frecuencia en una población es mayor al 1\% (Knudsen y col., 2001). Una mutación localizada dentro de la región codificante de un gen metabolizante, puede generar cambios en la secuencia de aminoácidos de la proteína resultante y producir alteraciones en su actividad enzimática. Esto explicaría en parte, el por qué algunos individuos presentan mayor susceptibilidad hacia ciertas sustancias tóxicas mientras que otros parecen verse afectados en menor medida (Agudo y col., 2006). Distintos individuos pueden experimentar efectos terapéuticos diferentes a la misma dosis de un medicamento debido a la distinta capacidad de inactivar las moléculas del fármaco. Por el contrario, pueden necesitarse dosis mayores para observar la respuesta terapéutica esperada en individuos capaces de eliminar rápidamente estos fármacos. De modo similar, algunos individuos pueden experimentar efectos colaterales dependiendo de su capacidad de metabolizar algunos agentes terapéuticos (Millar, 2001).

\subsection{MetABOLISMO DE XENOBióticos}

Un xenobiótico puede definirse como una sustancia dañina para el organismo de origen tanto endógeno como exógeno y de naturaleza hidrofóbica. Existe un gran número de enzimas involucradas en la detoxificación de xenobióticos (Kiyohara y col., 2002) y su expresión génica es inducida en respuesta a la presencia de estos compuestos. Sin embargo, los productos más solubles de algunos xenobióticos son carcinógenos aun más potentes que sus formas menos solubles. Por lo tanto, un cambio a nivel genético que afecte la actividad o expresión de un gen o proteína que participe en el metabolismo de estas sustancias, puede incrementar el riesgo de padecer enfermedades. El metabolismo de xenobióticos puede dividirse en reacciones de fase I y reacciones de fase II.

\subsubsection{REACCIONES DE FASE I}

Las reacciones principales de esta fase son de oxidación, reducción e hidrólisis siendo la más común la de oxidación, la cual es mediada por un sistema enzimático que contiene citocromo P450 (González y Kimura, 2001). Esta reacción de fase I convierte a los xenobióticos en sustancias electrófilas activas que pueden interactuar con moléculas como ADN, ARN y proteínas (Shibamoto y Bjeldanes, 1996). 


\subsubsection{REACCIONES DE FASE II}

En esta fase diversas reacciones de conjugación añaden una molécula orgánica al xenobiótico, ya sea en su forma original u oxidada proveniente de la fase I. Esto reduce sus efectos tóxicos convirtiéndolo en una sustancia más soluble (Dunning y col., 1999). Dentro de las reacciones que intervienen en la fase II, la acetilación es la conjugación con ácido acético catalizada por las acetiltransferasas. Entre los factores que afectan la actividad de las enzimas, podemos contar con uno de los más importantes: el nivel de variación genética en las poblaciones (Smith y Reynard, 1993).

\subsection{POLIMORFISMO DE ACETILACIÓN}

La clasificación de los humanos como acetiladores rápidos o lentos se basa en las diferencias hereditarias de las velocidades de $\mathrm{N}$-acetilación de agentes terapéuticos y carcinógenos (Krajinovic y col., 2000); un ejemplo clásico sería la reacción de eliminación de la isoniazida, un fármaco utilizado en el tratamiento contra la tuberculosis, cuyo tiempo de vida media en el organismo para acetiladores rápidos es de aproximadamente 70 minutos, mientras que para los acetiladores lentos es de más de 3 horas (Smith y Reynard, 1993). Esta heterogeneidad en la actividad de las enzimas $\mathrm{N}$-acetiltransferasas (NAT) se denomina polimorfismo de acetilación, el cual es una de las variaciones hereditarias más comunes que afectan el metabolismo de xenobióticos.

\subsubsection{N-ACETILTRANSFERASAS}

Las N-acetiltransferasas (NAT), identificadas por el Nomenclature Comitte (IUPAC) con el código EC 2.3.1.5, son enzimas citosólicas dependientes de la acetilcoenzima A (AcCoA) que participan en la fase II del metabolismo de xenobióticos. El ser humano expresa dos formas de $\mathrm{N}$ acetiltransferasa: NAT1 y NAT2, ambas participan en la detoxificación y/o activación de arilamidas encontradas en el medio ambiente, algunos componentes carcinógenos del humo del tabaco y algunas aminas aromáticas producidas durante la cocción de carnes (Gooderham y col., 2001). Se sabe además que la acción de las enzimas NAT sobre estos puede producir también iones electrofílicos capaces de inducir mutaciones en el ADN (Hein y col., 2000).

Ambas enzimas son productos de dos genes que presentan un alto nivel de homología (87\%) a nivel del ADN localizados en el brazo corto del cromosoma 8, en los sitios 8p21.3 (NAT1) y 8p23.1 (NAT2), con una región codificante sin intrones de 870 pb que genera sendas proteínas de 290 aminoácidos (Ohsako y Deguchi, 1990).

\subsubsection{NAT2}

La N-acetiltransferasa 2 (NAT2), se expresa, a diferencia de NAT1, principalmente en el hígado. Es responsable del metabolismo de varias arilamidas cancerígenas, incluidas, la $\beta$-naftilamina, el 4aminobifenil, y la bioactivación de sustancias mutagénicas presentes en los alimentos, como la 2amino-3-metilimidazo [4,5-f] quinolina (Brans y col., 2004). 
Esta enzima es considerada polimórfica en humanos y la presencia de una variedad de alelos defectuosos del gen NAT2 produce un rango de fenotipos que van de los acetiladores rápidos a lentos. Esto provoca diferencias en la velocidad del metabolismo de arilamidas dependiendo del genotipo del individuo. La proporción de los fenotipos de acetiladores rápidos y lentos varía de un grupo étnico a otro (Brans y col., 2004).

Una gran cantidad de polimorfismos se han descrito para el gen NAT2 (http://louisville.edu/medschool/pharmacology/NAT.html). Se ha reportado además, que los genotipos acetiladores rápidos pueden incrementar el riesgo a padecer cáncer de cólon (Turesky y col., 1991), hepatocelular y colorectal (Gil y Lechner, 1998) cuando los individuos que los presentan se exponen a arilamidas ambientales.

NAT2 $* 4$ es considerado como el alelo de tipo silvestre y todas las investigaciones publicadas hasta la fecha concuerdan en que las personas que presentan el fenotipo acetilador rápido portan genotípicamente al menos un alelo de este tipo para NAT2 (Gu y col., 2005; Torkaman y col., 2007); por su parte, las personas que presentan el genotipo acetilador lento presentan en homocigosis las mutaciones C481T, G590A y G857A, las cuales caracterizan los haplotipos ${ }^{4}$ NAT2 $* 5$, NAT2 $* 6$ y NAT2 $* 7$ respectivamente.

\section{ANCESTRALIDAD}

El ancestría es la variable demográfica que con mayor consistencia ha sido asociada con la prevalencia de LL/PH (Vanderas, 1987; Wyszynski y col., 1996). Palomino y col., (1997), analizando las bases del ECLAMC, indicaron una mayor prevalencia de LL/PH en los países andinos (Colombia, Ecuador, Perú, Bolivia y Chile), que en los países atlánticos de Sudamérica y ha demostrado un gradiente de frecuencia de LH/P de este a oeste en el continente, que se relaciona con un gradiente de mezcla amerindia en el mismo sentido. A partir de estos datos se ha sugerido que la susceptibilidad a las fisuras en América del Sur estaría relacionada a un componente genético amerindio (López-Camelo y Orioli, 1996; Vieira y col., 2002).

Debido a esta heterogeneidad de la contribución genética en nuestras poblaciones actuales, es de importancia analizar la ancestralidad. Los marcadores moleculares uniparentales revisten características únicas y han permitido, con una alta sensibilidad, caracterizar poblaciones (Bailliet y col., 1994; Bianchi y col., 1997).

Dado que el ADN mitocondrial (ADNmt) no recombina, los únicos cambios que han podido darse en su composición de bases se deben exclusivamente a la ocurrencia de mutaciones a lo largo de generaciones que permitieron la construcción de una filogenia absoluta del ADNmt

\footnotetext{
${ }^{4}$ Haplotipo. Combinación de los posibles estados alélicos de distintos marcadores polimórficos en una misma molécula de ADN (Jobling y col., 2004).
} 
humano. Estas variaciones acumulativas en la secuencia, pueden ser mutaciones puntuales (polimorfismos de nucleótido simple, o PNS), las mas frecuentes, o de varias bases (eventos de inserción-deleción o indels). A partir de la determinación de mutaciones haplogrupo ${ }^{5}$-específicas es posible realizar estudios sobre migraciones y asignar la procedencia continental de un linaje materno en particular. En nuestro continente se pueden distinguir trece linajes fundadores, los mismos pertenecen a los haplogrupos A, B, C, D y X que se encuentran tanto en Asia como en América. (Achilli y col., 2008; Kashani y col., 2012; Kemp y col., 2007; Kumar y col., 2011; Malhi y col., 2010; Perego y col., 2009; Perego y col., 2010; Tamm y col., 2007). Teniendo en cuenta los movimientos migratorios de Argentina y que el haplogrupo X está ausente en América del Sur, en este trabajo de tesis doctoral consideraremos a los haplogrupos A, B, C y D como indicadores de un origen nativo americano.

Por su parte, el cromosoma Y, mas precisamente la región Y específica del cromosoma Y es una región de ligamiento completo que se transmite en bloque, de una generación a la siguiente, es decir que carecen de recombinación y, por lo tanto, acumulan mutaciones que permitieron la construcción de un árbol filogenético de alta resolución y máxima parsimonia, relacionando 311 haplogrupos, basados en un total de 600 marcadores (Karafet y col., 2008). La variante genética (M3 o DYS199*T) que define al subhaplogrupo Q1a3a está presente en el 90\% de los varones amerindios, lo cual lo convierte en un marcador útil para el diagnóstico de origen amerindio (Bianchi y col., 1997; Underhill y col., 1996). El subhaplogrupo Q1a3a pertenece al haplogrupo Q, que está definido por la mutación M242, todos los linajes Q1a3a presentan M242. Pero, no todos los linajes Q tienen M3. En base a su distribución euroasiática y su posición en el árbol filogenético, se sostiene que su aparición ocurrió antes de la primera migración hacia América, constituyendo un haplogrupo fundador (Seielstad y col., 2003). Las diferentes frecuencias observadas para este marcador entre Norteamérica y Sudamérica, podrían indicar un proceso de ocupación con más de una migración desde Asia y con un impacto diferente entre el norte y el sur (Bortolini y col, 2003; Bailliet y col, 2009).

\footnotetext{
${ }^{5}$ Haplogrupo. Conjunto de haplotipos para los que puede suponerse un origen común.
} 


\section{Propósito del TRABajo}

"A new idea is delicate. It can be killed by a sneer or a yawn; it can be stabbed to death by a quip and worried to death by a frown on the right man's brow".

Charles D. Brower

La fisura labiopalatina no sindrómica constituye una malformación congénita que presenta las características de una patología multifactorial. Estudios epidemiológicos y de análisis segregacional complejo han determinado fehacientemente la importancia que tienen los factores genéticos en su etiología, aunque también se han descrito influencias de tipo ambiental (Murray, 1995; Wyszynski y Beaty, 1996). En consecuencia, los intentos para localizar loci en el genoma humano han dado origen a una considerable cantidad de información, pero con resultados discordantes (Murray, 1995). La gran mayoría de los estudios de asociación y ligamiento han sido llevados a cabo en poblaciones de origen europeo (Ardinger y col., 1989; Beiraghi y col., 1994) y recientemente un número menor en poblaciones de diferente origen étnico (Gaspar y col., 2002; Lidral y col., 1997). Hasta ahora, a ningún locus se le ha podido atribuir un rol preponderante en el desarrollo de LL/PH. El propósito del presente trabajo es contribuir a la búsqueda de componentes genéticos que podrían estar vinculados con la presencia de LL/PH. Como hemos descrito, la acetilación es la mejor ruta de biotransformación para arilaminas y fármacos de hidrazina, así como para un gran número de toxinas y carcinógenos presentes en la dieta, humo de cigarro y medio ambiente. Lo expuesto anteriormente ha despertado la sospecha de un posible rol de NAT2 en la manifestación de LL/PH en el recién nacido expuesto. De este modo, nuestra hipótesis de trabajo es que los alelos que determinan fenotipo acetilador lento están asociados con la ocurrencia de $\mathrm{LL} / \mathrm{PH}$. 


\section{OBJETIVO GENERAL}

"Pones tu pie en el camino y si no cuidas tus pasos, nunca sabes a donde te pueden llevar". J. R. R. Tolkien, El Señor de los Anillos

El objetivo de este trabajo de tesis doctoral es contribuir al conocimiento de los factores genéticos que estarían operando en la etiología compleja de la malformación labio leporino con o sin paladar hendido. Para alcanzar el objetivo principal se desarrollaran los siguientes objetivos específicos:

Evaluar la relación entre los genotipos del gen NAT2 que determinan fenotipo acetilador lento y el riesgo de aparición de fisuras orales. Se utilizará un diseño de base familiar, de tríos de caso-progenitores (TCP) como un método adecuado para evaluar asociaciones genotipo-enfermedad y minimizar el efecto de la estructuración étnica de la muestra.

Analizar la ancestralidad amerindia a través de marcadores del ADN mitocondrial y del cromosoma Y. A partir de estos últimos, es posible, en una población con mezcla génica como sucede en Argentina, identificar linajes maternos o paternos americanos, y conocer el porcentaje y aporte diferencial en relación a los componentes no americanos. 


\section{MATERIALES Y MÉTODOS}

"La mejor estructura no garantizará los resultados ni el rendimiento.

Pero la estructura equivocada, es una garantía de fracaso".

Peter Drucker

Para la realización de este trabajo hemos utilizado la base de datos y el banco de sangre del Estudio Colaborativo Latinoamericano de Malformaciones Congénitas (ECLAMC) (Castilla y Orioli, 1983). El ECLAMC es un programa de investigación clínica y epidemiológica de las anomalías del desarrollo que opera con nacimientos hospitalarios en países latinoamericanos.

Se inició en el mes julio de 1967 y fue programado como investigación de los factores de riesgo en la causalidad de las malformaciones, con metodología caso-control. En la actualidad, su principal función es la vigilancia epidemiológica o monitorización de las malformaciones. Dado que más de la mitad de las malformaciones tienen una causa desconocida, su principal objetivo es la prevención por la investigación científica.

La red del ECLAMC está compuesta de aproximadamente 100 hospitales distribuidos en 42 ciudades de 9 países sudamericanos. Todos los recién nacidos son diariamente examinados de acuerdo a idénticas definiciones operativas y los malformados diagnosticados son registrados y descriptos de acuerdo a un protocolo único: la ficha del malformado y del control (ver Apéndice, ficha del caso y del control). El control, es el recién nacido vivo no malformado y de igual sexo del malformado, que haya nacido en el hospital inmediatamente después del caso. En la coordinación del ECLAMC, localizada en Río de Janeiro y en Buenos Aires, un equipo de investigadores, recibe, cataloga, convalida, acusa, repara, archiva, tabula y analiza la información mensualmente.

En los últimos 45 años, más de 4 millones de nacimientos han sido sistemáticamente examinados por la red ECLAMC que cuenta con una base de datos con más de 80000 malformados registrados, constituyendo un material apto para el estudio de los factores genéticos y ambientales que interactúan en la compleja causalidad de las malformaciones. Desde 1994, el ECLAMC es reconocido por la Organización Mundial de la Salud como Centro Colaborador para la Prevención de las Malformaciones Congénitas. 


\section{Características de la muestra Utilizada}

Son considerados casos todos los nacimientos vivos o muertos que presentan LL/PH, ocurridos en 12 maternidades argentinas participantes del ECLAMC (ver Tabla 2 y Figura 2).

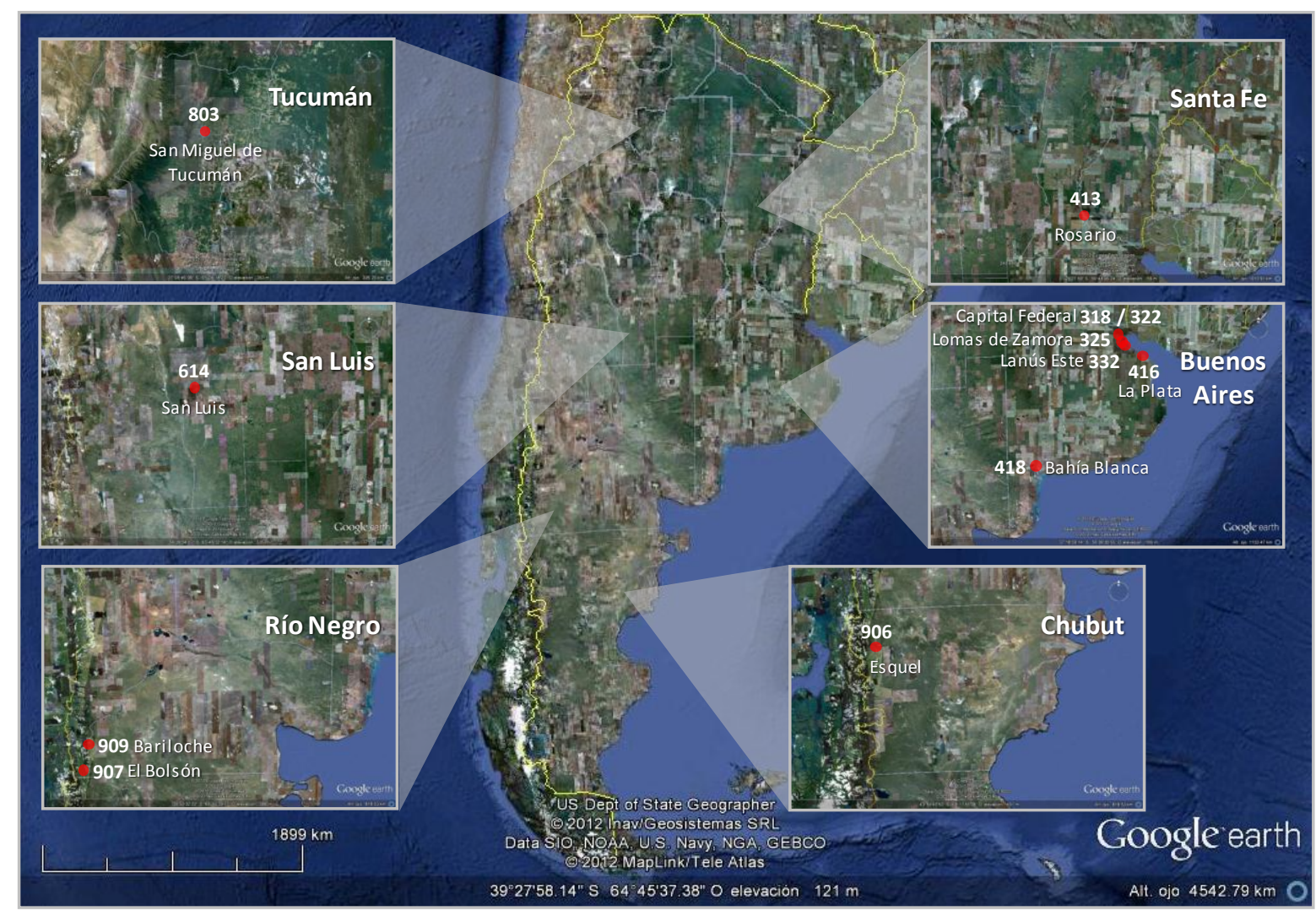

Figura 2. Maternidades argentinas del ECLAMC.

Los nacimientos están constituidos por los recién nacidos vivos de cualquier peso y los muertos de 500 gramos o más. La muestra está conformada por un total de 97 tríos completos (caso, padre y madre) y 77 incompletos (caso, padre; caso, madre). Todos incluyen al probando y no tienen relación de parentesco entre sí. El período de ocurrencia de los casos fue desde el año 2003 hasta el 2006 inclusive. Todas las familias seleccionadas presentan labio leporino con o sin paladar hendido como única anomalía. Los criterios de exclusión fueron casos sindrómicos, nacidos muertos y casos sindrómicos y no sindrómicos con paladar hendido solo. 
Tabla 2. Tríos completos e incompletos de las maternidades del ECLAMC.

\begin{tabular}{cccccc}
\hline Hospital & Región & Ciudad & Tríos & Tríos incompletos & Tríos completos \\
\hline 318 & Metropolitana & Buenos Aires & 36 & 11 & 25 \\
322 & Metropolitana & Buenos Aires & 3 & 3 & 0 \\
325 & Metropolitana & Lomas de Zamora & 2 & 1 & 1 \\
332 & Metropolitana & Lanús Este & 3 & 2 & 1 \\
413 & Pampa & Rosario & 16 & 4 & 12 \\
416 & Pampa & La Plata & 4 & 1 & 3 \\
418 & Patagonia & Bahía Blanca & 9 & 5 & 4 \\
614 & Cuyo & San Luis & 5 & 4 & 1 \\
803 & Nordeste & S.M de Tucumán & 37 & 14 & 23 \\
906 & Patagonia & Esquel & 5 & 3 & 2 \\
907 & Patagonia & El Bolsón & 33 & 18 & 15 \\
909 & Patagonia & Bariloche & 21 & 11 & 10 \\
\hline Total & & & $\mathbf{1 7 4}$ & $\mathbf{7 7}$ & $\mathbf{9 7}$ \\
\hline
\end{tabular}

\section{ANÁlisis Molecular}

Se extrajeron $10 \mathrm{ml}$ de sangre periférica a cada caso y a sus respectivos padres y se llevó a cabo la purificación del ADN genómico mediante el método comercial QiaAMP ADN blood midi kit de Quiagen (http://www.qiagen.com/system/404.aspx). Todos los métodos empleados en este trabajo de tesis doctoral están contemplados en los protocolos aprobados por el Comité Ética del CEMIC. Todas las muestras cuentan con los respectivos consentimientos informados (ver Anexo).

\subsection{DETERMINACIÓN DE POLIMORFISMOS DE NAT2: PCR-RFLP}

La identificación de las variantes alélicas se realizó mediante análisis de restricción a partir de un fragmento de $578 \mathrm{pb}$ (Figura 3). La amplificación de este último se llevó a cabo en reacciones de $20 \mu \mathrm{l}$, constando de 0,3 U de la enzima Taq Platinum Polymerase (Invitrogen), 1,5 mM de $\mathrm{MgCl}_{2}$, $200 \mu \mathrm{M}$ de desoxinucleótidos trifosfato (dNTPs), 0,25 $\mu \mathrm{M}$ de cada cebador, buffer estabilizante (Invitrogen), agua desionizada y $\sim 30$ ng de ADN genómico.

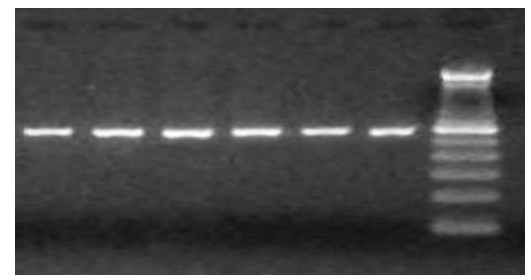

Figura 3. Verificación de la amplificación.

El tamaño de la banda es de 578 pb.

Los cebadores utilizados fueron:

NAT-2 forward 5'- GAGAGGATATCTGATAGCAC - 3'

NAT-2 reverse 5'- GGAAGCTCCTCC CAGATGTG - 3' 
Cada mezcla fue sometida a 30 ciclos de desnaturalización, reasociación y extensión a $94^{\circ} \mathrm{C}, 58^{\circ} \mathrm{C}$ y $72^{\circ} \mathrm{C}$, respectivamente. Cada etapa del ciclado tuvo una duración de un minuto y se agregó un período de extensión final de 5 minutos a $72^{\circ} \mathrm{C}$.

Fueron digeridos $4 \mu \mathrm{l}$ del amplicón durante 6 horas en un volumen final de 12 ul con 5U de la enzima de restricción apropiada (KpnI, TaqI o BamHI) según el polimorfismo que se quería analizar, con el buffer apropiado recomendado por el proveedor (New England Biolabs) durante 5 hs a $37^{\circ} \mathrm{C}$ (excepto $65^{\circ} \mathrm{C}$ para TaqI). Ver Tabla 3.

Tabla 3. Determinación de polimorfismos de NAT2.

\begin{tabular}{ccccc}
\hline Enzima de & Sustitución & Alelos & & Fragmentos obtenidos con la digestión para cada alelo (en pb) ${ }^{\mathrm{a}}$ \\
\cline { 4 - 5 } Restricción & Identificada & NAT2 & Alelo salvaje & Mutante \\
\cline { 4 - 5 } & & & $105 / 473$ & 578 \\
Kpn I & C481T & $* 5$ & $213 / 170 / 195$ & $383 / 195$ \\
Baq I & G590A & $* 6$ & $481 / 97$ & 578 \\
\hline
\end{tabular}

a Obsérvese que cada una de las sustituciones causa la pérdida del sitio de reconocimiento para las tres enzimas, exhibiendo de esta manera la presencia de la mutación y causando de este modo la variación en el tamaño del/los fragmentos. La ausencia de sustitución nos permite, en todos los casos, identificar el alelo salvaje o NAT-2*4.

Para la verificación de las amplificaciones $4 \mu 1$ de cada amplicón fueron mezclados con $1 \mu 1$ de solución de carga $(0,25 \%$ de azul de bromofenol, $0,25 \%$ de cianol de xileno, $40 \%$ p/v sacarosa en agua) y sembrados en geles de agarosa al $2 \%$. Los geles fueron sometidos a un campo eléctrico de $100 \mathrm{~V}$ sumergidos en solución TBE (90 mM Tris-borato, 2mM EDTA) con agregado de bromuro de etidio $(0,5 \mu \mathrm{g} / \mathrm{mL})$. Como marcadores de peso molecular se sembraron $500 \mathrm{ng}$ de una escalera de $100 \mathrm{pb}$ (Promega). Los fragmentos fueron visualizados en un transiluminador bajo radiación ultravioleta y documentados fotográficamente. Las reacciones de digestión fueron corridas en condiciones semejantes. Ver Figura 4.

Los genotipos homocigotas para el alelo $* 4$ y sus heterocigotas $(44,45,46$ y 47$)$ fueron asignados al fenotipo acetilador rápido. Los genoptipos homocigotas y heterocigotas con alelos mutados $(55,56,57,66,67$ y 77) fueron asignados al fenotipo acetilador lento (extraído de: http://louisville.edu/medschool/pharmacology/NAT.html). 
BamH I

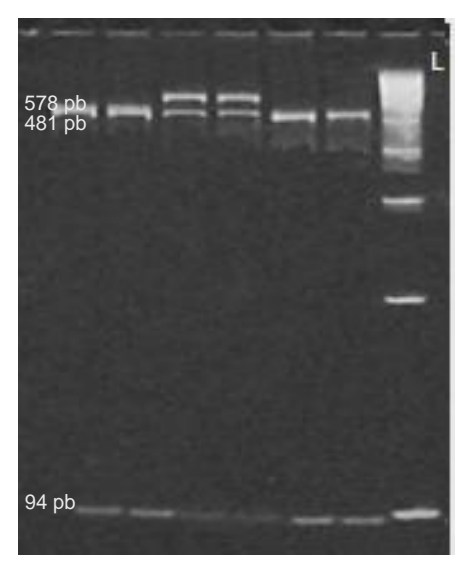

Kpn $\mathbf{I}$

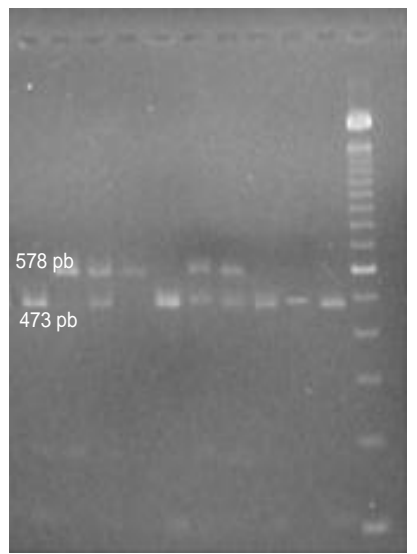

$\operatorname{Taq} \mathbf{I}$

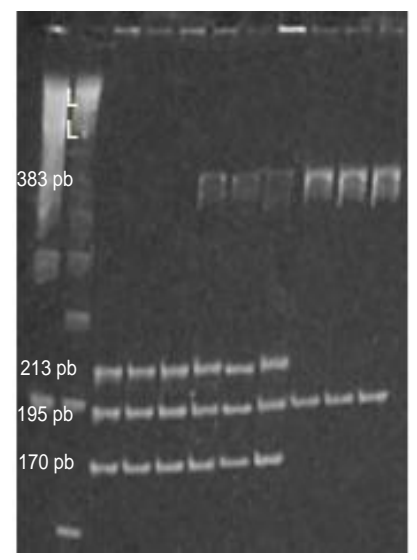

Figura 4. Digestión del fragmento de PCR con cada una de las enzimas.

\subsection{TIPIFICACIÓN DE HAPLOGRUPOS DEL CROMOSOMA Y}

Se emplearon 2 marcadores moleculares: M242 (Seielstad y col., 2003) y M3 (Underhill y col., 1996). Estos polimorfismos sólo tienen dos formas alélicas, una ancestral, compartida por los linajes más antiguos y otra derivada. Consisten en cambios de una sola base o SNP (del inglés "Single Nucleotide Polymorphism).

Las amplificaciones de ADN se llevaron a cabo en reacciones de $10 \mu 1$, constando de 0,25 $\mathrm{U}$ de Taq ADN polimerasa Platinum (Invitrogen), 0,25 $\mu \mathrm{M}$ de cada cebador, $200 \mu \mathrm{M}$ de desoxinucleótidos trifosfato (dNTP), 1,5 mM de Cloruro de Magnesio, buffer estabilizante 10X (Invitrogen), agua desionizada y 10-30 nanogramos de ADN genómico.

Los cebadores utilizados fueron:

\section{M242 forward 5'- TCAGATGGCAAGATTTTTAAGTACA - 3' \\ M242 reverse 5' - AAAAACACGTTAAGACCAATGTC - 3' \\ M3 forward 5' - TAATCAGTCTCCTCCCAGCA - 3' \\ M3 reverse 5'- TAGGTACCAGCTCTTCCCAATT - 3'}

El programa de ciclado, comprende un primer paso común de desnaturalización a $94^{\circ} \mathrm{C}$ seguido de dos pasos que varían según el marcador y se repiten entre 35 (locus M3) a 40 veces (locus M242).

a- Desnaturalización a $94^{\circ} \mathrm{C}$ durante 60 segundos.

b- Hibridación de $54{ }^{\circ} \mathrm{Cdurante} 1$ minuto para el locus M242 y de $61{ }^{\circ} \mathrm{C}$ durante 40 segundos para el locus M3. 
c- Elongación a $72^{\circ} \mathrm{C}$ durante 60 segundos.

Cumplidos los ciclos de amplificación, una última fase común de $72^{\circ} \mathrm{C}$ durante cinco minutos finaliza la elongación. Para corroborar los resultados del proceso, los productos de amplificación se sometieron a electroforesis directa en geles de agarosa. Ver Figuras 5 y 6.

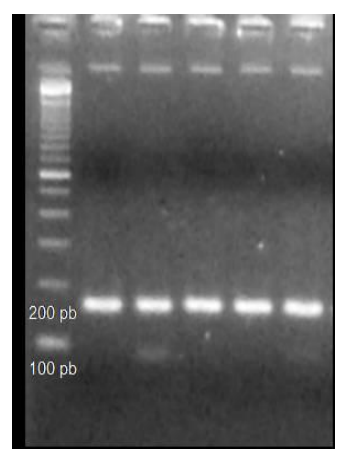

Figura 5. Verificación de la amplificación del locus M242. El tamaño de la banda es de $151 \mathrm{pb}$. La escalera de referencia de 100pb fue sembrada en la primera calle.

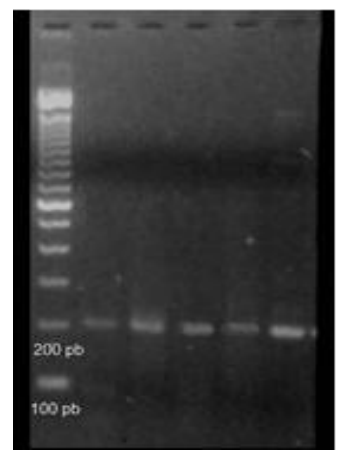

Figura 6. Verificación de amplificación de locus M3. El tamaño de la banda es de $201 \mathrm{pb}$. La escalera de referencia de 100pb fue sembrada en la primera calle.

Los SNP se analizaron mediante digestiones con endonucleasas de restricción (ver Tabla 4). Estas reacciones se llevaron a cabo en volúmenes de $10 \mu \mathrm{l}$, conteniendo entre 2-3 $\mu 1$ de producto de amplificación, el buffer adecuado para cada enzima, suero bovino, agua desionizada y entre 1-5 U de enzima de restricción (New England Biolabs) en un baño termostático a $37^{\circ} \mathrm{C}$ durante toda una noche.

Tabla 4. Polimorfismos que identifican los haplogrupos Q y Q1a3a.

\begin{tabular}{ccccc}
\hline \multirow{2}{*}{ Marcadores } & Enzima de & Sustitución & \multicolumn{2}{c}{ Fragmentos obtenidos con la digestión (en pb) } \\
\cline { 4 - 5 } & Restricción & Identificada & Alelo ancestral & Alelo derivado \\
\hline M242 & Hpy 188 III & C/T & $24 / 62 / 66$ & $62 / 90$ \\
M3 & Mfe I & C/T & $20 / 181$ & 201 \\
\hline
\end{tabular}

Para la verificación del proceso de digestión se utilizaron geles de poliacrilamida nativa (38:2, acrilamida: N, N'-metilen-bisacrilamida) con concentraciones al 10\%. La electroforesis se realizó en cubas verticales con TBE al $1 \mathrm{X}$ como buffer y el voltaje oscila entre 180 y $230 \mathrm{~V}$, en relación a 
la concentración de acrilamida. Finalmente, los geles se tiñen en solución de nitrato de plata al $1,6 \%$ y se revelan con solución de hidróxido de sodio $3 \%$ más formaldehído $0,5 \%$. Ver Figuras 7 y 8.

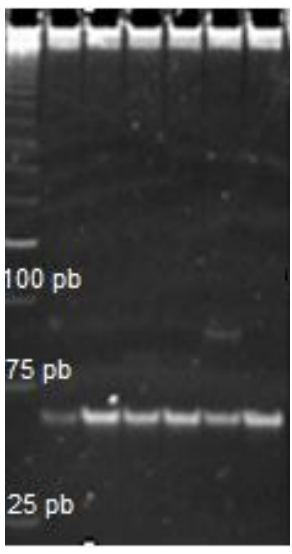

Figura 7. Productos de la digestión con la enzima Hpy 188 III. La escalera de referencia de $25 \mathrm{pb}$ fue sembrada en la primera calle. Las cuatro primeras muestras presentan el alelo ancestral (C). La quinta muestra presenta el alelo derivado (T).

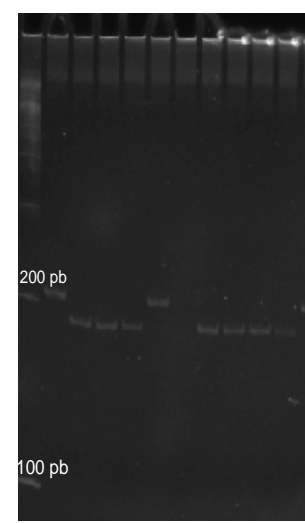

Figura 8. Productos de la digestión con la enzima $M f e I$. En la calle 1 se sembró la escalera de $100 \mathrm{pb}$ de referencia. Las muestras sembradas en las calles 3, 4, 5, 8, 9, 10 y 11 presentaron el estado ancestral (C) mientras que las calles 2 y 6 el estado derivado (T). En la calle 7 se sembró el control negativo.

\subsection{TIPIFICACIÓN DE HAPLOGRUPOS MITOCONDRIALES}

América presenta cuatro haplogrupos nativos A-D distribuidos en todo el territorio, en tanto que el $\mathrm{X}$ aparece en muy baja proporción y está limitado al norte del continente.

El haplogrupo A está definido por una mutación en la posición 663 que provoca la ganancia de un sitio de restricción para el enzima HaeIII (abreviada como e) respecto de la SRC. Se indica como +663e. El haplogrupo B se destaca por la deleción de 9pb en la Región V del ADNmt, denominada Del 9 pb. El haplogrupo $\mathrm{C}$ es definido por la co-ocurrencia de pérdida de sitio para el enzima HincII (o) en la posición 13259 y ganancia de sitio para AluI (a) en 13262, es decir, -13259o/+13262a, en tanto el haplogrupo D posee una -5176a, o sea, pérdida de sitio para AluI en 5176. Los polimorfismos que definen los haplogrupos (indicados con + o respectivamente) se detallan en la Tabla 5. Se destacan los cambios respecto de la SRC.

Analizamos 234 muestras para 3 sitios de restricción y un polimorfismo de longitud que definen los haplogrupos nativos A-D (Tabla 5). Toda muestra no asignable a los haplogrupos A-D fue considerada no americana. 
Tabla 5. Combinación de polimorfismos que definen los haplogrupos A-D, y mutaciones que los originan.

\begin{tabular}{|c|c|c|c|c|}
\hline \multicolumn{5}{|c|}{ Haplogrupos $^{1}$} \\
\hline RFLP/Indel $^{2}$ & $\mathbf{A}$ & B & $\mathbf{C}$ & D \\
\hline $663 \mathrm{e}$ & + & - & - & - \\
\hline Del 9pb & - & + & - & - \\
\hline$-13259 \mathrm{o} /+13262 \mathrm{a}$ & - & - & + & - \\
\hline $5176 a$ & + & + & + & - \\
\hline
\end{tabular}

${ }^{1} \overline{\text { Presencia o ausencia de determinado polimorfismo se indican con }+\mathrm{o}-\text {, respectivamente; }{ }^{2} \text { RFLP o indel involucrado en }}$ la definición de haplogrupos.

Las amplificaciones se llevaron a cabo en reacciones de $20 \mu$, constando de $0,3 \mathrm{U}$ de la enzima Taq Platinum Polymerase (Invitrogen), 1,5 $\mathrm{mM}$ de $\mathrm{MgCl}_{2}, 200 \mu \mathrm{M}$ de desoxinucleótidos trifosfato (dNTPs), 0,25 $\mu \mathrm{M}$ de cada cebador según el fragmento que se quería amplificar, buffer estabilizante (Invitrogen), agua desionizada y $\sim 30$ ng de ADN genómico (ver Figuras 9 y 10).
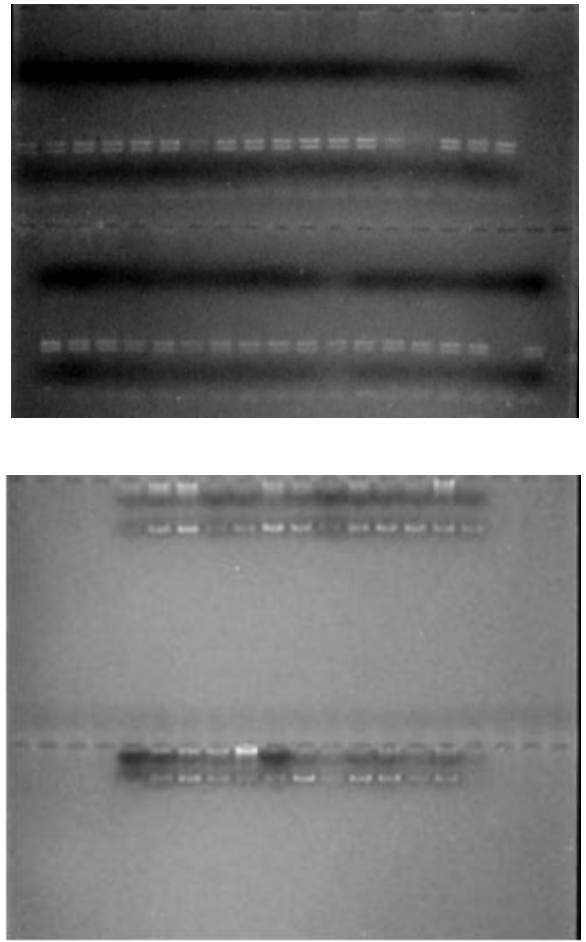

Los cebadores utilizados fueron:

Haplogrupo A:

Forward -582 5'- TGTAGCTTACCTCCTCAAAGC - 3'

Reverse -745 5'- TTGATCGTGGTGATTTAGAGG - 3
Figura 9. Los haplogrupos C (399 pb.) y D (343 pb.) se amplificaron en una misma reacción de PCR.

Figura 10. Amplificación del fragmento para Hg.A, de 163 pb. 


\section{Haplogrupo B}

Forward -8209 5'- CATCGTCCTAGAATTAATTCC - 3'

Reverse -8304 5’- CTTTACAGTGGGCTCTAGAGG - 3'

Haplogrupo C

Forward - F-13128 5'- CCCCCTAGCAGAAAATAGCC - 3'

Reverse - B-13526 5' - TCGATGATGTGGTCTTTGGA - 3'

Haplogrupo D

Forward - F-4983 5'- CAAACCCAGCTACGCAAAAT - 3'

Reverse -B-5325 5' - TGATGGTGGCTATGATGGTG - 3'

Cada mezcla fue sometida a 35 ciclos de desnaturalización, reasociación y extensión a $94^{\circ} \mathrm{C}, 55^{\circ} \mathrm{C}$ y $72^{\circ} \mathrm{C}$, respectivamente. Cada etapa del ciclado tuvo una duración de un minuto y se agregó un período de extensión final de 5 minutos a $72^{\circ} \mathrm{C}$.

Los $16 \mu$ de los fragmentos amplificados fueron digeridos durante 6 horas en un volumen final de $30 \mu \mathrm{l}$ con $5 \mathrm{U}$ de enzima de restricción diferente (HaeIII, AluI) según el cambio que se quería analizar, con el buffer apropiado recomendado por el proveedor (New England Biolabs) durante 5 hs a $37^{\circ} \mathrm{C}$. Tabla 6 .

Tabla 6. Determinación de haplogrupos mitocondriales.

\begin{tabular}{cccc}
\hline Fragmento amplificado & Enzima de restricción & Fragmentos obtenidos de la digestión \\
\hline Haplogrupo A & Hae III & $163 \mathrm{pb} \mathrm{ó} 80 \mathrm{pb}+83 \mathrm{pb}$ (Hg. A positivo) \\
\cline { 2 - 3 } Haplogrupo C & $399 \mathrm{pb}$ ó $136 \mathrm{pb}+263 \mathrm{pb}(\mathrm{Hg} . \mathrm{C}$ positivo $)$ \\
Haplogrupo D & Alu I & $334 \mathrm{pb}(\mathrm{Hg}$. D positivo) ó $148 \mathrm{pb}+186 \mathrm{pb}$ \\
\hline
\end{tabular}

La verificación del éxito de la amplificación para los fragmentos de A, C y D se realizó mediante electroforesis de una alícuota de $4 \mu \mathrm{l}$ de los amplicones en geles de agarosa al $2 \%$ a $90 \mathrm{~V}$ por 45 minutos. Los $16 \mu 1$ restantes se utilizaron en la reacción de digestión enzimática.

Para la tipificación de los haplogrupos A, C y D, se sembraron $25 \mu 1$ de las digestiones, mezclados con $3 \mu \mathrm{l}$ de buffer de carga, en geles de agarosa al 2,5\%. Se utilizó una escalera de 100 pb (Invitrogen). Las corridas electroforéticas se llevaron a cabo a $85 \mathrm{~V}$ por 60-90 minutos. 
Finalmente se expusieron los geles al transiluminador y se tomaron las fotografías. Ver Figuras 11 y 12.

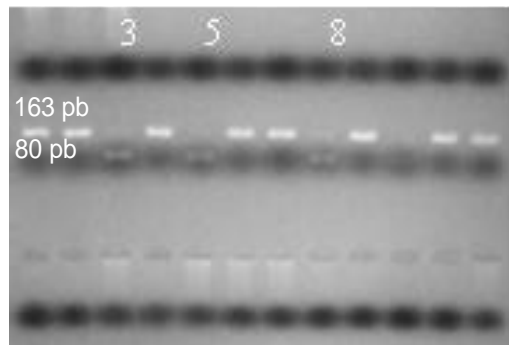

Figura 11. Digestión del amplicón de 163 pb., que determina el haplogrupo A, por Hae III. Se obtiene dos fragmentos de 80 y 83 pb. En las calles 3, 5 y 8 pueden verse muestras positivas para A. El control negativo se sembró en la calle 10 .

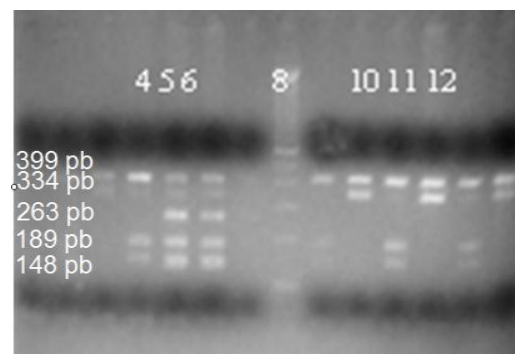

Figura 12. Productos de la digestión por Alu I de los fragmentos amplificados para determinar los haplogrupos $\mathrm{C}$ y D. En las calles 5 y 6 se observan muestras $\mathrm{Hg}$.C positivo, en las calles 10 y $12 \mathrm{Hg} . \mathrm{D}$ positivo, en tanto las número 4 y 11 dan negativo para $\mathrm{C}$ y $\mathrm{D}$. En la calle 8 se sembró la escalera de 100 pb.

La tipificación del haplogrupo B se realizó utilizando geles de policrialmida al 10\% (38:2, acrilamida: N, N'-metilen-bisacrilamida, $2 \mathrm{ml}$ de TBE 10X, agua desionizada y $15 \mu 1$ de TEMED (N,N,N',N'-tetrametilnediamina). Se sembraron $4 \mu \mathrm{l}$ de las amplificaciones mezclados con $1 \mu \mathrm{lde}$ buffer de carga y, junto con ellas un control negativo y una escalera de 100 pb. Finalizada la electroforesis se sumerge el gel en TBE $1 \mathrm{X}$ con bromuro de etidio $(0,15 \mu \mathrm{g} / \mathrm{ml})$ para luego ser fotografiado. Ver Figura 13.

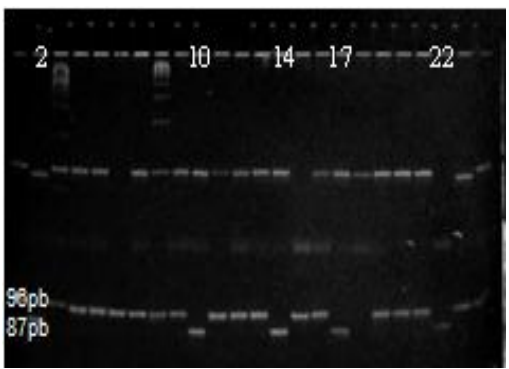

Figura 13. Amplificación de la secuencia presente en la Región V que determina el haplogrupo B. En la parte inferior del gel puede verse los productos de $87 \mathrm{pb}$. (calles $2,10,14,17,22)$ y $96 \mathrm{pb}$. en las calles restantes. 


\section{ANÁLISIS ESTADÍSTICO}

\subsection{VARIABILIDAD GENÉTICA}

Los análisis de la diversidad genética de los marcadores uniparentales y de las variantes estudiadas de NAT2 se realizaron a partir de las frecuencias alélicas calculadas de los padres de los casos con LL/PH mediante el programa Arlequin versión 3.11 (Excoffier y col., 2005). El test de desviación del equilibrio de Hardy-Weimberg de las frecuencias genotípicas fue llevado a cabo con el test exacto del mismo paquete estadístico, usando el método de la cadena de Markov descrito por Guo y Thompson (1992).

\subsection{ESTRUCTURA DE LA POBLACIÓN}

Para el estudio jerárquico de la población se realizó el análisis de la varianza molecular (AMOVA) incorporado en el programa Arlequin versión 3.1 (Excoffier y col., 2005). AMOVA permite las estimaciones de estructura de la población a diferentes niveles jerárquicos específicos.

Realizamos AMOVAs para verificar si existen diferencias geográficas en la distribución de las frecuencias alélicas bajo tres diferentes agrupamientos en relación a los clusters de Poletta y col., (2007). En primer lugar, comparamos los hospitales del ECLAMC que han registrado alta frecuencia de LL/PH, luego entre aquellos de alta frecuencia versus baja y el tercer grupo entre aquellos hospitales con las frecuencias más bajas de LL/PH

El estadístico $\mathrm{F}_{\mathrm{ST}}$ mide cuánto de la variación total en las frecuencias alélicas se debe a las diferencias entre las poblaciones. El valor de $\mathrm{F}_{\mathrm{ST}}$ varía entre 0 y 1 . Cuando el flujo genético es alto y existe poca diferencia entre las poblaciones, se aproxima a 0 .

Para realizar los test de significancia del índice $\mathrm{F}_{\mathrm{ST}}$, y así testear la hipótesis nula de no diferenciación en los correspondientes niveles jerárquicos, se realizaron análisis permutacionales descriptos por Excoffier y col., (1992).

\subsection{ANÁLISIS DE ASOCIACIÓN DE LOS POLIMORFISMOS DE NAT2 CON LL/PH}

Actualmente, dos tipos de análisis de asociación son comúnmente utilizados en estudios genéticos: poblacionales y familiares. Los poblacionales utilizan diseño caso-control, donde las frecuencias alélicas son comparadas entre casos (individuos afectados) versus controles (individuos no afectados). En los estudios poblacionales con diseño caso-control se toma una muestra representativa de sujetos con la anomalía congénita y de controles en los que se calcula la frecuencia de los posibles alelos y genotipos de susceptibilidad. La Figura 14 muestra un esquema del proceso por el cual asociaciones genotipo-enfermedad debidas a estratificación poblacional pueden surgir en un estudio de caso-control. El dibujo muestra una población heterogénea con dos subpoblaciones 1 y 2 en la que se pretende estudiar un gen con cuatro alelos A, B, C y D, donde el 
alelo D representaría un posible alelo de susceptibilidad o un alelo en desequilibrio de ligamiento con una variante genética hipotética de susceptibilidad. Es posible comprobar en la Figura 14 que la frecuencia de la enfermedad (sujetos marcados en negro) y la frecuencia del alelo D son bajas en la subpoblación 1 mientras que esas mismas frecuencias son altas en la subpoblación 2. Sin embargo, no existe asociación entre el alelo D y la enfermedad dentro de la subpoblación 1 ni dentro de la subpoblación 2. Si se condujera un estudio de caso-control sin un adecuado apareamiento de los sujetos, es muy posible que la gran mayoría de los casos provengan de la subpoblación 2, donde la enfermedad es muy frecuente, y una proporción considerable de los controles provengan de la subpoblación 1. En este escenario, una mayor frecuencia del alelo D en casos con respecto a los controles no sería debida a un efecto causal originado por la presencia de este alelo, sino que reflejaría únicamente las diferencias en la composición genética entre la subpoblación 1 y la subpoblación 2. En muchas ocasiones, estas subpoblaciones o estratos suelen corresponder con grupos étnicos en los que existen diferencias tanto en frecuencias de alelos de marcadores genéticos como en la prevalencia/incidencia de ciertas enfermedades. En términos epidemiológicos, se dice entonces que la ancestría es una variable confundente o un factor de confusión en la evaluación de la asociación genotipo-enfermedad. Por otra parte, se sabe que la población argentina contemporánea es consecuencia de sucesivos eventos de colonización. Por esta razón, no sería adecuado aplicar un estudio caso-control. En este sentido, los estudios de asociación de base familiar, entre los que se encuentra el diseño TCP (tríos casos-padres) permiten la evaluación genotipo enfermedad, sin que esta asociación sea afectada por la posible estratificación étnica en la población.

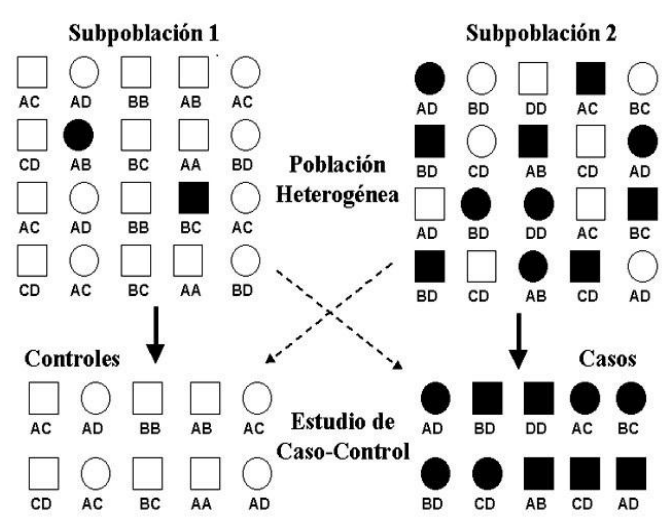

Figura 14. Estratificación poblacional y su efecto en estudios de caso control.

En los diseños TCP se seleccionan familias a través del caso índice, y a partir de ese caso se obtiene la información de los padres. La Figura 15 representa un ejemplo de una familia participante en un estudio. 


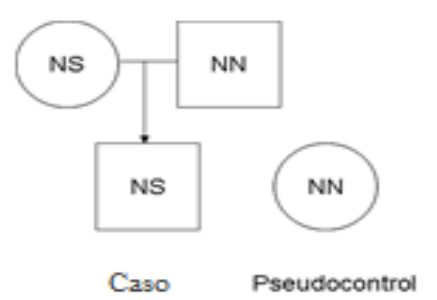

Figura 15. Familia ejemplo de un estudio caso-control pareado por origen étnico.

En esta familia ejemplo, el caso tiene genotipo NS, el padre tiene genotipo NN, mientras que la madre tiene un genotipo NS. El pseudocontrol sería N/N. Hay que señalar que el pseudocontrol no es un individuo concreto, sino que se trata de un genotipo construido con los alelos que los padres no transmiten a sus hijos. Así los tríos compuestos por casos y padres serán analizados en el contexto de un estudio de caso-control pareado por origen étnico.

Con este diseño TCP se aplicarán los siguientes análisis:

a) Análisis no pareado de genotipos de los casos y de los padres (GHRR) (Falk y Rubinstein, 1987) La significación en esta tabla se calcula a través de la habitual estadística chicuadrado con un grado de libertad. Ver Tabla 7.

Tabla 7. Casos y Pseudocontroles en análisis no pareado.

\begin{tabular}{cccc}
\hline & Alelo presente & Alelo ausente & Total \\
\cline { 2 - 4 } Caso & $\mathrm{a}$ & $\mathrm{b}$ & \\
Pseudocontroles & $\mathrm{c}$ & $\mathrm{d}$ & \\
Total & & & $\mathrm{n}$ \\
\hline Cálculo de $\mathrm{OR}^{6}=(\mathrm{a} \times \mathrm{d}) /(\mathrm{c} \times \mathrm{d})$ & &
\end{tabular}

b) Análisis pareado de genotipos de los casos y paternos (MGHR) (Terwilliger y Ott, 1992). Ver Tabla 8. La significación de la tabla se calcula:

$$
X^{2}=(b-c)^{2} / b+c
$$

\footnotetext{
${ }^{6}$ Odds ratio: Indica cuánto más probable es la ocurrencia de una enfermedad que su no-ocurrencia, si está expuesto a determinado factor de riesgo. $\mathrm{OR}=1$ (significa que no hay riesgo); $\mathrm{OR}<1$ (expresa que el factor de exposición protege de la enfermedad); OR $>1$ (el factor de exposición aumenta la probabilidad de ocurrencia de dicha afección).
} 
Tabla 8. Casos y Pseucontroles en análisis pareado.

\begin{tabular}{cccc}
\hline & $\begin{array}{c}\text { Pseudocontrol alelo } \\
\text { presente }\end{array}$ & $\begin{array}{c}\text { Pseudocontrol alelo } \\
\text { ausente }\end{array}$ & Total \\
\cline { 2 - 4 } Caso alelo ausente & $\mathrm{a}$ & $\mathrm{b}$ & $\mathrm{c}$ \\
Caso alelo presente & $\mathrm{d}$ & $\mathrm{e}$ & $\mathrm{f}$ \\
Total & & & $\mathrm{n}$ \\
\hline Cálculo de OR=b/c & &
\end{tabular}

Para el estudio de asociación genética con genes candidatos serán utilizados el Test de Desequilibrio de transmisión (Spielman y col., 1993) y el método de Weinberg (1999).

c) Test de desequilibrio de transmisión (TDT) (Spielman y col., 1993). Con esta prueba se evalúa la transmisión de alelos desde los padres heterocigotos hacia los hijos con LL/PH. Tomemos nuevamente el ejemplo de la familia de la Figura 15. Al seleccionar familias a través del caso índice, la asociación entre el factor genético y la anomalía origina que, en estas familias, la transmisión de alelos desde padres heterocigotos hacia sus hijos con LL/PH se aparten del valor esperado (probabilidad de transmisión=50\%). En nuestra familia ejemplo, la madre puede transmitir N o S. Si el gen no está asociado con la anomalía, N y S tienen la misma probabilidad de transmisión. Por el contrario, si el alelo S está asociado con un mayor riesgo de enfermar, entonces $\mathrm{S}$ será encontrado más frecuentemente que $\mathrm{N}$ en los hijos enfermos y con una probabilidad de transmisión aparente superior a 50\%. El padre sólo puede transmitir el alelo N, de modo que no es informativo en este tipo de análisis (los padres homocigotos no entregan información en el análisis de TDT). Ver Tabla 9. En un conjunto de tríos caso-padres, la estadística TDT se calcula de la siguiente forma TDT:

$$
\begin{aligned}
& \text { TDT }=(b-c)^{2} /(b+c) \\
& \mathrm{OR}=\mathrm{b} / \mathrm{c}
\end{aligned}
$$

Tabla 9. Test de desequilibrio de transmisión (TDT).

\begin{tabular}{lcc}
\hline & Alelo no transmitido $\mathrm{S}$ & Alelo transmitido N \\
\cline { 2 - 3 } Alelo transmitido $\mathrm{S}$ & $\mathrm{a}$ & $\mathrm{b}$ \\
Alelo transmitido $\mathrm{N}$ & $\mathrm{c}$ & $\mathrm{d}$ \\
\hline
\end{tabular}

d) El Método de Weinberg (1999). Al igual que el TDT usan pseudocontroles. Sin embargo, mientras que el TDT permite evaluar la distorsión en la transmisión, el Test de Weinberg 
permite calcular el efecto del genotipo materno, el efecto del genotipo fetal en variantes alélicas que se encuentran en equilibrio de Hardy-Weinberg y en poblaciones fuera de equilibrio. El modelo es basado en la siguiente estructura de datos e incluye los siguientes términos:

\begin{tabular}{ccccccccccccccc}
\hline Madre & Padre & Niño & Tipo & set & N & T2 & T3 & T4 & T5 & T6 & M1 & M2 & C1 & C2 \\
\hline 2 & 2 & 2 & 1 & 0.000 & 0 & 0 & 0 & 0 & 0 & 0 & 1 & 0 & 1 \\
2 & 1 & 2 & 2 & 0.000 & 1 & 0 & 0 & 0 & 0 & 0 & 1 & 0 & 1 \\
2 & 1 & 1 & 2 & 0.000 & 1 & 0 & 0 & 0 & 0 & 0 & 1 & 1 & 0 \\
1 & 2 & 2 & 2 & 0.000 & 1 & 0 & 0 & 0 & 0 & 1 & 0 & 0 & 1 \\
1 & 2 & 1 & 2 & 0.000 & 1 & 0 & 0 & 0 & 0 & 1 & 0 & 1 & 0 \\
2 & 0 & 1 & 3 & 0.000 & 0 & 1 & 0 & 0 & 0 & 0 & 1 & 1 & 0 \\
0 & 2 & 1 & 3 & 0.000 & 0 & 1 & 0 & 0 & 0 & 0 & 0 & 1 & 0 \\
1 & 1 & 2 & 4 & 0.000 & 0 & 0 & 1 & 0 & 0 & 1 & 0 & 0 & 1 \\
1 & 1 & 1 & 4 & 0.693 & 0 & 0 & 1 & 0 & 0 & 1 & 0 & 1 & 0 \\
1 & 1 & 0 & 4 & 0.000 & 0 & 0 & 1 & 0 & 0 & 1 & 0 & 0 & 0 \\
1 & 0 & 1 & 5 & 0.000 & 0 & 0 & 0 & 1 & 0 & 1 & 0 & 1 & 0 \\
1 & 0 & 0 & 5 & 0.000 & 0 & 0 & 0 & 1 & 0 & 1 & 0 & 0 & 0 \\
0 & 1 & 1 & 5 & 0.000 & 0 & 0 & 0 & 1 & 0 & 0 & 0 & 1 & 0 \\
0 & 1 & 0 & 5 & 0.000 & 0 & 0 & 0 & 1 & 0 & 0 & 0 & 0 & 0 \\
0 & 0 & 0 & 6 & 0.000 & 0 & 0 & 0 & 0 & 1 & 0 & 0 & 0 & 0 \\
\hline
\end{tabular}

Donde código "0" indica homocigosis de la variante salvaje, "1" indica heterocigosis y " 2 " homocigosis de la variante mutada.

$\mathrm{N}$ : número de casos en cada combinación

T1-T6: 6 tipos de apareamientos sin importar el orden materno/paterno.

T1: categoría de referencia.

M1: variante heterocigota mutada en el genotipo materno.

M2: variante homocigota mutada en el genotipo materno.

C1: variante heterocigota mutada en el genotipo del recién nacido.

C2: variante homocigota mutada en el genotipo del recién nacido.

El modelo usa una regresión de Poisson donde el número esperado de casos N1 bajo un modelo de transmisión sin asociación genética es:

$$
\mathrm{N} 1=\mathrm{R} 1 \mathrm{M} 1+\mathrm{R} 2 \mathrm{M} 2+\mathrm{C} 1 \mathrm{R} 1+\mathrm{C} 2 \mathrm{R} 2
$$

y la inclusión de los 6 tipos de apareamiento T1-T6 si la variante alélica no esta en equilibrio de HW.

R1M1 es el riesgo de la variante alélica mutada en heterocigosis en el genotipo materno.

R2M2 es el riesgo de la variante alélica mutada en homocigosis en el genotipo materno.

$\mathrm{R} 1 \mathrm{C} 1$ es el riesgo de la variante alélica mutada en heterocigosis en el genotipo del recién nacido.

$\mathrm{R} 2 \mathrm{C} 2$ es el riesgo de la variante alélica mutada en homocigosis en el genotipo del recién nacido. 
Fue calculada la Fracción Atribuible en la población expuesta para estimar la reducción del daño si los factores de riesgo causales desapareciesen de la población expuesta.

$$
\mathrm{FA}=\frac{\mathrm{Pe}(\mathrm{R}-1)}{1+\mathrm{Pe}(\mathrm{R}-1)} * 100
$$

Donde $\mathrm{Pe}=$ frecuencia de la variante alélica en los expuestos.

$\mathrm{R}=$ Odds ratio

También fue calculada la fracción prevenible para estimar la proporción de los casos que serían evitados si existiera la exposición entre la población. Se calculó de la siguiente manera:

$$
\mathrm{FP}=\frac{\mathrm{Pe}(1-\mathrm{R})}{1+\mathrm{Pe}(1-\mathrm{R})} * 100
$$

Donde Pe: frecuencia de la variante alélica en los expuestos.

$\mathrm{R}$ : Odds ratio

Los análisis de asociación se han realizado con los siguientes programas informáticos: LEM 1.0 (Vermunt, 1993) y Métodos Iterativos (programa desarrollado en el Departamento de Epidemiología Genética del CEMIC por Dr. Jorge López Camelo). 


\section{RESULTADOS}

"Every experiment may be said to exist only in order to give the facts a chance of disproving the null hypothesis".

R. A. Fisher, 1935

\section{CaRaCTERIZaCión de la POBlación}

En la Tabla 10 se detallan las frecuencias alélicas relativas del gen NAT2 con sus desviaciones estándar, en maternidades del ECLAMC. Cada hospital presentó una distribución de frecuencias alélicas particular, que lo diferenció del resto de los hospitales participantes de este estudio. Al analizar la muestra total de 326 individuos (652 cromosomas), las frecuencias obtenidas para las variantes alélicas fueron: $* 4=0,37 ; * 5=0,33 ; * 6=0,15 \mathrm{y} * 7=0,15$.

Tabla 10. Frecuencias relativas (FR) de las variantes alélicas del gen NAT2 en maternidades del ECLAMC.

\begin{tabular}{c|cc|cc|cc|cc|c}
\hline \multirow{2}{*}{ Hospital } & \multicolumn{2}{|c|}{ Alelo *4 } & \multicolumn{2}{|c|}{ Alelo $* \mathbf{5}$} & Alelo *6 & Alelo *7 & N \\
\cline { 2 - 8 } & $\mathbf{F R}$ & $\mathbf{n}$ & $\mathbf{F R}$ & $\mathbf{n}$ & $\mathbf{F R}$ & $\mathbf{n}$ & $\mathbf{F R}$ & $\mathbf{n}$ & \\
\hline 803 & $0,34 \pm 0,04$ & 51 & $0,37 \pm 0,04$ & 56 & $0,14 \pm 0,03$ & 21 & $0,15 \pm 0,03$ & 22 & 150 \\
318 & $0,35 \pm 0,04$ & 49 & $0,33 \pm 0,04$ & 46 & $0,12 \pm 0,03$ & 17 & $0,20 \pm 0,03$ & 28 & 140 \\
413 & $0,29 \pm 0,05$ & 21 & $0,46 \pm 0,06$ & 33 & $0,12 \pm 0,04$ & 9 & $0,13 \pm 0,04$ & 9 & 72 \\
325 & $0,43 \pm 0,14$ & 6 & $0,28 \pm 0,12$ & 4 & $0,08 \pm 0,07$ & 1 & $0,21 \pm 0,11$ & 3 & 14 \\
322 & $0,33 \pm 0,14$ & 4 & $0,25 \pm 0,13$ & 3 & $0,25 \pm 0,13$ & 3 & $0,17 \pm 0,11$ & 2 & 12 \\
332 & $0,10 \pm 0,10$ & 1 & $0,40 \pm 0,16$ & 4 & $0,10 \pm 0,10$ & 1 & $0,40 \pm 0,16$ & 4 & 10 \\
614 & $0,60 \pm 0,11$ & 12 & 0,00 & 0 & $0,15 \pm 0,08$ & 3 & $0,25 \pm 0,10$ & 5 & 20 \\
416 & $0,12 \pm 0,08$ & 2 & $0,44 \pm 0,13$ & 7 & $0,25 \pm 0,11$ & 4 & $0,19 \pm 0,10$ & 3 & 16 \\
418 & $0,20 \pm 0,08$ & 5 & $0,38 \pm 0,10$ & 10 & $0,27 \pm 0,09$ & 7 & $0,15 \pm 0,07$ & 4 & 26 \\
906 & $0,60 \pm 0,11$ & 12 & $0,20 \pm 0,09$ & 4 & $0,15 \pm 0,08$ & 3 & $0,05 \pm 0,05$ & 1 & 20 \\
907 & $0,47 \pm 0,04$ & 58 & $0,25 \pm 0,04$ & 32 & $0,14 \pm 0,03$ & 17 & $0,14 \pm 0,03$ & 17 & 124 \\
909 & $0,44 \pm 0,07$ & 21 & $0,33 \pm 0,07$ & 16 & $0,19 \pm 0,06$ & 17 & $0,04 \pm 0,03$ & 17 & 48 \\
\hline FR total & $\mathbf{0 , 3 7} \pm \mathbf{0 , 0 2}$ & $\mathbf{2 4 2}$ & $\mathbf{0 , 3 3} \pm \mathbf{0 , 0 2}$ & $\mathbf{2 1 5}$ & $\mathbf{0 , 1 5} \pm \mathbf{0 , 0 2}$ & $\mathbf{9 5}$ & $\mathbf{0 , 1 5} \pm \mathbf{0 , 0 2}$ & $\mathbf{1 0 0}$ & $\mathbf{6 5 2}$ \\
\hline
\end{tabular}

FR: frecuencia relativa $(\mathrm{n} / \mathrm{N})$.

n: número de cromosomas con la variante alélica por Hospital.

$\mathrm{N}$ : número total de cromosomas por Hospital. 
La Tabla 11 muestra la distribución de las frecuencias relativas de los genotipos, en las maternidades del ECLAMC. Las frecuencias calculadas son dispares entre las distintas maternidades. En la muestra total (326 individuos) el genotipo más frecuente fue el $45(0,22)$ mientras que los genotipos con frecuencias más bajas $(0,02$ a 0,03$)$ fueron los 66,67 y 77 . Los 6 genotipos restantes $(44,46,47,55,56,57)$ presentaron frecuencias intermedias $(0,11$ a 0,14$)$.

Tabla 11. Frecuencias relativas (FR) de los genotipos del gen NAT2 en maternidades del ECLAMC.

\begin{tabular}{|c|c|c|c|c|c|c|c|c|c|c|c|c|c|c|c|c|c|c|c|c|c|}
\hline \multirow{2}{*}{ Hospital } & \multicolumn{2}{|c|}{44} & \multicolumn{2}{|c|}{45} & \multicolumn{2}{|c|}{46} & \multicolumn{2}{|c|}{47} & \multicolumn{2}{|c|}{55} & \multicolumn{2}{|c|}{56} & \multicolumn{2}{|l|}{57} & \multicolumn{2}{|l|}{66} & \multicolumn{2}{|c|}{67} & \multicolumn{2}{|l|}{77} & \multirow{2}{*}{$\mathbf{N}$} \\
\hline & FR & $\mathbf{n}$ & FR & $\mathbf{n}$ & FR & $\mathbf{n}$ & FR & $\mathbf{n}$ & FR & $\mathbf{n}$ & FR & $\mathbf{n}$ & FR & $\mathbf{n}$ & FR & $\mathbf{n}$ & FR & $\mathbf{n}$ & FR & $\mathbf{n}$ & \\
\hline 803 & 0,13 & 10 & 0,23 & 17 & 0,12 & 9 & 0,07 & 5 & 0,13 & 10 & 0,12 & 8 & 0,15 & 11 & 0,01 & 1 & 0,03 & 2 & 0,03 & 2 & 75 \\
\hline 318 & 0,10 & 7 & 0,28 & 20 & 0,06 & 4 & 0,16 & 11 & 0,11 & 8 & 0,01 & 1 & 0,13 & 9 & 0,04 & 3 & 0,09 & 6 & 0,01 & 1 & 70 \\
\hline 413 & 0,11 & 4 & 0,22 & 8 & 0,08 & 3 & 0,06 & 2 & 0,22 & 8 & 0,11 & 4 & 0,14 & 5 & 0,03 & 1 & 0,00 & 0 & 0,03 & 1 & 36 \\
\hline 325 & 0,29 & 2 & 0,00 & 0 & 0,14 & 1 & 0,14 & 1 & 0,14 & 1 & 0,00 & 0 & 0,29 & 2 & 0,00 & 0 & 0,00 & 0 & 0,00 & 0 & 7 \\
\hline 322 & 0,00 & 0 & 0,00 & 0 & 0,33 & 2 & 0,33 & 2 & 0,17 & 1 & 0,17 & 1 & 0,00 & 0 & 0,00 & 0 & 0,00 & 0 & 0,00 & 0 & 6 \\
\hline 332 & 0,00 & 0 & 0,2 & 1 & 0,00 & 0 & 0,00 & 0 & 0,00 & 0 & 0,00 & 0 & 0,60 & 3 & 0,00 & 0 & 0,20 & 1 & 0,00 & 0 & 5 \\
\hline 614 & 0,30 & 3 & 0,00 & 0 & 0,20 & 2 & 0,40 & 4 & 0,00 & 0 & 0,00 & 0 & 0,00 & 0 & 0,00 & 0 & 0,10 & 1 & 0,00 & 0 & 10 \\
\hline 416 & 0,00 & 0 & 0,12 & 1 & 0,12 & 1 & 0,00 & 0 & 0,25 & 2 & 0,25 & 2 & 0,00 & 0 & 0,00 & 0 & 0,12 & 1 & 0,12 & 1 & 8 \\
\hline 418 & 0,08 & 1 & 0,00 & 0 & 0,07 & 1 & 0,15 & 2 & 0,153 & 2 & 0,31 & 4 & 0,15 & 2 & 0,08 & 1 & 0,00 & 0 & 0,00 & 0 & 13 \\
\hline 906 & 0,30 & 3 & 0,30 & 3 & 0,20 & 2 & 0,10 & 1 & 0,00 & 0 & 0,1 & 1 & 0,00 & 0 & 0,00 & 0 & 0,00 & 0 & 0,00 & 0 & 10 \\
\hline 907 & 0,22 & 13 & 0,24 & 15 & 0,14 & 9 & 0,13 & 8 & 0,05 & 3 & 0,08 & 5 & 0,10 & 6 & 0,01 & 1 & 0,01 & 1 & 0,01 & 1 & 62 \\
\hline 909 & 0,17 & 4 & 0,33 & 8 & 0,12 & 3 & 0,08 & 2 & 0,12 & 3 & 0,08 & 2 & 0,00 & 0 & 0,08 & 2 & 0,00 & 0 & 0,00 & 0 & 24 \\
\hline FR total & 0,14 & 47 & 0,22 & 74 & 0,11 & 37 & 0,12 & 38 & $\mathbf{0 , 1 2}$ & 38 & 0,09 & 29 & 0,12 & 38 & $\mathbf{0 , 0 3}$ & 9 & $\mathbf{0 , 0 3}$ & 12 & $\mathbf{0 , 0 2}$ & 6 & 326 \\
\hline Fenotipos & \multicolumn{8}{|c|}{ Metabolizadores rápidos } & \multicolumn{12}{|c|}{ Metabolizadores lentos } & \\
\hline
\end{tabular}

FR: frecuencia relativa $(\mathrm{n} / \mathrm{N})$.

n: número genotipos por Hospital.

$\mathrm{N}$ : número total de genotipos por Hospital. 
A partir de las frecuencias relativas genotípicas obtenidas (Tabla 11), se estimó la frecuencia porcentual de los genotipos que determinan fenotipos acetiladores lentos $(55,56,57,66,67,77)$. En la Figura 16 están representados los porcentajes de los genotipos acetiladores lentos de cada hospital. En concordancia con las frecuencias genotípicas halladas, el rango de frecuencias porcentuales de los fenotipos es también amplio (10-80\%) y geográficamente variable. Dos hospitales, San Luis (614) y Esquel (906) presentaron las frecuencias más bajas (10\%), mientras que las frecuencias superiores a 60\% fueron registradas en Bahía Blanca (418), La Plata (416) y Lanús (332). En los hospitales de El Bolsón (907), Bariloche (909), Capital Federal (322, 318), Lomas de Zamora (325), Tucumán (803) y Rosario (413), las frecuencias variaron entre 27 y $52 \%$.

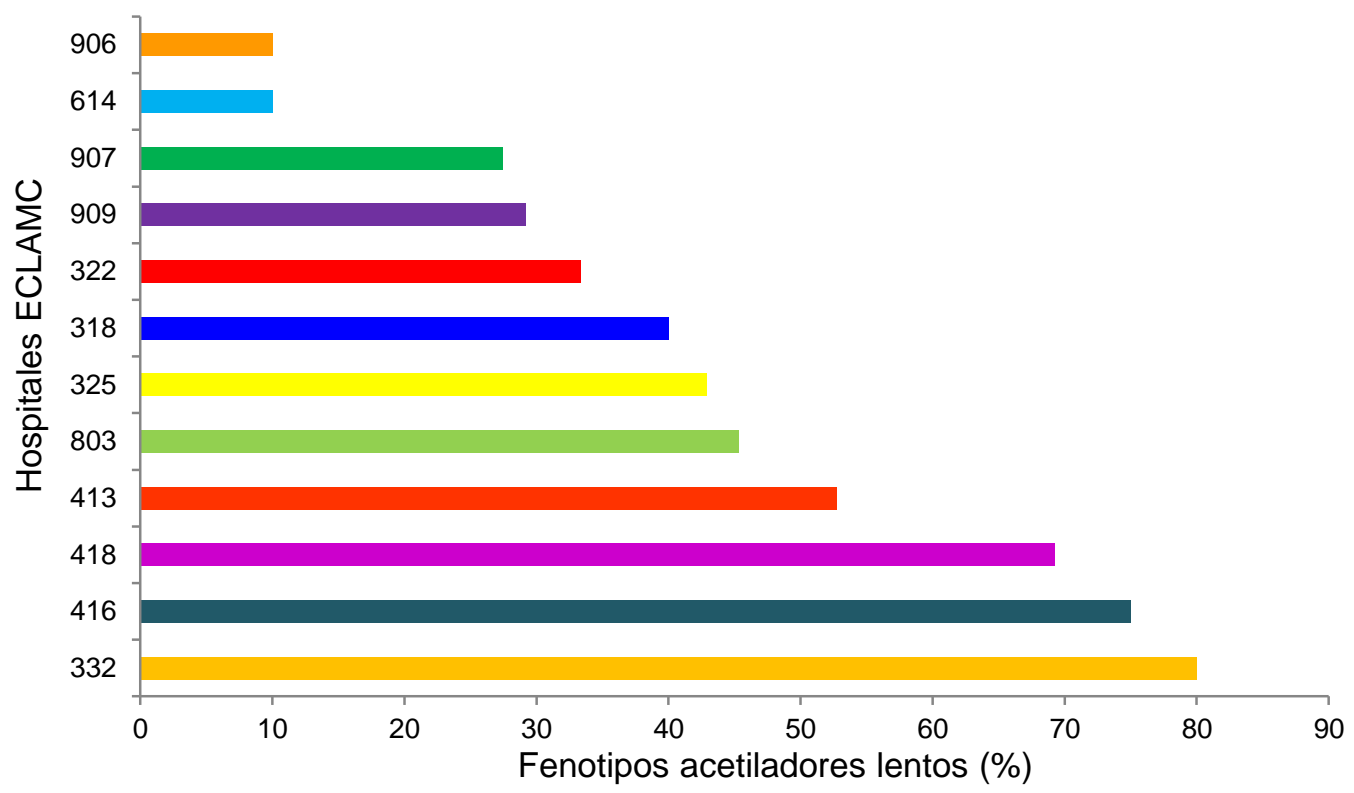

Figura 16. Frecuencia porcentual de fenotipos acetiladores lentos en maternidades del ECLAMC.

Mediante el ajuste al equilibrio de Hardy-Weinberg, fue valorada la distribución de frecuencias de los genotipos estudiados. Según este modelo las poblaciones se mantienen en equilibrio cuando son panmícticas (todos los individuos tienen la misma probabilidad de aparearse y el apareamiento es al azar), no están sometidas a migración, mutación o selección. De este análisis se desprende que las frecuencias alélicas de todas las maternidades se encuentran en equilibrio, con excepción de la maternidad $318(\mathrm{p}=0,035)$ (Tabla 12). Las maternidades del ECLAMC presentaron alta diversidad genética $(0,58-0,75)$, la maternidad de Bahía Blanca (418) registró el valor más alto, en tanto que la de San Luis (614) mostró la menor diversidad (Tabla 12). 
Tabla 12. Prueba de Hardy-Weinberg y diversidad genética en maternidades del ECLAMC.

\begin{tabular}{cccccc}
\hline & \multicolumn{2}{c}{ Heterocigotas } & & \\
\cline { 2 - 5 } Hospital & Genotipos & Observados & Esperados & $\begin{array}{c}\text { Diversidad } \\
\text { genética }\end{array}$ & \\
\cline { 2 - 5 } & 75 & 0,69 & 0,74 & $0,71 \pm 0,02$ & 0,777 \\
318 & 70 & 0,73 & 0,75 & $0,72 \pm 0,02$ & $\mathbf{0 , 0 3 5}$ \\
413 & 36 & 0,61 & 0,71 & $0,68 \pm 0,03$ & 0,702 \\
325 & 7 & 0,57 & 0,86 & $0,74 \pm 0,07$ & 0,271 \\
322 & 6 & 0,83 & 0,71 & $0,71 \pm 0,07$ & 1,000 \\
332 & 5 & 1,00 & 0,73 & $0,73 \pm 0,10$ & 0,391 \\
614 & 10 & 0,70 & 0,73 & $0,58 \pm 0,09$ & 1,000 \\
416 & 8 & 0,62 & 0,74 & $0,74 \pm 0,07$ & 0,457 \\
918 & 13 & 0,69 & 0,81 & $0,75 \pm 0,04$ & 0,254 \\
906 & 10 & 0,70 & 0,74 & $0,60 \pm 0,10$ & 1,000 \\
907 & 62 & 0,71 & 0,76 & $0,68 \pm 0,03$ & 0,959 \\
\hline & 24 & 0,62 & $0,67 \pm 0,03$ & 0,517 \\
\hline
\end{tabular}

Para determinar si existen diferencias geográficas en la distribución de frecuencias alélicas del gen NAT2, realizamos 4 AMOVAS, bajo 4 diferentes estrategias de agrupamiento, de acuerdo con Poletta y col. (2007). En primer lugar, comparamos la distribución de frecuencias de NAT2 entre aquellas maternidades ubicadas en regiones que registraron altas frecuencias de LL/PH (Tucumán 803- vs. Patagonia -906, 907, 909-).Tabla 13. En segundo lugar, comparamos la distribución de frecuencias de las variantes alélicas de NAT2 entre maternidades que registraron altas frecuencias de LL/PH versus maternidades con baja frecuencia de la anomalía (Tucumán + Patagonia -803, 906, 907, 909- vs. Buenos Aires + Rosario + San Luis -318, 325, 322, 332, 413, 416, 418, 614-). Tabla 14. En tercer lugar, la comparación fue realizada entre maternidades ubicadas en regiones con baja frecuencia de LL/PH (Capital Federal -318- vs. Buenos Aires + Rosario + San Luis -322, $325,332,413,416,418,614-)$. Tabla 15. Por último, la comparación consideró todos los hospitales como un único grupo. Tabla 16. En los 4 análisis el FST fue bajo $(0,01 ; 0,02 ; 0,02$ y 0,02 respectivamente). La mayor variabilidad encontrada fue dentro de las maternidades (98\%). 
Tabla 13. AMOVA entre regiones de altas frecuencias de LL/PH.

\begin{tabular}{lcccc}
\hline Fuente de variación & $\begin{array}{c}\text { Grados } \\
\text { de libertad }\end{array}$ & $\begin{array}{c}\text { Suma de } \\
\text { cuadrados }\end{array}$ & $\begin{array}{c}\text { Componentes de la } \\
\text { varianza }\end{array}$ & $\begin{array}{c}\text { Porcentaje de la } \\
\text { variación }\end{array}$ \\
\hline Entre grupos & 1 & 1,210 & 0,00659 & 1,89 \\
Entre maternidades dentro grupos & 3 & 0,823 & $-0,00204$ & $-0,58$ \\
Dentro maternidades & 341 & 117,623 & 0,34494 & 98,70 \\
\hline Total & $\mathbf{3 4 5}$ & $\mathbf{1 1 9 , 6 5 6}$ & $\mathbf{0 , 3 4 9 4 8}$ & \\
\hline
\end{tabular}

FST $=0,01301 ; p=0,000$

Tabla 14. AMOVA entre regiones de altas y bajas frecuencias de LL/PH.

\begin{tabular}{lcccc}
\hline Fuente de variación & $\begin{array}{c}\text { Grados } \\
\text { de libertad }\end{array}$ & $\begin{array}{c}\text { Suma de } \\
\text { cuadrados }\end{array}$ & $\begin{array}{c}\text { Componentes de la } \\
\text { varianza }\end{array}$ & $\begin{array}{c}\text { Porcentaje de la } \\
\text { variación }\end{array}$ \\
\hline Entre grupos & 1 & 1,344 & 0,00060 & 0,17 \\
Entre maternidades dentro grupos & 11 & 7,431 & 0,00793 & 2,22 \\
Dentro maternidades & 643 & 224,370 & 0,34894 & 97,61 \\
\hline Total & $\mathbf{6 5 5}$ & $\mathbf{2 3 3 , 1 4 5}$ & $\mathbf{0 , 3 5 7 4 7}$ & \\
\hline
\end{tabular}

FST $=0,02387 ; p=0,000$

Tabla 15. AMOVA entre regiones de bajas frecuencias de LL/PH.

\begin{tabular}{lcccc}
\hline Fuente de variación & $\begin{array}{c}\text { Grados } \\
\text { de libertad }\end{array}$ & $\begin{array}{c}\text { Suma de } \\
\text { cuadrados }\end{array}$ & $\begin{array}{c}\text { Componentes de la } \\
\text { varianza }\end{array}$ & $\begin{array}{c}\text { Porcentaje de la } \\
\text { variación }\end{array}$ \\
\hline Entre grupos & 1 & 0,386 & $-0,01369$ & $-3,78$ \\
Entre maternidades dentro grupos & 6 & 5,012 & 0,02240 & 6,19 \\
Dentro maternidades & 302 & 106,747 & 0,35347 & 97,59 \\
\hline Total & $\mathbf{3 0 9}$ & $\mathbf{1 1 2 , 1 4 5}$ & $\mathbf{0 , 3 6 2 1 8}$ & \\
\hline
\end{tabular}

$\overline{\mathrm{FST}}=0,02407 ; \mathrm{p}=0,000$

Tabla 16. AMOVA considerando todas las maternidades en un solo grupo LL/PH.

\begin{tabular}{lcccc}
\hline Fuente de variación & $\begin{array}{c}\text { Grados } \\
\text { de libertad }\end{array}$ & $\begin{array}{c}\text { Suma de } \\
\text { cuadrados }\end{array}$ & $\begin{array}{c}\text { Componentes de la } \\
\text { varianza }\end{array}$ & $\begin{array}{c}\text { Porcentaje de la } \\
\text { variación }\end{array}$ \\
\hline Entre maternidades & 12 & 8,775 & 0,00829 & 2,32 \\
Dentro maternidades & 643 & 224,370 & 0,34894 & 97,68 \\
\hline Total & $\mathbf{6 5 5}$ & $\mathbf{2 3 3 , 1 4 5}$ & $\mathbf{0 , 3 5 7 2 3}$ & \\
\hline
\end{tabular}

$\overline{\mathrm{FST}}=0,02320 ; \mathrm{p}=0,000$ 
Para conocer la ancestralidad nativa americana en las maternidades, se calcularon las frecuencias de los haplogrupos amerindios y no amerindios para los dos sistemas uniparentales, ADN mitocondrial y cromosoma Y. En relación con el cromosoma Y, las frecuencias de los haplogrupos foráneos fueron altas $(0,50$ a 1,00) y estuvieron presentes en todas las maternidades. La contribución de los haplogrupos amerindios al acervo genético siempre fue menor, a excepción de una maternidad -322- donde alcanzó una frecuencia de 0,50. En tres maternidades (325, 332 y 416) no se observaron haplogrupos nativos americanos. Así, de un total de 201 padres de niños con LL/PH, el $78 \%$ presentó haplogrupos no amerindios y el 22\% haplogrupos nativos americanos (Tabla 17).

Tabla 17. Frecuencias relativas (FR) de haplogrupos $\mathrm{Y}$ y diversidad genética en hospitales del ECLAMC.

\begin{tabular}{|c|c|c|c|c|c|c|c|c|}
\hline \multirow{2}{*}{ Hospital } & \multicolumn{2}{|c|}{ No amerindios } & \multicolumn{2}{|c|}{ Amerindio Q } & \multicolumn{2}{|c|}{ Amerindio QM3 } & \multirow{2}{*}{$\mathbf{N}$} & \multirow{2}{*}{$\begin{array}{l}\text { Diversidad } \\
\text { genética }\end{array}$} \\
\hline & FR & $\mathbf{n}$ & FR & $\mathbf{n}$ & FR & $\mathbf{n}$ & & \\
\hline 803 & 0,86 & 37 & 0,02 & 1 & 0,12 & 5 & 43 & $0,25 \pm 0,08$ \\
\hline 318 & 0.68 & 30 & 0,00 & 0 & 0,32 & 14 & 44 & $0,44 \pm 0,05$ \\
\hline 413 & 0,86 & 19 & 0,00 & 0 & 0,14 & 3 & 22 & $0,25 \pm 0,12$ \\
\hline 325 & 1,00 & 3 & 0,00 & 0 & 0,00 & 0 & 3 & $0,00 \pm 0,00$ \\
\hline 322 & 0,50 & 3 & 0,00 & 0 & 0,50 & 3 & 6 & $0,60 \pm 0,13$ \\
\hline 332 & 1,00 & 4 & 0,00 & 0 & 0,00 & 0 & 4 & $0,00 \pm 0,00$ \\
\hline 614 & 0,86 & 6 & 0,00 & 0 & 0,14 & 1 & 7 & $0,29 \pm 0,20$ \\
\hline 416 & 1,00 & 4 & 0,00 & 0 & 0,00 & 0 & 4 & $0,00 \pm 0,00$ \\
\hline 418 & 0,60 & 6 & 0,20 & 2 & 0,20 & 2 & 10 & $0,53 \pm 0,09$ \\
\hline 906 & 0,67 & 2 & 0,00 & 0 & 0,33 & 1 & 3 & $0,67 \pm 0,31$ \\
\hline 907 & 0,72 & 28 & 0,02 & 1 & 0,26 & 10 & 39 & $0,42 \pm 0,06$ \\
\hline 909 & 0,83 & 10 & 0,00 & 0 & 0,17 & 2 & 12 & $0,30 \pm 0,15$ \\
\hline Total & 0,78 & 156 & 0,02 & 4 & 0,20 & 41 & 201 & $\mathbf{0 , 3 5} \pm \mathbf{0 , 0 3}$ \\
\hline
\end{tabular}

FR: frecuencia relativa $(\mathrm{n} / \mathrm{N})$.

$\mathrm{n}$ : número de haplogrupos del cromosoma Y por Hospital.

$\mathrm{N}$ : número total de haplogrupos del cromosoma Y por Hospital.

Los haplogrupos mitocondriales fueron calculados en las maternidades. Las frecuencias de los haplogrupos nativo-americanos A, B, C y D en los 194 padres y madres fueron 0,13; 0,19; 0,33 y 0,23 respectivamente, mientras que la frecuencia del haplogrupo foráneo fue de 0,12 . Al contrario de los resultados hallados para el cromosoma Y, la contribución de haplogrupos amerindios al 
acervo genético fue muy alta en las distintas maternidades. De un total de 194 padres y madres, el $88 \%$ presentó haplogrupos amerindios y sólo el 12\% presentó haplogrupos no amerindios (Tabla $18)$.

Tabla 18. Frecuencias relativas de haplogrupos mitocondriales y diversidad genética en cuatro maternidades del ECLAMC.

\begin{tabular}{|c|c|c|c|c|c|c|c|c|c|c|c|c|}
\hline \multirow{3}{*}{ Hospitales } & \multicolumn{8}{|c|}{$\begin{array}{c}\text { Haplogrupos } \\
\text { amerindios }\end{array}$} & \multirow{2}{*}{\multicolumn{2}{|c|}{$\begin{array}{l}\text { Haplogrupos } \\
\text { no amerindio }\end{array}$}} & \multirow{3}{*}{$\mathbf{N}$} & \multirow{3}{*}{$\begin{array}{l}\text { Diversida } \\
\text { genética }\end{array}$} \\
\hline & \multicolumn{2}{|c|}{$\mathbf{A}$} & \multicolumn{2}{|c|}{ B } & \multicolumn{2}{|c|}{ C } & \multicolumn{2}{|c|}{ D } & & & & \\
\hline & FR & $\mathbf{n}$ & FR & $\mathbf{n}$ & FR & $\mathbf{n}$ & FR & $\mathbf{n}$ & FR & $\mathbf{n}$ & & \\
\hline 803 & 0,11 & 5 & 0,04 & 2 & 0,39 & 18 & 0,39 & 18 & 0,07 & 3 & 46 & $0,73 \pm 0,02$ \\
\hline 318 & 0,22 & 11 & 0,26 & 13 & 0,22 & 11 & 0,10 & 5 & 0,20 & 10 & 50 & $0,80 \pm 0,02$ \\
\hline 413 & 0,33 & 8 & 0,29 & 7 & 0,13 & 3 & 0,08 & 2 & 0,17 & 4 & 24 & $0,79 \pm 0,04$ \\
\hline 325 & 0,00 & 0 & 0,5 & 1 & 0,00 & 0 & 0,50 & 1 & 0,00 & 0 & 2 & $1,00 \pm 0,50$ \\
\hline 332 & 0,00 & 0 & 0,00 & 0 & 0,50 & 1 & 0,00 & 0 & 0,50 & 1 & 2 & $1,00 \pm 0,50$ \\
\hline 614 & 0,00 & 0 & 0,00 & 0 & 0,50 & 1 & 0,50 & 1 & 0,00 & 0 & 2 & $1,00 \pm 0,50$ \\
\hline 416 & 0,00 & 0 & 0,00 & 0 & 0,67 & 4 & 0,00 & 0 & 0,33 & 2 & 6 & $0,53 \pm 0,17$ \\
\hline 418 & 0,00 & 0 & 0,13 & 1 & 0,50 & 4 & 0,25 & 2 & 0,13 & 1 & 8 & $0,75 \pm 0,14$ \\
\hline 906 & 0,00 & 0 & 0,25 & 1 & 0,75 & 3 & 0,00 & 0 & 0,00 & 0 & 4 & $0,50 \pm 0,26$ \\
\hline 907 & 0,00 & 0 & 0,30 & 9 & 0,23 & 7 & 0,37 & 11 & 0,10 & 3 & 30 & $0,73 \pm 0,04$ \\
\hline 909 & 0,05 & 1 & 0,10 & 2 & 0,60 & 12 & 0,25 & 5 & 0,00 & 0 & 20 & $0,59 \pm 0,09$ \\
\hline Total & 0,13 & 25 & 0,19 & 36 & $\mathbf{0 , 3 3}$ & 64 & 0,23 & 45 & 0,12 & 24 & 194 & $0,77 \pm 0,01$ \\
\hline
\end{tabular}

FR: frecuencia relativa $(\mathrm{n} / \mathrm{N})$.

$\mathrm{n}$ : número de haplogrupos mitocondriales por Hospital.

$\mathrm{N}$ : número total de haplogrupos mitocondriales por Hospital.

\section{CÁlCULO DE RIESGO DE POLIMORFISMOS DEL GEN NAT2}

En la Tabla 19 se detallan las frecuencias porcentuales de los genotipos paternos, maternos y de los casos con la anomalía LL/PH que conforman las 97 tríadas. 
Tabla 19. Frecuencias porcentuales de los genotipos de los casos, maternos y paternos en las 97 tríadas.

\begin{tabular}{llccc}
\hline \multirow{2}{*}{ Individuos } & $\mathbf{n}$ & \multicolumn{3}{c}{ Genotipos $(\%)$} \\
\cline { 3 - 5 } & & $\mathbf{A A}$ & $\mathbf{A B}$ & $\mathbf{B B}$ \\
\hline casos & 97 & 9,28 & 45,36 & $45 ., 36$ \\
madres & 97 & 12,37 & 42,27 & 45,36 \\
padres & 97 & 11,34 & 50,52 & 38,14 \\
\hline $\mathrm{AA}=\mathrm{NAT} * 44 ; \mathrm{AB}=\mathrm{NAT} * 4 / 567 ; \mathrm{BB}=\mathrm{NAT} * 567 / 567$
\end{tabular}

\subsection{TRANSMISIÓN ALÉLICA}

En 97 casos con LL/PH de los 174 casos totales, se pudo determinar el genotipo de ambos padres. Estos 97 tríos permitieron calcular las frecuencias de todas las posibles combinaciones de genotipos parentales (Tabla 20).

Tabla 20. Combinación de genotipos maternos, paternos y de los casos en las 97 tríadas.

\begin{tabular}{|c|c|c|c|c|c|}
\hline Materno & Paterno & $\begin{array}{c}\text { Casos } \\
\text { AA } \\
\end{array}$ & $\begin{array}{c}\text { Casos } \\
\text { AB } \\
\end{array}$ & $\begin{array}{c}\text { Casos } \\
\text { BB } \\
\end{array}$ & total \\
\hline $\mathrm{AA}$ & AA & - & - & - & - \\
\hline AA & $\mathrm{AB}$ & 4 & 2 & - & 6 \\
\hline $\mathrm{AB}$ & AA & 4 & 2 & - & 6 \\
\hline $\mathrm{AB}$ & $\mathrm{AB}$ & 1 & 11 & 10 & 22 \\
\hline AA & $\mathrm{BB}$ & - & 5 & - & 5 \\
\hline BB & AA & - & 4 & - & 4 \\
\hline BB & $\mathrm{AB}$ & - & 13 & 9 & 22 \\
\hline $\mathrm{AB}$ & BB & - & 7 & 8 & 15 \\
\hline \multirow[t]{3}{*}{ BB } & BB & - & - & 17 & 17 \\
\hline & N Total & 9 & 44 & 44 & 97 \\
\hline & $\%$ & 9,4 & 45,3 & 45,3 & 100,0 \\
\hline
\end{tabular}

Los diferentes 4 métodos estadísticos empleados ponen a prueba la misma hipótesis nula: "la transmisión alélica es igual al 0,5\%”.

\subsubsection{Test de Weinberg (1999)}

En primer lugar aplicamos un modelo de regresión linear en la totalidad de los casos (n: 174). Este análisis es una herramienta poderosa para testear la transmisión alélica, aun cuando no esté disponible el genotipo de alguno de los progenitores, asumiendo equilibrio de Hardy-Weinberg 
(Tablas 21-24). En la tabla 21 se evalúa el conjunto de alelos de riesgo $* 5+* 6+* 7$ comparado con el alelo de referencia *4. También se analizó la contribución al riesgo de presentar la anomalía de cada alelo en forma individual (Tablas 22, 23 y 24, alelos *5, *6 y *7 respectivamente). Las categorías "Todos", "Tucumán + Patagonia", "Tucumán", "Patagonia” y "Resto" fueron establecidas de acuerdo con Poletta y col., (2007).

Tabla 21. Evaluación de los genotipos de riesgo maternos y de los casos en las 174 tríadas, mediante un modelo de regresión linear (alelos de riesgo: $* 5+* 6+* 7)$.

\begin{tabular}{|c|c|c|c|c|c|c|c|c|c|c|}
\hline \multirow{2}{*}{ Hospital } & \multirow{2}{*}{$\mathbf{n}$} & \multirow{2}{*}{ Genotipo } & \multicolumn{4}{|c|}{ Madre } & \multicolumn{4}{|c|}{ Caso } \\
\hline & & & OR & $95 \%$ & $\mathbf{z}$ & $\mathbf{p}$ & OR & $95 \%$ & $\mathbf{z}$ & $\mathbf{p}$ \\
\hline \multirow{2}{*}{ Todos } & \multirow{2}{*}{174} & $4 / 567$ & 0,74 & $0,37-1,49$ & $-0,83$ & 0,406 & 1,51 & $0,79-2,88$ & 1,25 & 0,211 \\
\hline & & $567 / 567$ & 0,96 & $0,49-1,87$ & $-0,12$ & 0,904 & 2,12 & $1,01-4,46$ & 1,96 & 0,049 \\
\hline \multirow{2}{*}{$\begin{array}{c}\text { Tucumán } \\
+ \\
\text { Patagonia }\end{array}$} & \multirow{2}{*}{96} & $4 / 567$ & 1,30 & $0,59-2,89$ & 0,65 & 0,516 & 1,70 & $0,77-3,74$ & 1,32 & 0,188 \\
\hline & & $567 / 567$ & 1,65 & $0,71-3,83$ & 1,17 & 0,242 & 4,37 & $1,55-12,35$ & 2,78 & 0,005 \\
\hline \multirow{2}{*}{ Tucumán } & \multirow{2}{*}{37} & $4 / 567$ & 3,97 & $0,83-19,03$ & 1,73 & 0,084 & 2,18 & $0,41-11,50$ & 0,92 & 0,359 \\
\hline & & $567 / 567$ & 1,77 & $0,50-6,19$ & 0,90 & 0,368 & 6,55 & $0,92-46,52$ & 1,88 & 0,060 \\
\hline \multirow[t]{2}{*}{ Patagonia } & \multirow{2}{*}{59} & $4 / 567$ & 0,80 & $0,29-2,23$ & $-0,42$ & 0.674 & 1,60 & $0,66-3,89$ & 1,04 & 0,299 \\
\hline & & $567 / 567$ & 1,97 & $0,55-7,06$ & 1,04 & 0,298 & 3,60 & $1,05-12,41$ & 2,03 & 0,042 \\
\hline \multirow[t]{2}{*}{ Resto } & \multirow{2}{*}{78} & $4 / 567$ & 0,27 & $0,06-0,85$ & $-1,75$ & 0.080 & 1,03 & $0,33-3,14$ & 0,05 & 0,963 \\
\hline & & $567 / 567$ & 0,38 & $0,35-1,44$ & $-1,43$ & 0,153 & 1,06 & $0,32-3,57$ & 0,10 & 0,918 \\
\hline
\end{tabular}

Todos: todos los hospitales $(803,906,907,909,325,322,332,413,416,418,614)$.

Tucumán + Patagonia: 803, 906, 907, 909.

Tucumán: 803.

Patagonia: 906, 907, 909.

Resto: resto de hospitales: $318,325,322,332,413,416,418,614$.

n: número de tríos.

Del análisis de los SNPs en conjunto que determinan haplotipos de riesgo $(* 5+* 6+* 7)$ se observó riesgo en la categoría "Todos", para los genotipos heterocigotas y homocigotas para los alelos *5, *6 y *7 (OR = 2,12; p = 0,049). Al desagregar esta muestra se observó riesgo en las categorías "Patagonia" $(\mathrm{OR}=3,60 ; \mathrm{p}=0,042)$ y "Tucumán + Patagonia" $(\mathrm{OR}=4,37 ; \mathrm{p}=0,005)$ para los genotipos 567/567 de los casos. No se pudo evidenciar riesgo para la categoría "resto de los hospitales". 
Tabla 22. Evaluación de los genotipos de riesgo maternos y de los casos en las 174 tríadas, mediante un modelo de regresión linear (alelo de riesgo: *5).

\begin{tabular}{lcc}
\hline Hospital & n & Genotipo \\
\hline Todos & 174 & $5 / 467$ \\
& 55 \\
\hline Tucumán + & 96 & $5 / 467$ \\
Patagonia & 55 \\
\hline Tucumán & 37 & $5 / 467$ \\
& & 55 \\
\hline Patagonia & 59 & $5 / 467$ \\
& & 55 \\
\hline Resto & 78 & $5 / 467$ \\
& & 55
\end{tabular}

\begin{tabular}{cccc}
\hline \multicolumn{4}{c}{ Madre } \\
\hline $\mathbf{O R}$ & $\mathbf{9 5 \%}$ & $\mathbf{z}$ & $\mathbf{p}$ \\
\hline 0,97 & $0,61-1,22$ & $-0,13$ & 0.896 \\
1,58 & $0,65-3,86$ & 1,00 & 0,317 \\
\hline 1,16 & $0,63-2,15$ & 0,48 & 0,632 \\
3,47 & $0,42-28,67$ & 1,15 & 0,248 \\
\hline 2,21 & $0,64-2,21$ & 1,26 & 0,208 \\
0,29 & $0,03-3,13$ & 1,02 & 0,309 \\
\hline 1,08 & $0,46-2,23$ & 0,02 & 0,984 \\
----- & ----- & ---- & ---- \\
\hline 0,81 & $0,38-1,72$ & $-0,55$ & 0.582 \\
1,02 & $0,34-2,98$ & 0,01 & 0,990 \\
\hline
\end{tabular}

\begin{tabular}{cccc}
\hline \multicolumn{4}{c}{ Caso } \\
\hline $\mathbf{O R}$ & $\mathbf{9 5 \%}$ & $\mathbf{z}$ & $\mathbf{p}$ \\
\hline 1,61 & $1,02-2,54$ & 2,07 & $\mathbf{0 , 0 3 8}$ \\
2,24 & $1,00-5,01$ & 1,95 & $\mathbf{0 , 0 5 0}$ \\
\hline 1,53 & $0,85-2,75$ & 1,44 & 0,151 \\
2,91 & $0,85-9,94$ & 1,70 & 0,088 \\
\hline 0,75 & $0,29-1,93$ & $-0,59$ & 0.555 \\
1,23 & $0,19-7,94$ & 0,22 & 0,824 \\
\hline 2,44 & $1,06-5,57$ & 2,09 & $\mathbf{0 , 0 3 7}$ \\
5,98 & $1,06-33,71$ & 2,01 & $\mathbf{0 , 0 4 4}$ \\
\hline 1,62 & $0,78-3,35$ & 1,30 & 0,194 \\
2,10 & $0,69-6,41$ & 1,30 & 0,194 \\
\hline
\end{tabular}

Todos: todos los hospitales $(803,906, \overline{, 907,909,325,322,332,413,416,418,614) .}$

Tucumán + Patagonia: 803, 906, 907,909.

Tucumán: 803.

Patagonia: 906, 907, 909.

Resto: resto de hospitales $(318,325,322,332,413,416,418,614)$.

n: número de tríos.

----: falta de convergencia en los estimados.

Para el alelo *5 se evidenció riesgo para los casos en la categoría "Todos" para heterocigotas (OR $=1,61 ; \mathrm{p}=0,038)$ y homocigotas $(\mathrm{OR}=2,24 ; \mathrm{p}=0,050)$. De la misma manera, en "Patagonia", se observó riesgo en los casos heterocigotas $(\mathrm{OR}=2,44 ; \mathrm{p}=0,037)$ y homocigotas $(\mathrm{OR}=5,98 ; \mathrm{p}=$ $0,044)$.

Tabla 23. Evaluación de los genotipos de riesgo maternos y de los casos en las 174 tríadas, mediante un modelo de regresión linear (alelo de riesgo: *6).

\begin{tabular}{|c|c|c|c|c|c|c|}
\hline \multirow{2}{*}{ Hospital } & \multirow{2}{*}{$\mathbf{n}$} & \multirow{2}{*}{ Genotipo } & \multicolumn{4}{|c|}{ Madre } \\
\hline & & & OR & $95 \%$ & $\mathbf{z}$ & $\mathbf{p}$ \\
\hline \multirow[t]{2}{*}{ Todos } & \multirow{2}{*}{174} & $6 / 457$ & 1,01 & $0,60-1,71$ & 0,05 & 0,959 \\
\hline & & 66 & 0,79 & $0,20-3,18$ & $-0,33$ & 0,739 \\
\hline \multirow{2}{*}{$\begin{array}{c}\text { Tucumán } \\
+ \\
\text { Patagonia } \\
\end{array}$} & \multirow{2}{*}{96} & $6 / 457$ & 1,28 & $0,70-2,34$ & 0,79 & 0,427 \\
\hline & & 66 & 0,86 & $0,12-6,14$ & $-0,15$ & 0,878 \\
\hline \multirow[t]{2}{*}{ Tucumán } & \multirow{2}{*}{37} & $6 / 457$ & 1,22 & $0,50-3,00$ & 0,44 & 0,657 \\
\hline & & 66 & ---- & ---- & ----- & ----- \\
\hline \multirow[t]{2}{*}{ Patagonia } & \multirow{2}{*}{56} & $6 / 457$ & 1,22 & $0,54-2,77$ & 0,48 & 0,630 \\
\hline & & 66 & 0,44 & $0,04-5,04$ & $-0,66$ & 0,507 \\
\hline \multirow[t]{2}{*}{ Resto } & \multirow{2}{*}{78} & $6 / 457$ & 0,60 & $0,21-1,70$ & $-0,96$ & 0,335 \\
\hline & & 66 & 0,67 & $0,05-10,64$ & $-0,26$ & 0,797 \\
\hline
\end{tabular}

\begin{tabular}{cccc}
\hline \multicolumn{4}{c}{ Caso } \\
\hline OR & $\mathbf{9 5 \%}$ & $\mathbf{z}$ & $\mathbf{p}$ \\
\hline 0,96 & $0,57-1,60$ & $-0,16$ & 0,870 \\
0,36 & $0,06-2,04$ & $-1,15$ & 0,250 \\
\hline 0,97 & $0,53-1,79$ & $-0,08$ & 0,935 \\
0,65 & $0,04-11,49$ & $-0,29$ & 0,771 \\
\hline 1,48 & $0,59-3,71$ & 0,84 & 0,401 \\
---- & ---- & ---- & ---- \\
\hline 0,70 & $0,31-1,62$ & $-0,82$ & 0,410 \\
0,49 & $0,03-9,11$ & $-0,48$ & 0,631 \\
\hline 1,00 & $0,39-2,53$ & 0,003 & 0,997 \\
----- & ---- & ---- & ---- \\
\hline
\end{tabular}

Todos: todos los hospitales $(803,906,907,909,325,322,332,413,416,418,614)$.

Tucumán + Patagonia: 803, 906, 907, 909.

Tucumán: 803.

Patagonia: 906, 907, 909.

Resto: resto de hospitales $(318,325,322,332,413,416,418,614)$.

n: número de tríos.

----: falta de convergencia en los estimados. 
No se detectaron genotipos de riesgo de los casos cuando se consideró la variante alélica $* 6$, en ninguna de las categorías estudiadas (Tabla 23).

Tabla 24. Evaluación de los genotipos de riesgo maternos y de los casos en las 174 tríadas, mediante un modelo de regresión linear (alelo de riesgo: *7).

\begin{tabular}{|c|c|c|c|c|c|c|c|c|c|c|}
\hline \multirow{2}{*}{ Hospital } & \multirow{2}{*}{$\mathbf{n}$} & \multirow{2}{*}{ Genotipo } & \multicolumn{4}{|c|}{ Madre } & \multicolumn{4}{|c|}{ Caso } \\
\hline & & & OR & $95 \%$ & $\mathbf{z}$ & $\mathbf{p}$ & OR & $95 \%$ & $\mathbf{z}$ & $\mathbf{p}$ \\
\hline \multirow{2}{*}{ Todos } & \multirow{2}{*}{174} & $7 / 456$ & 0,78 & $0,47-1,31$ & $-0,94$ & 0,348 & 1,06 & $0,66-1,70$ & 0,24 & 0,811 \\
\hline & & 77 & 0,88 & $0,19-3,96$ & $-0,17$ & 0,865 & 0,30 & $0,06-1,54$ & $-1,44$ & 0,148 \\
\hline \multirow{2}{*}{$\begin{array}{c}\text { Tucumán } \\
+ \\
\text { Patagonia }\end{array}$} & \multirow{2}{*}{96} & $7 / 456$ & 0,85 & $0,41-1,77$ & $-0,44$ & 0,663 & 2,32 & $1,04-5,15$ & 2,07 & $\mathbf{0 , 0 3 9}$ \\
\hline & & 77 & 1,28 & $0,41-1,77$ & 0,20 & 0,842 & 2,19 & $0,12-40,32$ & 0,53 & 0,598 \\
\hline \multirow[t]{2}{*}{ Tucumán } & \multirow{2}{*}{37} & $7 / 456$ & 1,13 & $0,34-3,75$ & 0,21 & 0,837 & 2,87 & $0,81-10,31$ & 1,63 & 0,104 \\
\hline & & 77 & 0,83 & $0,05-12,83$ & $-0,14$ & 0,890 & ----- & ----- & ----- & ----- \\
\hline \multirow{2}{*}{ Patagonia } & \multirow{2}{*}{56} & $7 / 456$ & 0,79 & $0,31-2,00$ & $-0,50$ & 0,615 & 2,10 & $0,76-5,79$ & 1,43 & 0,153 \\
\hline & & 77 & ---- & ---- & ----- & ---- & 2,19 & $0,12-40,32$ & 0,53 & 0,598 \\
\hline \multirow[t]{2}{*}{ Resto } & \multirow{2}{*}{78} & $7 / 456$ & 0,77 & $0,37-1,61$ & $-0,69$ & 0,493 & 0,61 & $0,32-1,18$ & $-1,48$ & 0,139 \\
\hline & & 77 & 0,82 & $0,10-5,75$ & $-0,26$ & 0,796 & 0,14 & $0,01-1,43$ & $-1,65$ & 0,098 \\
\hline \multicolumn{11}{|c|}{ Todos: todos los hospitales $(803,906, \overline{907,}$} \\
\hline \multicolumn{11}{|c|}{ Tucumán + Patagonia: 803, 906, 907, 909 . } \\
\hline \multicolumn{11}{|c|}{ Tucumán: 803.} \\
\hline \multicolumn{11}{|c|}{ Patagonia: 906, 907, 909.} \\
\hline \multicolumn{11}{|c|}{ Resto: resto de hospitales $(318,325,322,332,413,416,418,614)$. } \\
\hline
\end{tabular}

Para el alelo *7 se observó riesgo para el genotipo heterocigota de los casos $(\mathrm{OR}=2,32 ; \mathrm{p}=0,039)$ sólo en la categoría "Tucumán + Patagonia" (Tabla 24). Cabe aclarar que el riesgo para los genotipos homocigotas para "Tucumán y Patagonia” fue extrapolado de la categoría "Patagonia" por ausencia de homocigotos mutados en la categoría “Tucumán”.

El modelo de regresión linear permite además calcular los riesgos aportados por los genotipos maternos. El análisis de la muestra en su totalidad "Todos los hospitales", como así también de las maternidades agrupadas bajo las categorías "Tucumán”, "Patagonia”, "Tucumán y Patagonia" y el "resto de las maternidades", no evidenció efecto materno para ninguna de las variantes analizadas en conjunto o individualmente (Tablas 21-24).

Para las tres pruebas estadísticas que se detallan a continuación fueron empleadas las 97 tríadas, es decir que se cuenta con el caso y ambos progenitores. Estas pruebas comparan la frecuencia de los alelos transmitidos y los no transmitidos. Tienen la ventaja de ser robustas, aún cuando los datos no se encuentren en equilibrio de Hardy-Weinberg. 


\subsubsection{Test de Desequilibrio de Transmisión (TDT, Spielman y col., 1993)}

La prueba estadística TDT compara la transmisión alélica a partir de padres heterocigotas para detectar si existe un sesgo en la transmisión de los alelos de baja capacidad metabolizadora. La Tabla 25 muestra el número absoluto de trasmisiones y no transmisiones a los casos, a partir de los padres heterocigotas. De un total de 137 transmisiones parentales, el alelo $* 4$ mostró una frecuencia de transmisión de 30,9\% (23+20/137), el alelo $* 5$ de 39,0\%; el $* 6$ de $16,1 \%$ y el alelo $* 7$ de $14,0 \%$.

Tabla 25. Transmisión alélica de padres heterocigotas en tríadas padre-madre-caso.

\begin{tabular}{ccccc}
\hline \multirow{2}{*}{ Alelos } & \multicolumn{2}{c}{ Madre } & \multicolumn{2}{c}{ Padre } \\
\cline { 2 - 5 } & transmitido & no transmitido & transmitido & no transmitido \\
\hline 4 & 23 & 20 & 20 & 29 \\
5 & 25 & 17 & 28 & 16 \\
6 & 10 & 13 & 12 & 11 \\
7 & 9 & 17 & 10 & 14 \\
\hline total & $\mathbf{6 7}$ & $\mathbf{6 7}$ & $\mathbf{7 0}$ & $\mathbf{7 0}$ \\
\hline
\end{tabular}

A continuación se muestra el análisis TDT (Spielman y col., 1993) para cada uno de los alelos en forma independiente.

Tabla 26. Análisis TDT en tríadas padre-madre-casos.

\begin{tabular}{ccccccccc}
\hline Alelo & ++ & +- & -+ & -- & OR $(\mathbf{9 5 \%}$ IC) & TDT & p & FA $(\%)$ \\
\hline$* 4$ & 0 & 43 & 48 & 46 & $0,90(0,59-1,35)$ & 0,27 & 0,603 & 3,3 \\
$* 5$ & 0 & 53 & 33 & 51 & $1,61(1,04-2,47)$ & 4,65 & $\mathbf{0 , 0 3 1}$ & 18,0 \\
$* 6$ & 0 & 22 & 25 & 90 & $0,88(0,50-1,56)$ & 0,19 & 0,663 & 1,7 \\
$* 7$ & 0 & 19 & 31 & 87 & $0,61(0,35-1,08)$ & 2,88 & 0,090 & 5,9 \\
\hline
\end{tabular}

++ : transmitieron ambos progenitores.

+ -: transmitió la madre y no transmitió el padre.

- +: no transmitió la madre y transmitió el padre.

- - : ningún progenitor transmitió.

FA: fracción atribuible.

Puede observarse que con la presencia del alelo $* 5$ existe un $60 \%$ riesgo de tener la anomalía (OR $=1,61 ; \mathrm{p}=0,031)$. El 18\% de la ocurrencia de los casos con LL/PH podría atribuirse a la presencia del alelo *5. Mientras que el 10,9\% de los casos fueron prevenidos por la presencia de los alelos $* 4$ $+* 6+* 7$. Tabla 26 . 


\subsubsection{Análisis no pareado de genotipos de los casos y de los padres (GHRR, Falk y}

\section{Rubinstein, 1987)}

Este análisis no diferencia entre la presencia de homocigotas o heterocigotos para los alelos de riesgo tanto en los casos como en los pseudocontroles y considera la presencia del alelo en el conjunto de los casos y en el conjunto de los pseudocontroles.

Tabla 27. Test GHRR en tríadas padre-madre-casos.

\begin{tabular}{ccccccccc}
\hline Alelo & A & B & C & D & OR $(\mathbf{9 5 \%}$ IC) & GHRR & p & FA $(\%)$ \\
\hline$* 4$ & 53 & 58 & 44 & 39 & $0,81(0,46-1,43)$ & 0,53 & 0,468 & 6,1 \\
$* 5$ & 62 & 42 & 35 & 55 & $2,32(1,30-4,13)$ & 8,29 & $\mathbf{0 , 0 0 4}$ & 32,2 \\
$* 6$ & 26 & 29 & 71 & 68 & $0,86(0,46-1,60)$ & 0,23 & 0,633 & 1,9 \\
$* 7$ & 21 & 31 & 76 & 66 & $0,58(0,31-1,12)$ & 2,63 & 0,105 & 6,3 \\
\hline
\end{tabular}

A: presencia del alelo en el caso.

B: presencia del alelo en el pseudocontrol.

C: ausencia del alelo en el caso.

D: ausencia del alelo en el pseudocontrol.

FA: fracción atribuible.

Se observa un riesgo dos veces mayor de tener la variante alélicas $* 5$ y presentar la anomalía $(\mathrm{OR}=$ $2,32 ; \mathrm{p}=0,004)$. El 32,2\% de la ocurrencia de los casos con LL/PH podría atribuirse a la presencia del alelo $* 5$. De otro modo, el 14,3\% de los casos fueron prevenidos por la presencia de los alelos $* 4+* 6+* 7$. Tabla 27.

\subsubsection{Análisis pareado de genotipos de los casos y paternos (MGHR, Terwilliger y Ott, 1992)}

Este análisis, al igual que el GHRR, no diferencia entre la presencia homocigotos y heterocigotos para los alelos de riesgo tanto en los casos como en los pseudocontroles y considera la presencia del alelo en el caso y su pseudocontrol apareado.

Se observa un riesgo dos veces mayor de tener la variante $* 5$ y presentar la anomalía. (OR $=2,32 ; \mathrm{p}=0,005)$. Tabla 28 . 
Tabla 28. Test MGHR en tríadas padre-madre-casos.

\begin{tabular}{ccccccccc}
\hline Alelo & A & B & C & D & OR $(\mathbf{9 5 \%}$ IC) & MGHR & p & FA (\%) \\
\hline$* 4$ & 32 & 21 & 26 & 18 & $0,81(0,45-1,43)$ & 0,53 & 0,466 & 6,1 \\
$* 5$ & 27 & 35 & 15 & 20 & $2,32(1,29-4,20)$ & 8,00 & $\mathbf{0 , 0 0 5}$ & 32,2 \\
$* 6$ & 9 & 17 & 20 & 51 & $0,86(0,45-1,62)$ & 0,24 & 0,622 & 1,9 \\
$* 7$ & 6 & 15 & 25 & 51 & $0,58(0,32-1,13)$ & 2,50 & 0,114 & 6,3 \\
\hline
\end{tabular}

A: presencia del alelo en el caso.

B: presencia del alelo en el pseudocontrol.

C: ausencia del alelo en el caso.

D: ausencia del alelo en el pseudocontrol.

FA: fracción atribuible.

El 32,2\% de la ocurrencia de los casos con LL/PH podría atribuirse a la presencia del alelo $* 5$. De otro modo, el 14,3\% de los casos fueron prevenidos por la presencia de los alelos $* 4+* 6+$ *7. 


\section{DISCUSIÓN}

“Como un ganso desplumado y escuálido, me preguntaba a mí mismo con voz indecisa si de todo lo que estaba leyendo haría el menor uso alguna vez en la vida". James Clerk Maxwell, sobre su educación en Cambridge

\section{CARACTERIZACIÓN DE LA POBLACIÓN}

La prevalencia de las fisuras orales varía según el origen geográfico, la ancestría y las condiciones socioeconómicas. Si los factores genéticos estuvieran contribuyendo al riesgo de desarrollar LL/PH, la distribución de los alelos de susceptibilidad podría estar influenciada por la diversidad étnica. Consistente con esta hipótesis, varios estudios han demostrado que las frecuencias de NAT2 difieren a lo largo de las diversas poblaciones humanas (Agúndez y col., 1996; Garte y col., 2001).

En Europa y África, la variante *5 registra altas frecuencias 50-60\% (Agúndez y col., 1996; Bradford, 2002; Hamdy y col., 2003), una baja frecuencia (4\%) en asiáticos (Lin y col., 1993) y frecuencias intermedias (10-33,3\%) en nativos americanos (Bailliet y col., 2007; Fuselli y col., 2007). El alelo *6 es frecuente en poblaciones europeas $(28,5 \%)$, asiáticas (31\%) y africanas (26\%), pero infrecuente (6\%) en poblaciones nativas americanas (Bailliet y col., 2007; Garte y col., 2001; Lin y col., 1993). Este alelo, cuando se observa en poblaciones americanas en moderadas frecuencias, podría indicar mezcla post-colombina. Por su parte, el alelo $* 7$ es característico de poblaciones asiáticas y nativas americanas con frecuencias entre 15-24\% e infrecuente en poblaciones africanas (2,8\%). (Bailliet y col., 2007; Fuselli y col. 2007; Hamdy y col., 2003; Lin y col., 1993) En este trabajo, las frecuencias de los SNPs de NAT2 que definen los haplotipos $* 4, * 5$, $* 6$ y $* 7$ en las maternidades estudiadas del ECLAMC fueron 37\%, 33\%, $15 \%$ y $15 \%$ respectivamente. Del mismo modo, las frecuencias de los genotipos que determinan fenotipos acetiladores lentos, varían en función de la zona geográfica y la ancestría. En europeos, la población de metabolizadores lentos oscila entre un 40\% y un 70\%. En particular, en España, dicho porcentaje es de un 57\% (Ladero y col., 1979). Sin embargo, en poblaciones orientales la frecuencia es mucho más baja con valores próximos a 10\% (Evans, 1992). En otras poblaciones como en egipcios y marroquíes el porcentaje de acetiladores lentos alcanza un 60,5\% (Hamdy y col., 2003). En nativos-americanos el promedio de los fenotipos metabolizadores lentos es de $25 \%$ (Fuselli y col., 2007). En particular, en nuestra muestra, el rango de individuos con fenotipo metabolizador lento fue amplio (10\%-69\%), alcanzando una frecuencia promedio de $41 \%$. De la comparación de estos trabajos con nuestros resultados, observamos que las frecuencias alélicas y los genotipos que determinan fenotipo bajo acetilador de las maternidades del ECLAMC son 
intermedias, evidenciando la contribución europea e indígena al acervo genético de las poblaciones argentinas actuales.

Las frecuencias halladas en este trabajo para las variantes alélicas de NAT2 revelan en parte la historia de la conformación de la población argentina. En relación con esto último, se sabe que la población contemporánea es consecuencia de sucesivos eventos de colonización e inmigración. La población actual es el resultado de múltiples interacciones ocurridas entre la población nativa del continente y las personas llegadas luego de la Conquista Española, que incluyó no sólo a individuos provenientes de Europa sino también a africanos traídos como mano de obra esclava. Desde 1850, la Argentina se constituyó en un polo de atracción de inmigración europea y de países limítrofes (Censo Nacional de Población y Vivienda 2001, INDEC).

Al estudiar la distribución de frecuencias de las variantes alélicas de NAT2 en las maternidades del ECLAMC, se pudo determinar que el coeficiente de diferenciación genética $\left(\mathrm{F}_{\mathrm{ST}}\right)$, fue bajo $(0,01-0,02)$ entre los hospitales que se analizaron en los diferentes abordajes. En los 4 análisis, el $98 \%$ de variabilidad fue encontrada dentro de las maternidades y el $2 \%$ restante dentro de los grupos, entre maternidades, siendo la diferenciación entre grupos menor al 0,2\%. Sólo la AMOVA realizada entre maternidades ubicadas en regiones de alta frecuencia de LL/PH registró un $2 \%$ de la variabilidad entre grupos. El mismo valor fue hallado en la categoría entre grupos en el AMOVA que considera todos los hospitales en conjunto. Es decir, la diferencia entre grupos calculado entre las maternidades de Tucumán y Patagonia es responsable de las diferencias entre maternidades en el análisis de todos los hospitales en conjunto. Estos resultados concuerdan con los publicados por Poletta y col., (2007) quienes hallaron en Argentina dos regiones geográficas con alta frecuencia de LL/PH: Tucumán y Patagonia.

Las frecuencias de los genotipos de NAT2 estudiados fueron valoradas mediante el equilibrio de Hardy-Weinderg. Mediante esta prueba, la presencia de una asociación estadística independiente del azar entre el genotipo y el fenotipo podría implicar algún tipo de asociación biológica, directa o indirecta, o de riesgo de padecer la anomalía en función de determinado genotipo. Tradicionalmente, la desviación del equilibrio se ha considerado como una indicación de que los alelos no segregan de forma independiente, que el apareamiento no es al azar, o que los alelos reflejan una mutación reciente que aún no ha alcanzado el equilibrio. Las frecuencias de las maternidades del ECLAMC se encuentran en equilibrio de Hardy-Weinberg, a excepción de la Maternidad Sardá de la ciudad autónoma de Buenos Aires (Hospital 318). Este resultado podría deberse a que este hospital funciona como un Centro Perinatológico de alta complejidad que recibe derivación de otros nosocomios y atiende grupos poblacionales diversos.

Si bien el análisis molecular de la varianza no mostró diferencias entre las maternidades y las frecuencias alélicas estudiadas se encuentran en equilibrio de Hardy-Weinberg (excepto la 
Maternidad Sardá), no se pueden descartar que existan asociaciones desconocidas que no han sido controladas o la existencia de una subestructura poblacional. Para tratar de eliminar estos potenciales inconvenientes, se empleó en este trabajo un diseño de tríos caso-progenitores para controlar la variable de confusión ancestralidad. Debido a la existencia, en la población argentina, de una alta mezcla génica y dado que las frecuencias de LL/PH son variables según grupo étnico, se considera inadecuado el empleo de diseños caso-control y se promueve el uso de tríos casoprogenitores para el estudio de asociaciones.

Otra forma de caracterizar a la población es mediante el análisis de ancestralidad empleando marcadores uniparentales como el ADN mitocondrial y el cromosoma Y. Su análisis complementa y enriquece la información obtenida a partir de polimorfismos autosómicos. Los marcadores binarios del cromosoma $\mathrm{Y}$ empleados en este trabajo permiten definir dos grandes grupos: los linajes nativos americanos por un lado y todos los linajes alóctonos por el otro. Para la muestra empleada en este trabajo el $78 \%$ de los padres presentaron haplogrupos no amenidios y el $22 \%$ restante presentaron haplogrupos nativos americanos, de un total de 201 padres de niños con LL/PH. La distribución de frecuencias de los haplogrupos nativos americanos (QM242 + QM3) fue variable entre los distintos hospitales, estas frecuencias en general fueron bajas y nunca superaron el 50\%. Estas observaciones podrían ser resultado de un sesgo en el muestreo o bien ser consecuencia de eventos histórico-poblacionales que caracterizan a la población que asiste a cada uno de los centros hospitalarios. Wang y col., (2008), de acuerdo con nuestros resultados, reportaron en un estudio realizado en 13 ciudades latinoamericanas en las que fueron analizados 249 individuos, que la fracción poblacional con ancestría amerindia presentó frecuencias muy variables (Tucumán 30\%, Salta 72\% y Catamarca 44\%). En un estudio realizado en la región Centro de Argentina (García y col., 2008), fueron identificaron haplogrupos nativos americanos en de distintas localidades de Córdoba y San Luis y sólo el 7,3\% de 109 varones, presentó el haplogrupo nativo americano Q1a3a. Este porcentaje constituye una estimación mínima pues los autores no han considerado el linaje paterno autóctono definido por la mutación M242(Q). Asimismo, Corach y col., (2010) analizaron al ancestralidad de 246 varones de ocho provincias argentinas y determinaron que sólo el $2 \%$ presentaban haplogrupos nativos americanos. Ambos trabajos, en concordancia con nuestras observaciones, evidencian que la presencia de linajes autóctonos varía considerablemente en la Argentina.

El análisis sobre diversidad de ADN mitocondrial presentó un panorama muy diferente al del cromosoma Y. De un total de 194 padres y madres de niños con LL/PH, el 88\% presenta un antepasado femenino natural del continente, resultando representados los cuatro haplogrupos panamericanos detallados en la literatura (Achilli y col., 2008). En Argentina, las frecuencias de ADNmt amerindio son variables. Dipierri y col. (1998) hallaron el 100\% de ADNmt amerindio en dos poblaciones en la provincia de Jujuy (San Salvador y Humahuaca) y Demarchi y col., (2001) 
reportaron un 98\% de contribución de genes amerindios en poblaciones indígenas del Gran Chaco. En el centro de Argentina, García (2011) halló una frecuencia promedio de 78\% en las poblaciones de Córdoba y de 87\% en San Luis. En el área metropolitana de Buenos Aires 44\% (Dejean y col., 2003), en Bahía Blanca 47\% (Avena y col., 2007) y en Comodoro Rivadavia fue del 70\% (Avena y col., 2009) En las poblaciones indígenas, el porcentaje supera el 97\% (Bravi, 2004; Lalueza y col., 1997). Por su parte, Corach y col., (2010) en un estudio que abarcó el análisis de 246 individuos de varias provincias argentinas estimaron una frecuencia promedio de 54\%. Nuestros resultados, como los reportados en la literatura, revelan el aporte de los pueblos originarios a la conformación de las poblaciones actuales, a pesar de haber sido diezmadas por dos prácticas tan inhumanas como sistemáticas: las campañas militares de conquista y de represión contra las reiteradas formas de resistencia y las terribles condiciones de explotación y miseria a la que fueron sometidos. Para las Leyes de Indias, los nativos americanos sometidos por los conquistadores eran vasallos de la corona, supuestamente libres e iguales a los del reino de Castilla. Estaban, como esos súbditos, obligados a pagar tributo al monarca y diezmo a la Iglesia. Pero a diferencia de otros vasallos (los peninsulares y criollos), su condición jurídica era asimilada a la de un menor o "rústico", que para la antigua legislación castellana significaba que no podía valerse por sí mismo, sino que siempre alguien debia tutelar sus intereses. En principio, el sistema de esta tutela fue el de la encomienda, que ponía a un poblado indígena completo bajo el control de un encomendero, quien supuestamente a cambio de velar por los intereses de esa comunidad y promover su conversión al cristianismo - tenía el derecho de exigir servicio personal, que se convertía en la explotación de la mano de obra de sus encomendados. El encomendero podía sacarlos de la comunidad que integraban y en las que vivían, el sistema se parecía así al de la servidumbre feudal europea, en el cual los siervos debían trabajar parte del tiempo en las tierras señoriales y el resto en sus tierras comunales o familiares. Sin embargo, la práctica era diferente. Muchos nativos americanos encomendados eran, de hecho, forzados a trabajar en forma permanente en las propiedades del encomendero, lo que de hecho los convertía en siervos personales de los dueños de haciendas y obrajes. Esto último reducía el cobro del tributo o diezmo que debían recibir las autoridades y la Iglesia. Por esta razón se establecieron las reducciones y pueblos de nativos, que formalmente continuaban con sus autoridades y supervisados por corregidores. Esta medida significó un mayor control oficial y un despoblamiento de las comunidades. A pesar del doble genocidio, el impuesto por las conquistas militares y las extremas condiciones de explotación a las que fueron sometidos, el acervo genético autóctono en poblaciones urbanas actuales es aún significativo.

En cuanto a su origen continental, Dipierri y col., (1998), en un estudio sobre muestras de San Salvador de Jujuy y la Quebrada de Humahuaca, reportaron completa ancestría americana por vía materna, en tanto 40,5\% de los linajes masculinos serían introducidos, con frecuencias que disminuyen en relación con la altura sobre el nivel del mar de la población considerada. En el 
noroeste colombiano se registró la misma tendencia asimétrica, con un $90 \%$ de linajes mitocondriales americanos y un $99 \%$ de cromosomas Y de procedencia extracontinental (Bedoya y col., 2006; Carvajal-Carmona y col., 2000). Los linajes femeninos y masculinos de la muestra del ECLAMC fueron absolutamente dispares entre sí. Mientras que un $88 \%$ de los haplogrupos maternos se clasifican como americanos, el 78\% de los haplogrupos masculinos tienen procedencia foránea. Estos resultados convalidan los registros históricos sobre mestizajes en Centro y Sudamérica, involucrando mayormente a mujeres americanas y hombres extranjeros. Este fenómeno de sesgo de origen según el sexo, sería común a toda América Latina.

\section{¿HAY EVIDENCIA DE ASOCIACIÓN ENTRE LOS ALELOS QUE DETERMINAN FENOTIPO ACETILADOR LENTO Y LL/PH?}

A fin de evaluar la asociación entre las variantes alélicas que determinan el fenotipo acetilador lento y la presencia de LL/PH, en un primer análisis se consideraron en conjunto las variantes $* 5, * 6 \mathrm{y} * 7$, combinando los tríos de todas las maternidades en detrimento de la homogeneidad genética. En la muestra total se encontró un riesgo significativo dos veces mayor de tener LL/PH cuando el genotipo fetal es homocigota para los alelos de riesgo. Las maternidades fueron categorizadas según los agrupamientos geográficos detectados por Poletta y col., (2007), quienes identificaron dos áreas geográficas en Argentina con alta prevalencia al nacimiento de LL/PH: Noroeste y Patagonia. La ventaja de estos agrupamientos radica en que permite suponer, por un principio de parsimonia, que la anomalía sea resultado de un único factor causal que compromete específicamente al agregado. Nuestros resultados mostraron riesgos significativos para las categorías "Tucumán + Patagonia" y "Patagonia", para los genotipos con 2 alelos de riesgo en los casos. La categoría "Tucumán” mostró el mayor riesgo pero no evidenció significancia estadística, debido probablemente al bajo número de tríos caso-progenitores en esta región (error de tipo $\beta)$.

Posteriormente, se evaluó de manera individual el riesgo de las variantes alélicas *5, *6 y *7 en las mismas categorías definidas previamente. De estos análisis se desprende que no hay evidencia de asociación de LL/PH y la variante *6. En relación con el haplotipo *7, se observa riesgo para el genotipo heterocigota $(\mathrm{OR}=2,32 ; \mathrm{p}=0,039)$, sólo en la categoría "Tucumán + Patagonia". En relación con el haplotipo *5 evidenciamos asociación en "Todos los hospitales" $(\mathrm{OR}=1,61 ; \mathrm{p}=0,038$ para heterocigotas $\mathrm{y} \mathrm{OR}=2,24 ; \mathrm{p}=0,050$ para homocigotas $), \mathrm{y}$ en Patagonia ( $O R=2,44 ; \mathrm{p}=0,037$ para heterocigotas y $\mathrm{OR}=5,98 ; \mathrm{p}=0,044$ para homocigotas), de estos resultados se desprende que Patagonia es la responsable del riesgo aumentado en la categoría "Todos". Así, las variantes *5 $\mathrm{y}^{* 7}$ pero no la variante $* 6$, son responsables del riesgo calculado 
para las SNPs $* 5+* 6+* 7$ en el conjunto de todos los hospitales. Se observa además que en Patagonia el alelo *5 es el responsable del riesgo, mientras que en Tucumán es el alelo*7.

El modelo de regresión linear permite además, conocer la relativa importancia de los genotipos maternos a la causalidad de la anomalía estudiada. Mediante esta prueba no pudimos detectar efecto materno para ninguna de las variantes analizadas en forma individual o en conjunto. De igual modo, Lie y col., (2008) no evidenciaron efecto materno en una muestra de 314 tríos casoprogenitores en Noruega ( $\mathrm{OR}=1,00 ; \mathrm{IC}=0,5-1,8)$. Contrariamente Shi y col., (2007) evidenciaron un $20 \%$ más de riesgo $(\mathrm{p}=0,03)$ de padecer la anomalía si la madre del caso tiene un alelo de riesgo.

Un acercamiento diferente para detectar asociación es a través de la prueba conocida como Test de Desequilibrio de Transmisión (TDT). La misma, demostró un riesgo significativo 60\% mayor de desarrollar la malformación LL/PH en presencia del alelo *5. Asimismo, este mismo alelo demostró estar asociado de forma positiva con la ocurrencia de la malformación en las pruebas MGHR y GHRR que comparan las frecuencias alélicas entre casos y pseudocontroles. La diferencia entre ambos, es que el GHRR, controla la variabilidad intrafamiliar.

En relación con la hipótesis planteada en este trabajo, nuestros resultados confirman la asociación del alelo *5 y la ocurrencia de LL/PH. Los resultados hallados en la literatura son contradictorios. Lammer y col., (2004), en una muestra de la población de California (EE.UU) no detectaron asociación entre LL/PH y variantes fetales del gen NAT2 ( $\mathrm{OR}=0,85$; IC $=0,57-1,3)$. También, Van Rooij y col., (2002), determinaron el estatus acetilador a partir de la medición de metabolitos de cafeína en la orina, concluyendo que los individuos caracterizados como acetiladores lentos no presentaban riesgo para fisuras orales $(\mathrm{OR}=1,0 ; \mathrm{p}>0,05)$ en comparación con los acetiladores rápidos. Ambos estudios utilizaron metodología caso-control, susceptible de sesgo debido a la estratificación genética o mezcla racial de la población.

Lie y col., (2008) en un estudio combinado caso-control y de tríadas en Noruega, confirmaron el riesgo del consumo de tabaco en el primer trimestre para LL/PH (OR $=1,6 ; 95 \%$ intervalo de confianza $=1,0-2,5)$ para fumadoras pasivas y hasta $1,9(0,9-0,4)$ para madres que fuman más de 10 cigarrillos al día. Hallaron a partir del estudio de tríadas, pero no a través del caso-control, una asociación entre el haplotipo NAT2* 6 y LL/PH $(\mathrm{OR}=1,6$ para heterocigotas y 2,5 para homocigotas) pero con poca evidencia de interacción con consumo de tabaco. Los haplotipos de los casos *4, *5 y *7 no fueron factores de riesgo para esta malformación. Asimismo, los SNPs maternos *4, *5, *6 y *7 no mostraron asociación con la anomalía. La misma relación fue puesta a prueba por Shi y col., (2007) en una muestra conformada por 5.427 individuos de Dinamarca e Iowa, estudiaron 25 SNPs en 16 genes de la ruta de detoxificación del humo del cigarrillo. A través del método de análisis TDT, evidenciaron una sobretransmisión del alelo NAT2 
G590A (alelo *6) ( $\mathrm{p}<0,05)$. Asimismo, Zöllner y col., (2004), utilizando análisis de ligamiento en 148 familias, demostraron evidencia de transmisión diferencial en varias regiones del genoma humano, en una de las cuales se encuentra ubicado el cromosoma 8, coincidiendo con la ubicación cromosómica de NAT2.

Paralelamente a los trabajos de genes candidatos, varios estudios poblacionales a gran escala basados en mapas SNPs han sido publicados (Beiraghi y col., 2007; Radhakrisha y col., 2006). Marazita y col., (2004), a partir de un meta-análisis, hallaron asociación positiva en seis regiones del genoma, ninguna en el cromosoma 8. Birnbaum y col., (2009) a partir de un estudio caso-control basado en mapas de SNPs hallaron evidencia significativa de asociación en la región 8q24.21. Este trabajo confirmó el marcador rs987525 como el más significativo ( $\mathrm{p}=3,34 \times 10^{(-24)}$; $\mathrm{OR}=2,57$ para heterocigotas y $\mathrm{OR}=6,05$ para homocigotas). El riesgo poblacional atribuible para este marcador fue de 0,41 , sugiriendo ser el principal locus de susceptibilidad para LL/PH. Beaty y col., (2010), en un estudio tríos caso-progenitores confirmaron los hallazgos de Birnbaun y col., (2009) en la misma región.

En este complejo escenario, hay varias posibles razones para los resultados discordantes de NAT2 en los estudios de asociación. A pesar de que la mayor cantidad de estudios se ha realizado en poblaciones europeas, las muestras han sido heterogéneas en varios sentidos. Existe controversia en la literatura acerca de la anomalía LL/PH como grupo único y homogéneo. Clásicamente el labio leporino, ya sea con o sin paladar hendido, se ha considerado como una única entidad, difiriendo solamente en su grado de severidad (Mitchell y col., 2002). No obstante, y a pesar de la escasa literatura existente, por algunas diferencias clínico-epidemiológicas y diferencias fenotípicas, algunos autores recomiendan considerarlos para su análisis como entidades separadas (Harville y col., 2005). Las fisuras pueden variar desde bilaterales completas hasta fisuras mínimas, como por ejemplo micro formas o filtro labial plano. Podríamos suponer que cada subfenotipo de LL/PH podría contar con factores de riesgo específicos. Los diferentes resultados también podrían deberse a la posibilidad de que exista heterogeneidad alélica o de locus. La primera ocurre cuando el fenotipo o anomalía de interés es causado por distintos alelos y la heterogeneidad de locus sucede cuando distintos loci pueden causar el mismo fenotipo. Además, las discrepancias halladas en la literatura, podrían deberse a la existencia de una heterogeneidad genética intra e interpoblacional. Es probable que, los diferentes genes candidatos involucrados en esta patología, difieran en su importancia relativa en cada población analizada, dependiendo ello de la frecuencia alélica que presenten en diferentes poblaciones ya sean o no del mismo origen étnico. Finalmente, los resultados disidentes podrían deberse a diferentes tipos de diseños (caso control-versus tríadas), diferentes tipos de análisis, diferentes marcadores de NAT2 empleados y/o diferentes tamaños muestrales. Cualquiera de estos factores pudo haber sido responsable de la discordancia en los resultados, registrándose asociaciones positivas y negativas. 


\section{HAY EVIDENCIA DE ASOCIACIÓN: ¿CUÁL ES SU SIGNIFICADO?}

La interpretación de la asociación no es trivial y puede deberse a distintas causas:

a) la asociación es debida a la estratificación poblacional.

b) el alelo por sí mismo es el responsable de la susceptibilidad a la anomalía.

c) el alelo asociado está en desequilibrio de ligamiento (LD) con el alelo de susceptibilidad.

Se sabe que para un estudio genético lo más importante es que los controles sean del mismo acervo genético. La estrategia de este trabajo fue reclutar tríos (sujeto afectado con sus dos padres) y utilizar la información genotípica del cromosoma no transmitido de los padres como control, a fin de reducir la posibilidad de encontrar falsos positivos por estratificación poblacional. Por este motivo, la opción "a" es desestimada pues el factor de confusión ancestralidad ha sido ajustado con el diseño empleado.

Para reconocer si estamos en presencia de loci causales o de predisposición, la condición indispensable es conocer el modo de herencia de esta anomalía. Actualmente, ningún agente causal específico ha sido identificado para la mayoría (50-70\%) de las FO (Mitchell, 2002). Sin embargo para LL/PH, el factor de riesgo identificado más consistente, es la presencia de una historia familiar positiva. Los patrones de recurrencia familiar de LL/PH rechazan el modelo de segregación mendeliana de un solo gen de penetrancia completa, al observar patrones de recurrencia familiar con valores de concordancia menores al $100 \%$ en gemelos monocigóticos, disminución de riesgo de forma no lineal a medida que el grado de parentesco disminuía en relación al probando y riesgos de recurrencia concordantes con grado de severidad del paciente y cantidad de miembros de la familia afectados (Carter, 1969). Por esta razón LL/PH es clasificado como una anomalía genéticamente compleja.

Otro modelo propuesto para explicar la herencia de LL/PH son los estudios multifactoriales de hipótesis umbral. Estos modelos trabajan con el supuesto que un determinado rasgo está determinado por pequeños, iguales y aditivos efectos genéticos y ambientales. La dicotomía de los fenotipos está determinada por un umbral a partir del cual los individuos padecen la anomalía. Estos modelos son compatibles con valores de concordancia menores al $100 \%$ en gemelos monocigóticos, disminución de riesgo de forma no lineal a medida que el grado de parentesco disminuye en relación al probando y riesgos dependientes de la severidad del probando y casos familiares. 
El modelo de un solo gen y el de hipótesis umbral representan los extremos de la variedad de modos de herencia. Actualmente se reconoce que el modo de herencia de LL/PH se ubica entre estos dos extremos.

En la actualidad, los análisis de segregación compleja permiten evaluar simultáneamente modelos de herencia de un único locus y de hipótesis umbral. Estos estudios permiten una estimación probabilística de varios factores genéticos: probabilidades de transmisión, frecuencias genéticas y parámetros de penetrancia para los modelos mendelianos; heredabilidad, promedios muestrales y varianzas para los modelos poligénicos; y ambos tipos de parámetros para lo que se denomina el modelo mixto. En relación con los trabajos publicados, los resultados que se desprenden de este tipo de análisis son muy variados, incluyendo herencia multifactorial como así también un solo gen en forma dominante o recesiva con o sin componente multifactorial. La inconsistencia de los resultados desprendidos de los estudios de segregación compleja podría ser atribuida a una heterogeneidad genética, es decir, en las diferentes poblaciones podrían operar mecanismos diferentes. Sin embargo, existe un patrón similar de recurrencia familiar a lo largo de las variadas poblaciones, de modo tal que la discordancia de los resultados parecería deberse más a un bajo poder de discriminación (Smith, 1971; Ott, 1990).

En Patagonia, en la misma población que hemos analizado en esta tesis, a partir de un estudio de segregación compleja, Poletta (2010) sugiere el efecto de un gen principal en la ocurrencia de LL/PH, cuya acción podría ser modificada por la acción de otro locus y/o de un factor de exposición ambiental. Este gen principal dominante tendría una baja penetrancia (6 a $15 \%)$ y la frecuencia del alelo de riesgo sería entre 1 y $9 \%$, sumada a la de un componente multifactorial (o varianza residual familiar no explicada por el gen principal). Otro aporte, relevante para la interpretación de nuestros resultados, y que significó un hallazgo trascedental en el estudio de LL/PH, fue la evidenca de la contribución de IRF6 a LL/PH (Zucchero y col., 2004). Estos autores evaluaron 8.003 individuos en 1.968 familias de poblaciones asiáticas, euopeas y de Norte y Sudamérica. Este trabajo reveló que todos los genes que contribuyen a la anomalía LL/PH, que aún no han sido identificados, tienen efectos muy pequeños comparados con el de IRF6 en la ocurrencia de LL/PH. En relación con los estudios de segregación de Poletta (2010) y la evidencia reportada por Zuchero y col., (2004), NAT2 no es un factor necesario ni suficiente para la producción de LL/PH. Sin embargo, no podemos desestimar alguna participación en la generación de fisuras como parte de ese componente multifactorial o varianza residual no explicada por el gen principal. Esta afirmación está sustentada además por el valor calculado de la fracción atribuible para la variante $* 5(32,2 \%)$. Claramente la mayor proporción de casos de LL/PH son resultado de otros agentes etiológicos, no asociados a estos alelos. 
Cuando el alelo asociado está en desequilibrio de ligamiento (LD) con el alelo de susceptibilidad, significa específicamente que existe una asociación no al azar entre dos marcadores alélicos heredados. Para apreciar la naturaleza de las asociaciones debidas a desequilibrio de ligamiento es necesario comprender cómo ocurren. Cuando una mutación aparece inicialmente en el genoma, ésta se produce en una zona particular del cromosoma y está en completo desequilibrio de ligamiento con cualquier marcador polimórfico adyacente en el ADN. Por ejemplo, si una mutación, M, ocurre próxima al locus A (con frecuencias alélicas de 0,6 y 0,4 para las variantes A1 y A2 respectivamente), A1 estará asociado un 100\% con M. Esto es una asociación de base poblacional entre A1 y $\mathrm{M}$ debido a un completo desequilibrio de ligamiento entre $\mathrm{M}$ y el locus A. Con el tiempo y los mecanismos de recombinación, M eventualmente estará en el mismo cromosoma que A1 un 60\% de las veces y un $40 \%$ con A2. Es decir, el ligamiento todavía existe, pero la asociación debido a desequilibrio de ligamiento desapareció y M y A alcanzaron así equilibrio de ligamiento.

En ausencia de selección, el grado de desequilibrio de ligamiento depende de dos factores: la distancia entre el marcador y la mutación que confiere susceptibilidad y el tiempo transcurrido tanto para la mutación que confiere susceptibilidad como para el marcador. Una reciente mutación que confiere susceptibilidad estará en desequilibrio de ligamiento con su adyacente marcador genético en relación con la distancia que los separe. Por ejemplo, mutaciones ocurridas alrededor de 60.000 años atrás demostraron estar en desequilibrio de ligamiento con marcadores adyacentes cuando el grado de recombinación entre ellos era de 1 en 1.000 (Cavalli-Sforza y Bodmer, 1971). Sin embargo, las más antiguas mutaciones demuestran que no sólo el desequilibrio de ligamiento depende de las distancia sino también de la tasa mutacional de los marcadores adyacentes. De esta manera las mutaciones recientes de los marcadores estarán en diverso grado en desequilibrio con los alelos de la anomalía, mientras que las antiguas no, aún aunque estén en proximidad con el alelo de susceptibilidad. Por esto, la falta de asociación aún permite pensar la posibilidad de que el marcador está tan próximo al alelo putativo y en equilibrio de ligamiento con él. En casos específicos, como son las poblaciones genéticamente aisladas, puede existir desequilibrio de ligamiento aún si las distancias entre el marcador y el alelo de susceptibilidad son mayores a 1cM. En síntesis, la extensión de estas regiones cromosómicas en desequilibrio de ligamiento disminuye en cada generación, producto de recombinación y conversión génica. En base a los resultados hallados, creemos que lo más probable es que el haplotipo NAT2 $* 5$ no constituye una variante funcionalmente relevante sino que estaría actuando como un marcador. Quizás sirva como tal en ciertas poblaciones y en otras no, pues no estaría en desequilibrio de ligamiento con el gen causal, situación que depende de la historia particular de cada población. 


\section{Plausibilidad biológica: MeCANiSMos biológicos involucrados. NAT2 Y LA ANOMALÍA LL/PH}

La manera en que estos polimorfismos afectan al riesgo de padecer la anomalía LL/PH no se sabe con claridad. No obstante, la relevancia de la suplementación de ácido fólico (vitamina B9) para la prevención de FO puede ofrecernos algunos indicios. La vitamina B9 ha demostrado ser relevante en la viabilidad fetal y desarrollo normal de la región craneana. Sin embargo, el mecanismo por el cual su escasez produce FO no se conoce aún. Nelson en el año 1947 estableció métodos para inducir en ratas deficiencia nutricional de folatos y exacerbó el uso de antagonistas para producir muertes fetales, FO y otras malformaciones. Este trabajo fue replicado por Giroud y Boisselot (1951) quienes delinearon una descripción detallada de la importancia del momento de deficiencia durante la gestación. La carencia inducida en ratas entre los días 1 a 9 de gestación producían un $100 \%$ de reabsorciones fetales y entre los días 10 y 11 los embriones morían y el 94\% presentaban PH. Si la privación se retrasaba hasta el día 15 , el resultado era un $6 \%$ de nacidos muertos y ninguno con PH. La falta de folatos demostró también ser relevante aún en prevención de FO en perros: una dosis diaria de $5 \mathrm{mg}$ de ácido fólico disminuyó la frecuencia de FO en una línea de Boston terriers que tenían una predisposición genética para este desorden.

La relevancia de la suplementación de ácido fólico para la prevención de FO es aún desconocida. Sin embargo, estudios de medicamentos que modifican el metabolismo de folatos podrían clarificar la relación del NAT2 con las FO. La falta de ácido fólico provocada por antagonistas demostró ser causa de malformaciones en picos de pollos (Karnofsky y col., 1949). Naga y col., (2002) a través de un estudio caso-control, observaron una frecuencia significativamente mayor de paladar hendido en ratas que habían sido expuestas a 2,5 mg/kg/día a aminofenil-norharman (una amina heterocíclica) durante los días gestacionales 6 y 15. Asimismo, el consumo materno de tabaco es un comprobado factor de riesgo para FO. Un meta-análisis de 4 estudios estimó que madres que han fumando tabaco durante el embarazo tenían un riesgo 1,3 veces mayor de tener un niño con LL/PH. El mecanismo biológico que subyace a esta asociación es aún desconocido. El tabaco contiene una gran cantidad de toxinas. Los trabajos que estudian la relación consumo de tabaco y producción de diferentes cánceres han evidenciado riesgos asociados a diferentes variantes de enzimas involucradas en los mecanismos de detoxificación (Vineis, 2002). Como hemos descrito, la acetilación es la mejor ruta de biotransformación para arilaminas y fármacos de hidrazina, así como para un gran número de toxinas y carcinógenos presentes en la dieta, humo de cigarro y medio ambiente. De este modo, compuestos cuya vía de metabolización sea la acetilación, podrían ser factores de riesgo para LL/PH en individuos portadores de alelos de NAT2 que determinan baja capacidad metabolizadora. En ellos, la acumulación de aminas podría generar toxicidad, deprimiendo el ciclo de los folatos y provocando finalmente disrupciones en la 
embriología. Por lo dicho anteriormente, NAT2 podría tener un rol en el aumento de la susceptibilidad a LL/PH. Pero no sólo para esta malformación. Avalan esa afirmación investigaciones que han explorado el riesgo de variantes alélicas de este gen y el desarrollo del tubo neural. En relación con esto último, la literatura es extensa y relevante para fisuras orales debido a que ambas estructuras se originan de las crestas neurales, por lo tanto podrían compartir eventos durante el desarrollo embrionario (Lammer y col., 1985).

El patrón de expresión de NAT2 en el desarrollo embrionario no ha sido intensamente estudiado en mamíferos. Sin embargo el gen homólogo NAT1 ha sido detectado en el estadío de blastocisto y en placentas humanas tempranamente, en las 5,5 semanas de gestación (Smelt y col., 2000). En ratones, la expresión de Nat fue evidenciado en el dia 10 de gestación tanto en embriones como en tejidos placentarios (Mitchell y col., 1999; Stanley y col., 1998). Estos trabajos evidencian la expresión de estos genes en la ventana temporal crítica del desarrollo del labio y el paladar.

Otra razón importante para vincular las variantes de NAT2 y su relación con fisuras orales son los resultados previos de asociación con otras patologías (Bell y col., 1995; Brockton y col., 2000). El polimorfismo de NAT2 se ha relacionado con la posibilidad de tener mayor riesgo de desarrollar determinadas enfermedades, además de sufrir con más facilidad los efectos adversos de fármacos metabolizados por acetilación. Dentro de estas enfermedades, aquellas que han recibido más atención han sido las neoplásicas. Ello se debe a que determinadas sustanias cancerígenas del tipo de aminas aromáticas son metabolizadas por la enzima NAT2, por lo cual se podría especular que aquellos individuos metabolizadores lentos tendrían más posibilidades de desarrollar determinadas neoplasias. Pero la acetilación no sólo es la via de detoxificación de ciertos compuestos potencialmente cancerígenos, sino que en ocasiones, determinadas sustancias procancerígenas pueden ser activadas mediante O-acetilación produciendose acetoxiarilamidas. Éstas se rompen espontáneamente originando iones aril-nitrenios, altamente reactivos y responsables de mutaciones en el ADN. Además no sólo intervienen estas enzimas, sino que intervienen otras vías metabólicas como la del citocromo P450 122 (CYP1A2). Dependiendo de la selectividad de las diferentes enzimas, los distintos productos químicos seguirán unas vías metabólicas u otras. El cáncer que parece estar más relacionado con el polimorfismo de NAT2 es el de vejiga. Diferentes estudios relacionan claramente el fenotipo y el genotipo acetilador lento con cáncer de vejiga (Evans y col., 1983; Marcus y col., 2000). De otro modo, son numerosos los estudios que vinculan a los metabolizadores rápidos con una mayor propensión a padecer cáncer colorectal (Ilett y col., 1987; Lang y col., 1986). Brockton y col., (2000) en una revisión concluyeron que si NAT2 juega un rol en el desarrollo de neoplasias, es probable que este gen tenga un rol en la modificación en la relación entre exposición ambiental y desarrollo de enfermedades. 
En resumen, este trabajo intentó dilucidar la contribución de la región 8p23.1 a la etiología de LL/PH. Los resultados hallados en este trabajo permiten la aceptación de la hipótesis alternativa que afirma que los alelos que determinan fenotipo acetilador están asociados con la ocurrencia de LL/PH. Sin embargo, debemos ser prudentes con nuestros resultados. Es indudable que dado el carácter multifactorial de la anomalía LL/PH, el análisis de una o dos variantes genéticas de enzimas asociadas al metabolismo de xenobióticos no es sufieciente como herramienta de evaluación de susceptibilidad. Creemos que el haplotipo NAT2 $* 5$ no constituye una variante funcionalmente relevante sino que estaría actuando como un marcador. Quizás sirva como tal en ciertas poblaciones y en otras no, pues no estaría en desequilibrio de ligamiento con el gen causal, situación que depende de la historia particular de cada población. Así, el hallazgo de asociación, constituye el primer paso en el inicio del mapeo fino en busca de la región o locus que contiene el gen causal o de susceptibilidad. Sin embargo, identificar cuál de los genes es el causante y cuál de los polimorfismos y mutaciones encontradas en ese gen son los funcionales, las vías mediante las cuales interactúan los múltiples productos génicos junto a los factores ambientales para la expresión de fenotipos complejos, es aún una tarea muy difícil. Algunos criterios son los estudios de expresión en el tejido enfermo, conservación de las secuencias a través de la evolución y estudios funcionales en animales genéticamente modificados. Actualmente no hay pruebas genéticas disponibles. El fin último de los trabajos de asociación, es la identificación de genes de susceptibilidad genética para incrementar el uso rutinario de análisis genotípicos con fines diagnósticos y terapéuticos, para permitir entonces el desarrollo de estrategias preventivas más eficaces. 


\title{
CONCLUSiOneS
}

\author{
¿Qué te parece desto, Sancho? Dijo Don Quijote \\ Bien podrán los encantadores quitarme la ventura, \\ pero el esfuerzo y el ánimo, será imposible. \\ Segunda parte del Ingenioso Caballero \\ Don Quijote de la Mancha Miguel de Cervantes
}

Nuestro trabajo, mediante un diseño caso-control de base familiar, confirma la asociación entre el alelo *5 que determina fenotipo acetilador lento y la ocurrencia de la anomalía congénita LL/PH. Los SNPs seleccionados en este trabajo podrían servir como marcadores en desequilibrio de ligamiento de haplotipos que sí lo son. Como marcadores, algunos SNPs podrían ser más informativos en unas poblaciones que en otras y esto podría explicar algunas discrepancias en los resultados de asociación de estos SNPs de NAT2. Asimismo, no podemos desestimar alguna participación en la generación de fisuras como parte del componente multifactorial o varianza residual no explicada por el gen principal.

En relación con la contribución del componente amerindio en la muestra estudiada, en los linajes mitocondriales, se observó una alta frecuencia de haplogrupos nativos americanos (88\%). De otro modo, para el cromosoma $\mathrm{Y}$, los haplogrupos nativos mostraron una frecuencia promedio de $22 \%$ con una representatividad muy diferente de un hospital a otro. Estos resultados sugieren una fuerte contribución nativa para la línea materna pero no para la paterna, indicando de esta forma concordancia con los los registros históricos sobre mestizajes en Centro y Sudamérica, involucrando mayormente a mujeres americanas y hombres extranjeros. 


\section{BIBLIOGRAFÍA}

"Y así, del mucho leer y del poco dormir, se le secó el cerebro de manera que vino a perder el juicio".

Miguel de Cervantes Saavedra

ACHILLI A, PEREGO UA, BRAVI CM, COBLE MD, KONG QP, WOODWARD SR, SALAS A, ANTONIO TORRONI A y BANDELT HJ (2008). The phylogeny of the four PanAmerican MtDNA Haplogroups: Implications for evolutionary and disease studies. Plos ONE 3: 3 e1764.

AGUdo A, SALA N, PERA G, CAPELlÁ G, BERENGUER A, GARCÍA N y col. (2006). Polymorphisms in metabolic genes related to tobacco smoke and the risk of gastric cancer in the European prospective investigation into cancer and nutrition. Cancer Epidemiol Biomark Prev. 15(12): 2427-2434.

AGÚNDEZ JAG, OLIVERA M, MARTÍNEZ C, LADERO JM y BENÍTEZ J (1996). Identification and prevalence study of 17 allelic variants of the human NAT2 gene in a white population. Pharmacogenetics 6(5): 423-428.

ARDINGER HH, BUETOW KH, BELL GI, BARDACH J, VANDEMARK DR y MURRAY JC (1989). Association of genetic variation of the transforming growth factor-alpha gene with cleft lip and palate. Am J Hum Genet. 45(3): 348-353.

ARTAMA M, AUVINEN A, RAUDASKOSKI T, ISOJÄRVI RN y ISOJÄRVI J (2005). Antiepileptic drug use of women with epilepsy and congenital malformations in offspring. Neurology 64(11): 1874-1878.

AVENA SA, GOICOECHEA AS, BARTOMIOLI M, FERNÁNDEZ V, CABRERA A, DUGOUJON JM, DEJEAN CB, FABRYKANT G y CARNESE FR (2007). Mestizaje en el sur de la región pampeana (Argentina). Su estimación mediante el análisis de marcadores proteicos y moleculares uniparentales. Rev Arg Antropol Biol. 9(2): 59-76.

AVENA SA, PAROLIN ML, DEJEAN CB, RÍOS PART MC, FABRIKANT G, GOICOECHEA AS, DUGOUJON JM y CARNESE FR (2009). Mezcla génica y linajes uniparentales en Comodoro Rivadavia (Provincia de Chubut, Argentina). Rev Arg Antropol Biol. 11(1): 2541. 
BAILLIET G, ROTHHAMMER F, CARNESE FR, BRAVI CM y BIANCHI NO (1994). Founder mitochondrial haplotypes in Amerindian populations. Am J Hum Genet. 54: 27-33.

BAILLIET G, SANTOS MR, ALFARO EL, DIPIERRI JE, DEMARCHI DA, CARNESE FR y BIANCHI NO (2007). Allele and genotype frequencies of metabolic genes in Native Americans from Argentina and Paraguay. Mutat Res. 627(2): 171-177.

BAILLIET G, RAMALLO V, MUZZIO M, GARCÍA A, SANTOS MR, ALFARO EL, DIPIERRI JE, SALCEDA S, CARNESE FR, BRAVI CM, BIANCHI NO y DEMARCHI DA (2009). Brief communication: restricted geographic distribution for $\mathrm{Y}-\mathrm{Q}^{*}$ paragroup in South America. Am J Phys Anthropol. 140(3): 578-582.

BEATY TH, MURRAY JC, MARAZITA ML, MUNGER RG, RUCZINSKI I, HETMANSKI JB, LIANG KY, WU T, MURRAY T, FALLIN MD, REDETT RA, RAYMOND G, SCHWENDER H, JIN SC, COOPER ME, DUNNWALD M, MANSILLA MA, LESLIE E, BULLARD S, LIDRAL AC, MORENO LM, MENEZES R, VIEIRA AR, PETRIN A, WILCOX AJ, LIE RT, JABS EW, WU-CHOU YH, CHEN PK, WANG H, YE X, HUANG S, YEOW V, CHONG SS, JEE SH, SHI B, CHRISTENSEN K, MELBYE M, DOHENY KF, PUGH EW, LING H, CASTILLA EE, CZEIZEL AE, MA L, FIELD LL, BRODY L, PANGILINAN F, MILLS JL, MOLLOY AM, KIRKE PN, SCOTT JM, ARCOS-BURGOS M, y SCOTT AF (2010). A genome-wide association study of cleft lip with and without cleft palate identifies risk variants near MAFB and ABCA4. Nat Genet. 42(6): 525-529.

BEDOYA G, MONTOYA P, GARCÍA J, SOTO I, BOURGEOIS S, CARVAJAL L, LABUDA D, ALVAREZ V, OSPINA J, HEDRICK PW, y RUIZ-LINARES A (2006). Admixture dynamics in Hispanics: A shift in the nuclear genetic ancestry of a South American population isolate. Proc of the Natl Ac Sc. 103: 7234-7239.

BEIRAGHI S, FOROUD T, DIOUHY S, BIXLER D, CONNEALLY PM, DELOZIERBLANCHET D y HODES ME (1994). Possible localization of a major gene for cleft lip and palate to 4q. Clin Genet. 46(3): 255-256.

BEIRAGHI S, NATH SK, GAINES M, MANDHYAN DD, HUTCHINGS D, RATNAMALA U, MCELREAVEY K, BARTOLONI L, ANTONARAKIS GS, ANTONARAKIS SE, RADHAKRISHNA U (2007). Autosomal dominant nonsyndromic cleft lip and palate: significant evidence of linkage at 18q21.1. Am J Hum Genet. 81(1): 180-188.

BELL DA, BADAWI AF, LANG NP, ILETT KF, KADLUBAR FF y HIRVONEN A (1995). Polymorphism in the N-Acetyltransferase 1 (NAT1) polyadenylation signal: association of 
NAT1*10 allele with higher N-Acetylation activity in bladder and colon tissue. Cancer Res. 55: 5226-5229.

BENDER PL (2000). Genetics of cleft lip and palate. J Pediatr Nurs. 15(4): 242-249.

BIANCHI NO, BAILLIET G, BRAVI CM, CARNESE RF, ROTHHAMMER F, MARTINEZMARIGNAC VL y PENA SD (1997). Origin of Amerindian Y-chromosomes as inferred by the analysis of six polymorphic markers. Am J Phys Anthropol. 102(1): 79-89.

BIRNBAUM S, LUDWIG KU, REUTTER H, HERMS S, STEFFENS M, RUBINI M, BALUARDO C, FERRIAN M, ALMEIDA DE ASSIS N, ALBLAS MA, BARTH S, FREUDENBERG J, LAUSTER C, SCHMIDT G, SCHEER M, BRAUMANN B, BERGÉ SJ, REICH RH, SCHIEFKE F, HEMPRICH A, PÖTZSCH S, STEEGERS-THEUNISSEN RP, PÖTZSCH B, MOEBUS S, HORSTHEMKE B, KRAMER F-J, WIENKER TF, MOSSEY PA, PROPPING P, CICHON S, HOFFMANN P, KNAPP M, NÖTHEN MM y MANGOLD E (2009). Key susceptibility locus for nonsyndromic cleft lip with or without cleft palate on chromosome 8q24. Nat Genet. 41: 473-477.

BORTOLINI MC, SALZANO FM, THOMAS MG, STUART S, NASANEN SP, BAU CH, HUTZ MH, LAYRISSE Z, PETZL-ERLER ML, TSUNETO LT, HILL K, HURTADO AM, CASTRO-DE-GUERRA D, TORRES MM, GROOT H, MICHALSKI R, NYMADAWA P, BEDOYA G, BRADMAN N, LABUDA D y RUIZ-LINARES A (2003). YChromosome evidence for differing ancient demographic histories in the Americas. Am J Hum Genet. 73: 524-539.

BRADFORD LD (2002). CYP2D6 allele frequency in european caucasians, asians, africans and their descendants. Pharmacogenomics 3: 229-243.

BRANS R, LAIZANE D, KHAN A y BLÖMEKE B (2004). N-acetyltransferase 2 genotyping: an accurate and feasible approach for simultaneous detection of the most common NAT2 alleles. Clin Chem. 50(7): 1264-1266.

BRAVI CM (2004). Análisis de linajes maternos en poblaciones indígenas americanas. Tesis Doctoral. Facultad de Ciencias Naturales y Museo. Universidad Nacional de La Plata.

BROCKTON N, LITTLE J SHARP L y COTTON SC (2000). N-acetyltransferase polymorphisms and colorectal cancer: a HuGE Review. Am J Epidemiol.151: 846-861.

BURDI AR y FAIST K (1967). Morphogenesis of the palate in normal human embryos with special emphasis on the mechanisms involved. Am J Anat. 120(1): 149-159. 
CARTER CO (1969). Genetics of common disorders. Br Med Bull. 25(1): 52-57.

CARVAJAL-CARMONA LG, SOTO ID, PINEDA N, ORTÍZ-BARRIENTOS D, DUQUE C, OSPINA-DUQUE J, MCCARTHY M, MONTOYA P, ALVAREZ VM, BEDOYA G y RUIZ-LINARES A (2000). Strong amerind/white sex bias and a possible sephardic contribution among the founders of a population in northwest Colombia. Amer J Hum Genet. 67(5): 1287-1295.

CASTIGLIA VC (1998). Principios de Investigación Biomédica. 2da edición. Ed Gráfica Sur.

CASTILLA EE y ORIOLI IM (1983). El Estudio Colaborativo Latinoamericano de Malformaciones Congénitas: ECLAMC/MONITOR. Interciencia. 8: 271-278.

CAVALLI-SFORZA LL y BODMER WF (1971). The genetics of Human populations. San Francisco: W.H. Freeman.

CHRISTENSEN K y FOGH-ANDERSEN P (1993). Cleft lip (+/- cleft palate) in danish twins, 1970-1990. Am J Med Genet. 47(6): 910-916.

CHRISTENSEN K y MITCHELL LE (1996). Familial recurrence-pattern analysis of nonsyndromic isolated cleft palate-a Danish Registry study. Am J Hum Genet. 58(1): 182190.

CORACH D, LAO O, BOBILLO C, VAN DER GAAG K, ZUNIGA S, VERMEULEN M, VAN DUIJN K, GOEDBLOED M, VALLONE PM, PARSON W, DE KNIJFF P, y KAYSER M (2010). Inferring continental ancestry of argentineans from Autosomal, Y-chromosomal and mitochondrial DNA. Ann Hum Genet. 74(1): 65-76.

CROEN LA, SHAW GM, WASSERMAN CR y TOLAROVA MM (1998). Racial and ethnic variations in the prevalence of orofacial clefts in California, 1983-1992. Am J Med Genet. 79(1): 42-47.

DEJEAN CB, GOICOECHEA AS, AVENA SA, SALABERRY MT, SLEPOY AS y CARNESE FR (2003). Linajes mitocondriales amerindios en una muestra poblacional de la Región Metropolitana de Buenos Aires. Rev Arg Antropol Biol. 5(1): 65.

DEMARCHI DA, PANZETTA-DUTARI MG, LO’PEZ DE BASUALDO M, MOTRAN CC y MARCELLINO AJ (2001). Mitochondrial DNA haplogroups in Amerindian populations from the Gran Chaco. Am J Phys Anthropol. 115(3): 199-203.

DIERWERT VM y SHIOTA K (1990). Morphological observations in normal primary palate and cleft lip embryos in the Kioto collection. Teratology 41(6): 663-677. 
DIERWERT VM y WANG KY (1992). Recent advances in primary palate and midfacial morphogenesis research. Crit Rev Oral Biol Med. 4: 111-130.

DIPIERRI JE, ALFARO E, MARTÍNEZ-MARIGNAC VL, BAILLIET G, BRAVI CM, CEJAS S y BIANCHI NO (1998). Paternal directional mating in two Amerindian subpopulations located at different altitudes in northwestern Argentina. Hum Biol. 70(6):1001-1010.

DUNNING AM, HEALEY CS, PHAROAH PD, TEARE MD, PONDER BA y EASTON DF (1999). A systematic review of genetic polymorphisms and breast cancer risk. Cancer Epidemiol Biomark Prev. 8(10): 843-854.

EVANS DAP (1992). N-acetiltransferase. En: Kalow W (ed.). Pharmacogenetics of drug metabolism. New York: Pergamon Press. Pp. 95-178.

EVANS DAP, EZE LC y WHIBLEY EJ (1983). The association of the slow acetylator phenotype with bladder cancer. J Med Gen. 20: 330-333.

EXCOFFIER L, SMOUSE P y QUATTRO J (1992). Analysis of molecular variance inferred from metric distances among DNA haplotypes: Application to human mitochondrial DNA restriction data. Genetics 131: 479-491.

EXCOFFIER L, LAVAL G y SCHNEIDER S (2005). Arlequin (Ver. 3.0): An integrated software package for population genetics data analysis. Evolutionary Bioinformatics Online 1: 4750.

FALK CT y RUBINSTEIN P (1987). Haplotype relative risks: an easy reliable way to construct a proper control sample for risk calculations. Ann Hum Genet. 51(3): 227-233.

FARRALL M y HOLDER S (1992). Familial recurrence-pattern analysis of cleft lip with or without cleft palate. Am J Hum Genet. 50(2): 270-277.

FERGUSON CA, TUCKER AS, SHARPE PT (2000). Temporospatial cell interactions regulating mandibular and maxillary arch patterning. Development 127: 403-412.

FUSELLI S, GILMAN RH, CHANOCK SJ, BONATTO SL, DE STEFANO G, EVANS CA, LABUDA D, LUISELLI D, SALZANO FM, SOTO G, VALLEJO G, SAJANTILA A, PETTENER D y TARAZONA-SANTOS E (2007). Analysis of nucleotide diversity of NAT2 coding region reveals homogeneity across Native American populations and high intra-population diversity. The Pharmacogenomics J. 7(2): 144-152. 
GARCIA A (2011). Historia evolutiva de las poblaciones originarias del actual territorio de la provincia de Córdoba: evidencias moleculares. Tesis doctoral. Facultad de Ciencias Exactas, Físicas y Naturales. Universidad de Córdoba.

GARCÍA A, RAMALLO V, BAILLIET G y DEMARCHI DA (2008). Análisis de linajes paternos en poblaciones rurales del centro de Argentina. Revista de la Sociedad Argentina de Genética. Actas del XXXVII Congreso Argentino de Genética, Vol. XIX p. 209.

GARTE S, GASPARI L, ALEXANDRIE AK, AMBROSONE C, AUTRUP H, AUTRUP JL, y col. (2001). Metabolic gene polymorphism frequencies in control populations. Can Epidemiol Biomark Prevent. 10: 1239-1248.

GASPAR DA, MATIOLI SR, PAVANELLO RC, ARAUJO BC, ANDRÉ M, STEMAN S, OTTO PA, y PASSOS-BUENO MR (2002). Evidence that BCL3 plays a role in the etiology of nonsyndromic oral clefts in Brazilian families. Genetic Epidemiol. 23(4): 364-374.

GIL JP y LECHNER MC (1998). Increased frequency of wild-type arylamine-N-acetyltransferase allele NAT2*4 homozygotes in Portuguese patients with colorectal cancer. Carcinogenesis 19(1): 37-41.

GIROUD A y BOISSELOT J (1951). Influence tératogène de la carence en acide folique. CR Soc Biol. 145: 526-527.

GONZALEZ FJ y KIMURA S (2001). Understanding the role of xenobiotic-metabolism in chemical carcinogenesis using gene knockout mice. Mutat Res. 477(1-2): 79-87.

GOODERHAM NJ, MURRAY S, LYNCH AM, YADOLLAHI-FARSANI M, ZHAO K, BOOBIS AR y DAVIES DS (2001). Food-derived heterocyclic amine mutagens: variable metabolism and significance to humans. Drug Metab Dispos. 29(4 Parte 2): 529-534.

GU J, LIANG D, WANG Y, LU C y WU X (2005). Effects of N-acetyl transferase 1 and 2 polymorphisms on bladder cancer risk in caucasians. Mutat Res. 581(1-2): 97-104.

GUO SW y THOMPSON EA (1992). Performing the exact test of Hardy-Weinberg proportion for multiple alleles. Biometrics 48(2): 361-372.

HAMDY SI, HIRATSUKA M, NARAHARA K, ENDO N, EI-ENANY M, MOURSI N, AHMED MS-E, y MIZUGAKI M (2003). Genotype and allele frequencies of TPMT, NAT2, GST, SULT1A1 and MDR-1 in the egyptian population. Br J Clin Pharmacol. 55(6): 560-569. 
HARVILLE EW, WILCOX AJ, LIE RT, VINDENES H y ÅBYHOLM F (2005). Cleft Lip and Palate versus Cleft Lip Only: Are They Distinct Defects? Am J Epidemiol. 162(5): 448453.

HAYES C (2002). Environmental risk factors and oral clefts. Cleft Lip and Palate: From Origin to treatment. Oxford University Press, USA.

HEIN DW, DOLL MA, FRETLAND AJ, LEFF MA, WEBB SJ, XIAO GH, DEVANABOYINA US, NORMA A. NANGJU N y FENG Y (2000). Molecular Genetics and Epidemiology of the NAT1 and NAT2 Acetylation Polymorphisms. Cancer Epidemiol Biomark Prev. 9: 2942.

ILETT KF, DAVIS BM, DETCHON P, CASTLEDEN WM y KWA R (1987). Acetylation phenotype in colorectal carcinoma. Cancer Res. 47: 1466-1469.

JOBLING MA, HURLES M y TYLER-SMITH C (2004). Human evolutionary genetics: origins, peoples \& disease. Abingdon and New York, Garland Science.

KARAFET TM, MENDEZ FL, MEILERMAN MB, UNDERHILL PA, ZEGURA SL y HAMMER MF (2008). New binary polymorphisms reshape and increase resolution of the human Y chromosomal haplogroup tree. Genome Res. 18: 830-838.

KARNOFSKY DA, PATTERSON PA, RIDGWAY LR y col. (1949). Effect of folic acid, "4amino"-folic acids, and related substances on growth of chick embryo. Proc Soc Exp Biol Med. 71(3): 447-452.

KASHANI BH, PEREGO UA, OLIVIERI A, ANGERHOFER N, GANDINI F, CAROSSA V, LANCIONI H, SEMINO O, WOODWARD SR, ACHILLI A y TORRONI A (2012). Mitochondrial Haplogroup C4c: a rare lineage entering America through the ice-free corridor? Am J Phys Anthropol. 147: 35-39.

KEMP BM, MALHI RS, MCDONOUGH J, BOLNICK DA, ESHLEMAN JA, RICKARDS O, MARTINEZ-LABARGA C, JOHNSON JR, LORENZ JG, DIXON EJ, FIFIELD TE, HEATON TH, WORL R y SMITH DG (2007). Genetic analysis of early Holocene skeletal remains from Alaska and its implications for the settlement of the Americas. Am J Phys Anthropol. 132: 605-621.

KIMES KR, MOONEY MP, SIEGEL MI y TODHUNTER JS (1991). Size and growth rate of the tongue in normal and cleft lip and palate human fetal specimens. Cleft Palate Craniofac J. 28(2): 212-216. 
KIYOHARA C, OTSU A, SHIRAKAWA T, FUKUDA S y HOPKIN JM (2002). Genetic polymorphisms and lung cancer susceptibility: a review. Lung Cancer 37(3): 241-256.

KNUDSEN LE, LOFT SH y AUTRUP H (2001). Risk assessment: the importance of genetic polymorphisms in man. Mutat Res. 482(1-2): 83-88.

KRAJINOVIC M, RICHER C, SINNETT H, LABUDA D y SINNETT D (2000). Genetic polymorphisms of $\mathrm{N}$-acetyltransferases 1 and 2 and gene-gene interaction in the susceptibility to childhood acute lymphoblastic leukemia. Cancer Epidemiol Biomarkers Prev. 9(6): 557-562.

KUMAR S, BELLIS C, ZLOJUTRO M, MELTON PE, BLANGERO J y CURRAN JE (2011). Large scale mitochondrial sequencing in mexican americans suggests a reappraisal of native american origins. Evolutionary Biology 11: 29.

LADERO JM, ARROJO A y GILSANZ V (1979). Acetilación hepática en la población española. Gastroenterol Hepatol. 2: 236-240.

LALUEZA C, PÉREZ-PÉREZ A, PRATS DE, CORNUDELLA L y TURBÓN D (1997). Lack of founding Amerindian mitochondrial DNA lineages in extinct aborigines from Tierra del Fuego-Patagonia. Hum Mol Genet. 6(1): 41-46.

LAMMER EJ, CHEN DT, HOAR RM, AGNISH ND, BENKE PJ, BRAUN JT, CURRY CJ, FERNHOFF PM, GRIX AW Jr, LOTT IT y col. (1985). Retinoic acid embryopathy. $N$ Engl J Med. 313(14): 837-841.

LAMMER EJ, SHAW GM, IOVANNISCI DM, VAN WAES J y FINNELL RH (2004). Maternal smoking and the risk of orofacial clefts: Susceptibility with NAT1 and NAT2 polymorphisms. Epidemiology 15: 150-156.

LANG NP, CHU DZJ, HUNTER CF, KENDALL DC, FLAMMANG TJ y KADLUBAR FF (1986). Role of aromatic amine acetyltransferase in human colorectal cancer. Arch Surg. 121: $1259-1261$.

LETTIERI J (1993). Human Malformations and Related Anomalies. En: Stevenson RE, Hall JG y Goodman RM (eds.). New York: Oxford University Press. Pp. 367-381.

LIE RT, WILCOX AJ, TAYLOR J, GJESSING HK, SAUGSTAD OD, AABYHOLM F y VINDENES H (2008). Maternal smoking and oral clefts: the role of detoxification pathway genes. Epidemiology 19(4): 606-15. 
LIDRAL AC, MURRAY JC, BUETOW KH, BASART AM, SCHEARER H, SHIANG R, NAVAL A, LAYDA E, MAGEE K y MAGEE W (1997). Studies of the candidate genes TGFB2, MSX1, TGFA, and TGFB3 in the etiology of cleft lip and palate in the Philippines. Cleft Palate Craniofac J. 34(1): 1-6.

LIDRAL AC y MURRAY JC (2004). Genetic approaches to identify disease genes for birth defects with cleft lip/palate as a model. Birth Defects Res A: Clin Mol Teratology. 70(12): 893-901.

LIN HJ, HAN CY, LIN BK y HARDY S (1993). Slow acetylator mutations in the human polymorphic N-acetyltransferase gene in 786 Asians, blacks, Hispanics, and whites: application to metabolic epidemiology. Am J Hum Genet. 52: 827-834.

LÓPEZ-CAMELO JS y ORIOLI IM (1996). Heterogeneous rates for birth defects in Latin America: Hints on causality. Genet Epidemol. 13(5): 469-481.

MALHI RS, CYBULSKI JS, TITO RY, JOHNSON J, HARRY H y DAN C (2010). Brief Communication: Mitochondrial haplotype $\mathrm{C} 4 \mathrm{c}$ confirmed as a founding genome in the Americas. Am J Phys Anthropol. 141: 494-497.

MARAZITA ML, MURRAY JC, LIDRAL AC, ARCOS-BURGOS M, COOPER ME, GOLDSTEIN T, MAHER BS, DAACK-HIRSCH S, SCHULTZ R, MANSILLA MA y col. (2004). Meta-analysis of 13 genome scans reveals multiple cleft lip/palate genes with novel loci on 9q21 and 2q32-35. Am J Hum Genet. 75: 161-173.

MARCUS PM, VINEIS P y ROTHMAN N (2000). NAT2 slow acetylation and bladder cancer risk: a meta-analysis of 22 case control studies conducted in general population. Pharmacogenetics 10: 115-122.

MILERAD J, LARSON O, HAGBERG C y IDEBERG M (1997). Associated malformations in infants with cleft lip and palate: a prospective, population-based study. Pediatrics 100(2 Parte 1): $180-186$.

MILLAR JS (2001). Consultations owing to adverse drug reactions in a single practice. $\mathrm{Br} J \mathrm{Gen}$ Pract. 51(463): 130-131.

MITCHELL L (2002). Mode of inheritance of Oral cleft. En: Wyszynski DF (ed.). Cleft Lip and Palate: From Origin to Treatment. Oxford University Press, Nueva York. Pp. 234-239.

MITCHELL LE, BEATY TH, LIDRAL AC, MUNGER RG, MURRAY JC, SAAL HM y WYSZYNSKI DF e INTERNATIONAL CONSORTIUM FOR ORAL CLEFT 
GENETICS (2002). Guidelines for the Design and Analysis of Studies on Nonsyndromic Cleft Lip and Cleft Palate in Humans: Summary Report from a Workshop of the International Consortium for Oral Clefts Genetics. Cleft Palate-Craniofac J. 39(1): 93-100.

MITCHELL MK, FUTSCHER BW y MCQUEEN CA (1999). Developmental expression of Nacetyltransferases in C57BI/6 mice. Drug Metab Dispos. 27: 261-264.

MOONEY MP, SIEGEL MI, KIMES KR y TODHUNTER J (1991). Premaxillary development in normal and cleft lip and palate human fetuses using three-dimensional computer reconstruction. Cleft Palate Craniofac J. 28: 49-53.

MOONEY MP, SIEGEL MI, KIMES KR y JANOSKY J (1992). Multivariate analysis of second trimester midfacial morphology in normal and cleft lip and palate human fetal specimens. Am J Phys Anthropol. 88: 203-209.

MURRAY JC (1995). Face facts: genes, environment, and clefts. Am J Hum Genet. 57(2): 227232.

MURRAY JC (2002). Gene/environment causes of cleft lip and/or palate. Clin Genet. 61(4): 24856.

NAGA T, YOSHIMURA S, TOTSUKA Y y WAKABAYASHI K (2002). Maternal and developmental toxicity in mice by aminophenylnorharman, formed from norharman and aniline. Hum Exp Toxicol. 21(3): 147-151.

NELSON MM y EVANS HM (1947). Reproduction in the rat on purified diets containing succinylsulfathiazole. Proc Soc Exp Biol Med. 66: 289.

OHSAKO S y DEGUCHI T (1990). Cloning and expression of cDNAs for polymorphic and monomorphic N-acetyltransferase from human liver. J Biol Chem. 265: 4630-4634.

OOSTROM CA, VERMEIJ-KEERS C, GILBERT PM y VAN DER MEULEN JC (1996). Median cleft of the lower lip and mandible: case reports, a new embryologic hypothesis, and subdivision. Plast Reconstr Surg. 97(2): 313-320.

OTT J (1990). Cutting a Gordian knot in linkage analysis of complex human traits. Am J Hum Genet. 46: 219-221.

PALOMINO HM, PALOMINO H, CAUVI D, BARTON S y CHAKRABORTY R (1997). Facial clefting and amerindian admixture in populations of Santiago, Chile. Am J Human Biol. 9: 225-232. 
PEREGO UA, ACHILlI A, ANGERHOFER N, ACCETTURO M, PALA M, OLIVIERI A, HOOSHIAR KASHANI B, RITCHIE KH, SCOZZARI R, KONG QP, MYRES NM, SALAS A, SEMINO O, BANDELT HJ, WOODWARD SR, y TORRONI A (2009). Distinctive Paleo-Indian migration routes from Beringia marked by two rare mtDNA haplo- groups. Curr Biol. 19: 1-8.

PEREGO UA, ANGERHOFER N, PALA M, OLIVIERI A, LANCIONI H, KASHANI BH, CAROSSA V, EKINS JE, GOMEZ-CARBALLA A, HUBER G, ZIMMERMANN B, CORACH D, BABUDRI N, PANARA F, MYRES NM, PARSON W, SEMINO O, SALAS A, WOODWARD SR, ACHILLI A, TORRONI A (2010). The initial peopling of the Americas: A growing number of founding mitochondrial genomes from Beringia. Genome Res. 20: 1174-1179.

POLETTA FA, CASTILLA EE, ORIOLI IM y LOPEZ-CAMELO JS (2007). Regional analysis on the occurrence of oral clefts in South America. Am J Med Genet A. 143A(24): 3216-3227.

POLETTA FA (2010). Epidemiología Genética de Fisuras Orales en Sudamérica: Estudio de Patagonia como Área Endémica. Tesis de Doctorado. Facultad de Medicina, Universidad de Buenos Aires.

RADHAKRISHNA U, RATNAMALA U, GAINES M, BEIRAGHI S, HUTCHINGS D, GOLLA J, HUSAIN SA, GAMBHIR PS, SHETH JJ, SHETH FJ, CHETAN GK, NAVEED M, SOLANKI JV, PATEL UC, MASTER DC, MEMON R, ANTONARAKIS GS, ANTONARAKIS SE y NATH SK (2006). Genomewide scan for nonsyndromic cleft lip and palate in multigenerational Indian families reveals significant evidence of linkage at 13q33.1-34. Am J Hum Genet. 79(3): 580-585.

ROSSEL M y CAPECCHI MR (1999). Mice mutant for both Hoxa1 and Hoxb1 show extensive remodeling of the hindbrain and defects in craniofacial development. Development 126(22): 5027-5040.

SCHUTTE BC y MURRAY JC (1999). The many faces and factors of orofacial clefts. Human Mol Genet. 8(10): 1853-1859.

SEIELSTAD M, YULDASHEVA N, SINGH N, UNDERHILL P, OEFNER P, SHEN P y WELLS RS (2003). A novel Y-chromosome variant puts an upper limit on the timing of first entry into the Americas. Am J Hum Genet. 73(3): 700-705.

SHAW GM y LAMMER EJ (1999). Maternal periconceptional alcohol consumption and risk for orofacial clefts. J Pediatr. 134(3): 298-303. 
SHI M, CHRISTENSEN K, WEINBERG CR, ROMITTI P, BATHUM L, LOZADA A, MORRIS RW, LOVETT M y MURRAY JC (2007). Orofacial Cleft Risk Is Increased with Maternal Smoking and Specific Detoxification-Gene Variants. Am J Hum Genet. 80(1): 76-90.

SHIBAMOTO T y BJELDANES LF (1996). Introducción a la toxicología de los alimentos. Editorial Acribia, S.A. Zaragoza.

SIEGEL MI, MOONEY MP, KIMES KR y TODHUNTER J (1991). Developmental correlates of midfacial components in a normal and cleft lip and palate human fetal sample. Cleft Palate Craniofac J. 28(4): 408-412.

SMELT VA, UPTON A, ADJAYE J, PAYTON MA, BOUKOUVALA S, JOHNSON N, MARDON HJ y col. (2000). Expression of arylamine $\mathrm{N}$-acetyltransferases in pre-term placentas and in human pre-implantation embryos. Hum Mol Genet. 9: 1101-1107.

SMITH CM y REYNARD AM (1993). Farmacología. Editorial Médica Panamericana.

SMITH C (1971). Discriminating between different modes of inheritance in genetic disease. Clin Genet. 2(5): 303-314.

SPERBER GH (2001). Craniofacial Development. Hamilton, Canada: B.C. Decker.

SPIELMAN RS, MCGINNIS RE y EWENS WJ (1993). Transmission test for linkage disequilibrium: the insulin gene region and insulin dependent diabetes mellitus. Am J Hum Genet. 52: 506-516.

STANLEY LA, COPP AJ, POPE J, ROLLS S, SMELT V, PERRY VH y SIM E (1998). Immunochemical detection of arylamine $\mathrm{N}$-acetyltransferase during mouse embryonic development and in adult mouse brain. Teratology 58(5): 174-182.

TAMM E, KIVISILD T, REIDLA M, METSPALU M, GLENN SMITH D, MULLIGAN CJ, BRAVI CM, RICKARDS O, MARTINEZ-LABARGA C, KHUSNUTDINOVA EK, FEDOROVA SA, GOLUBENKO MV, STEPANOV VA, GUBINA MA, ZHADANOV SI, OSSIPOVA LP, DAMBA L, VOEVODA MI, DIPIERRI JE, VILLEMS R, MALHI RS (2007). Beringian standstill and spread of Native American founders. PLoS ONE 2: e829.

TERWILLIGER JD y OTT J (1992). A haplotype-based 'haplotype relative risk' approach to detecting allelic associations. Hum Hered. 42(6): 337-346.

TOLAROVA MM y CERVENKA J (1998). Classification and birth prevalence of orofacial clefts. Am J Med Genet. 75(2): 126-137. 
TORKAMAN-BOUTORABI A, HOORMAND $\mathrm{M}$, NAGHDI $\mathrm{N}$, BAKHSHAYESH $\mathrm{M}$ у MILANIAN I (2007). Genotype and allele frequencies of N-acetyltransferase 2 and glutathione S-transferase in the Iranian population. Clin Exp Pharmacol Physiol. 34(11): 1207-1211.

TURESKY RJ, LANG NP, BUTLER MA, TEITEL CH y KADLUBAR FF (1991). Metabolic activation of carcinogenic heterocyclic aromatic amines by human liver and colon. Carcinogenesis 12(10): 1839-1845.

UNDERHILL PA, JIN L, ZEMANS R, OEFNER PJ y CAVALLI-SFORZA LL (1996). A preColumbian Y chromosome-specific transition and its implications for human evolutionary history. Proc Natl Acad Sc. 93: 196-200.

VANDERAS AP (1987). Incidence of cleft lip, cleft palate, and cleft lip and palate among races: a review. Cleft palate J. 24(3): 216-225.

VAN ROOIJ IA, GROENEN PM, VAN DRONGELEN M, Te MORSCHE RH, PETERS WH y STEEGERS-THEUNISSEN RP (2002). Orofacial clefts and spina bifida: Nacetyltransferase phenotype, maternal smoking, and medication use. Teratology 66: 260266.

VAN ROOIJ IA, VERMEIJ-KEERS C, KLUIJTMANS LA, OCKÉ MC, ZIELHUIS GA, GOORHUIS-BROUWER SM, VAN DER BIEZEN JJ, KUIJPERS-JAGTMAN AN y STEEGERS-THEUNISSEN RP (2003). Does the Interaction between maternal folate intake and the methylenetetrahydrofolate reductase polymorphisms affect the risk of cleft lip with or without cleft palate? Am J Epidemiol. 157(7): 583-591.

VERMUNT JK (1993). LEM 0.1: Log-linear and event history analysis with missing data using the EM algorithms. Tilburg: Tilburg University.

VIEIRA AR (2008). Unraveling human cleft lip and palate research. J Dent Res. 87(2): 119-125.

VIEIRA AR, KARRAS JC, ORIOLI IM, CASTILLA EE y MURRAY JC (2002). Genetic origins in a South American clefting population. Clin Genet. 62(6): 458-463.

VINEIS P (2002). The relationship between polymorphisms of xenobiotic metabolizing enzymes and susceptibility to cancer. Toxicology 181-182: 457-462.

WANG S, RAY N, ROJAS W, PARRA MV, BEDOYA G y col. (2008). Geographic patterns of genome admixture in Latin American mestizos. PLoS Genet. 4(3): e1000037. 
WARKANY J y SCHRAFFENBERGER E (1946). Congenital malformations induced in rats by maternal vitamin A deficiency; defects of the eye. Arch Ophthal. 35: 150-169.

WEINBERG C (1999). Methods for detection of parent-of-origin effects in genetic studies of caseparents triads. Am J Hum Genet. 65: 229-235.

WYSZYNSKI DF y BEATY TH (1996). Review of the role of potential teratogens in the origin of human nonsyndromic oral clefts. Teratology 53(5): 309-317.

WYSZYNSKI DF, BEATY TH y MAESTRI NE (1996). Genetics of nonsyndromic oral clefts revisited. Cleft Palate Craniofac J. 33(5): 406-417.

ZÖLLNER S, WEN X, HANCHARD NA, HERBERT MA, OBER C y PRITCHARD JK (2004). Evidence for extensive transmission distortion in the Human Genome. Am J Hum Genet. 74: $62-72$.

ZUCCHERO TM, COOPER ME, MAHER BS, DAACK-HIRSCH S, NEPOMUCENO B, RIBEIRO L, CAPRAU D, CHRISTENSEN K, SUZUKI Y, MACHIDA J, NATSUME N, YOSHIURA K, VIEIRA AR, ORIOLI IM, CASTILLA EE, MORENO L, ARCOSBURGOS M, LIDRAL AC, FIELD LL, LIU YE, RAY A, GOLDSTEIN TH, SCHULTZ RE, SHI M, JOHNSON MK, KONDO S, SCHUTTE BC, MARAZITA ML y MURRAY JC (2004). Interferon regulatory factor 6 (IRF6) gene variants and the risk of isolated cleft lip or palate. $N$ Engl J Med. 351(8): 769-780. 
Anexos

- 72 - 
Formulario de Consentimiento para la toma de muestras de sangre

Programa de Tratamiento y Prevención de Malformaciones Congénitas.

Prevención Terciaria mediante Tratamiento Pediátrico Sistemático llevado a cabo

por Estudio Colaborativo Latino-Americano de Malformaciones Congénitas

(ECLAMC).

Investigadores responsables:

Dr. Eduardo E Castilla: ECLAMC/GENETICA/FIOCRUZ Av. Brasil 4365, Pav. 26, sala 617 21045-900, Rio de Janeiro, Brasil. Tel: (55-21) 3865-8141 Fax (55-21) 22604282 castilla@centroin.com.br

Dr. Jorge S. López Camelo: Laboratorio de Epidemiología Genética. Instituto Multidisciplinario de Biología Celular (IMBICE). 526 e/10 y 11. CC 403. 1900 La Plata. Argentina. Tel: (54 221) 4210112, Fax (54 221) 4210112 int 222

\section{EXPLICACION:}

La mayoría de las malformaciones congénitas no tienen causa conocida. Es posible que factores familiares y ambientales sean conjuntamente la causa de estas malformaciones. Usted está siendo invitada a participar de una investigación para ayudar a comprender mejor por qué estas malformaciones ocurren y cómo tratar a niños con fisuras orales. El objetivo de este formulario de consentimiento es solicitarle una muestra de sangre porque usted es familiar de un niño recién nacido con una fisura oral que está participando de este estudio.

Su participación es voluntaria y su bebé continuará recibiendo el tratamiento habitual, participe o no de este estudio.

Su participación en esta parte del estudio incluye la extracciòn de una pequeña cantidad de sangre (alrededor de $3 \mathrm{ml}$ ) a usted. Ésta, como cualquier otra extracción de sangre, puede ocasionar una molestia, así como una pequeña mancha roja en el lugar del pinchazo, y más raramente que le baje la tensión arterial. Usaremos la sangre para estudiar las causas, tanto de fisuras orales como de otros defectos asociados. Las muestras de ADN extraídas de la sangre serán almacenadas mientras dure este estudio y otros relacionados con él. Esto será hecho sin costo alguno para usted y se le informará acerca de los resultados que podrían ser beneficiosos para su futura familia. Ningún otro análisis será hecho con estas muestras.

Esta investigación podrá ayudar mucho a las personas en el futuro, porque podremos estimar mejor el riesgo de tener un bebé con estas malformaciones y así tratar de prevenirlas. Usted podría ser convocada en el futuro para participar en otros estudios relacionados con éste.

$\mathrm{Su}$ identidad no será nunca revelada. Para preservar el anonimato las muestras se identificarán con un código. Usted puede interrumpir su participación en este estudio en cualquier momento y en ese caso puede solicitar que los remanentes de las muestras de sangre sean eliminados, llamando a Jorge S. López Camelo al teléfono (54221) 4210112.

Si usted tuviera dudas más tarde sobre sus derechos como participante del estudio, podrá entrar en contacto con Jorge S. López Camelo al teléfono (54221) 4210112. 
Si usted quisiera participar, firme este formulario después de leerlo cuidadosamente y de hacerle todas las preguntas que considere necesarias al médico a cargo de su hijo.

$\mathrm{Su}$ firma debajo indica que usted entendió y aceptó.

Firma del familiar al que se le extrae la muestra de sangre

Firma del testigo

\section{Dr. Jorge S. López Camelo}

Nombre y Apellido del Investigador Responsable

Lugar y fecha

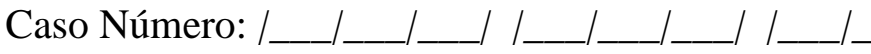


Ficha del caso y del control.

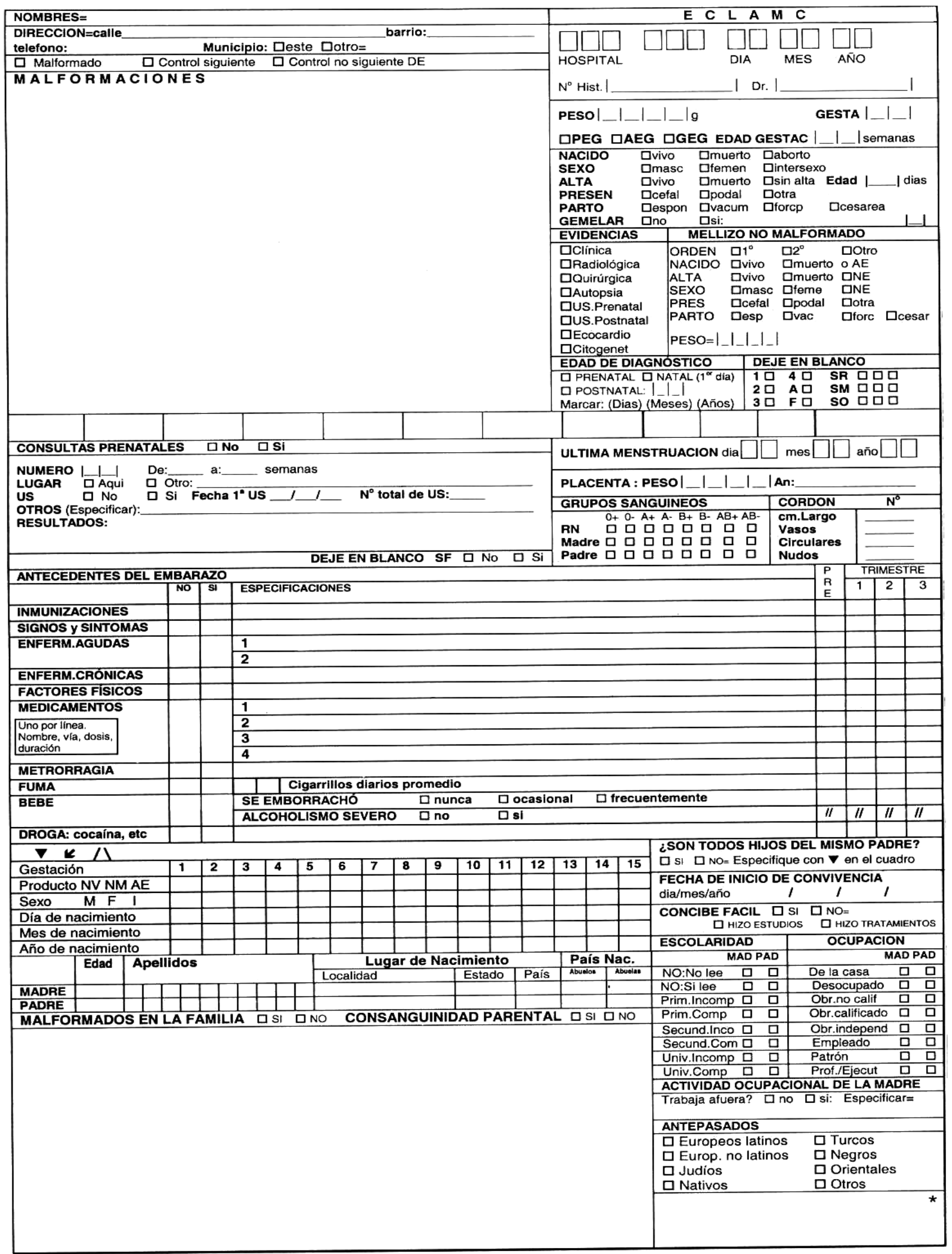

